\title{
Aldehydes: magnificent acyl equivalents for direct acylation
}

Article

Accepted Version

Kumar, P., Dutta, S., Kumar, S., Bahadur, V., Van der Eycken, E. V., Vimaleswaran, K. S., Parmar, V. S. and Singh, B. K. (2020) Aldehydes: magnificent acyl equivalents for direct acylation. Organic \& Biomolecular Chemistry, 18 (40). ISSN 1477-0520 doi: https://doi.org/10.1039/D0OB01458C Available at https://centaur.reading.ac.uk/93413/

It is advisable to refer to the publisher's version if you intend to cite from the work. See Guidance on citing.

To link to this article DOI: http://dx.doi.org/10.1039/D0OB01458C

Publisher: Royal Society of Chemistry

All outputs in CentAUR are protected by Intellectual Property Rights law, including copyright law. Copyright and IPR is retained by the creators or other copyright holders. Terms and conditions for use of this material are defined in the End User Agreement.

\section{www.reading.ac.uk/centaur}

\section{CentAUR}

Central Archive at the University of Reading 
Reading's research outputs online 


\section{Accepted Manuscript}

This article can be cited before page numbers have been issued, to do this please use: P. Kumar, S.

Dutta, S. Kumar, V. Bahadur, E. V. Van der Eycken, K. Vimaleswaran, V. S. Parmar and B. K. Singh, Org.

Biomol. Chem., 2020, DOI: 10.1039/D0OB01458C.

\section{Organic \& Biomolecular Chemistry}

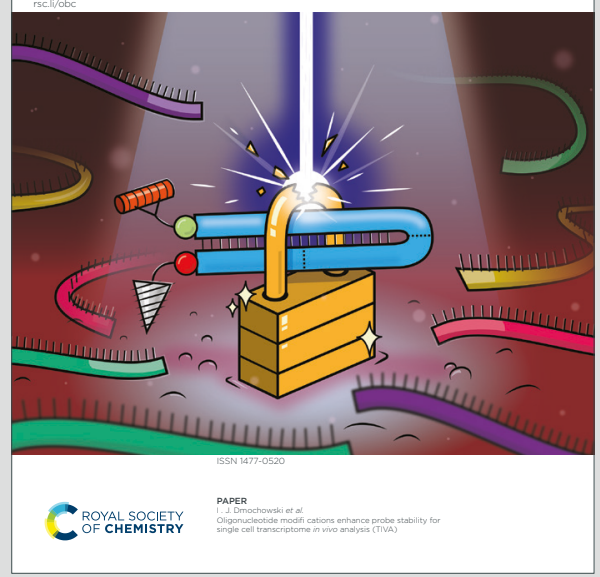

This is an Accepted Manuscript, which has been through the Royal Society of Chemistry peer review process and has been accepted for publication.

Accepted Manuscripts are published online shortly after acceptance, before technical editing, formatting and proof reading. Using this free service, authors can make their results available to the community, in citable form, before we publish the edited article. We will replace this Accepted Manuscript with the edited and formatted Advance Article as soon as it is available.

You can find more information about Accepted Manuscripts in the Information for Authors.

Please note that technical editing may introduce minor changes to the text and/or graphics, which may alter content. The journal's standard Terms \& Conditions and the Ethical guidelines still apply. In no event shall the Royal Society of Chemistry be held responsible for any errors or omissions in this Accepted Manuscript or any consequences arising from the use of any information it contains. 


\title{
ARTICLE
}

Received 00th January 20xx, Accepted 00th January 20xx DOI: $10.1039 / \times 0 \times x 00000 x$

\section{Aldehydes: magnificent acyl equivalents for direct acylation}

\begin{abstract}
Prashant Kumar ${ }^{*}, \mathrm{a}, \mathrm{b}$ Sriparna Dutta, ${ }^{\mathrm{b}}$ Sandeep Kumar, ${ }^{\mathrm{b}}$ Vijay Bahadur, ${ }^{\mathrm{a}, \mathrm{b}}$ Erik V. Van der Eycken, ${ }^{\mathrm{c}, \mathrm{d}}$ Karani S Vimaleswaran, ${ }^{e}$ Virinder S. Parmar ${ }^{f}$ and Brajendra K. Singh*b

From the viewpoint of meeting the current Green Chemistry challenges in chemical synthesis, there is a need to disseminate how the cocktail of acylation and activation can play a pivotal role in affording bioactive acylated products comprising of substituted ketone motifs in fewer reaction steps, with higher atom-economy and improved selectivity. In recent years, a significant number of articles employing the title compounds "aldehydes" as magnificent acylation surrogates have been developed which are less toxic and widely applicable. This review sheds light on their use for selective acylation of arenes, heteroarenes and alkyls ( $\mathrm{sp}^{3}, \mathrm{sp}^{2}$ and $\mathrm{sp}$ ) $\mathrm{C}-\mathrm{H}$ bonds by proficient utilization of $\mathrm{C}-\mathrm{H}$ activation strategy. Critical insights on selective acylation of diverse moieties for the synthesis of bioactive compounds are presented in this review that will enable the academic as well as the industrial researchers to understand the mechanistic aspects involved and fruitfully employ these strategies in designing novel molecules.
\end{abstract}

\section{Introduction}

The concise forging of substituted ketone motifs by means of direct functionalization using $\mathrm{C}-\mathrm{H}$ activation strategies presents the incredible state of the art in synthetic organic chemistry. Ketones are commonly used ubiquitous structural units for developing pharmaceuticals, dyes, agrochemicals, electronic materials and natural products. These are the fundamental building blocks of various bioactive molecules and drugs such as tiaprofenic acid and ketoprofen which are used as anti-photoallergic agents ${ }^{1}$ and nonsteroidal antiinflammatory drugs, ${ }^{2}$ fenofibrate that is used as the classical lipid regulating agent ${ }^{3}$, benzbromarone (BBR) which is employed as a uricosuric agent ${ }^{4}$, and mebendazole that works as a broad-spectrum human anthelmintic agent. ${ }^{5}$ Over the course of time, structural diversity of the disubstituted ketone moieties has rapidly expanded as evident from the literature reports. However, the practical challenges associated with the conventional methodologies employed for the synthesis of these significant motifs have in turn engaged the researchers in exploration of improved methods of synthesis. Some of the inherent drawbacks associated with the classical Friedel-

a. Department of Chemistry, SRM University Delhi-NCR, Sonepat Haryana-131029, India

b. Department of Chemistry, University of Delhi, Delhi-110007, India

c. Laboratory for Organic \& Microwave-Assisted Chemistry (LOMAC), Department of Chemistry, University of Leuven (KU Leuven), Celestijnenlaan 200F, B-3001

Leuven, Belgium

d. Peoples' Friendship University of Russia, (RUDN University) Miklukho-Maklaya, street 6, Moscow, 117198, Russia

e. Hugh Sinclair Unit of Human Nutrition, School of Chemistry, Food and Pharmacy, University of Reading, UK

f. Department of Chemistry and Environmental Science, Medgar Evers College, The City University of New York, 1638 Bedford Avenue, Brooklyn, NY 11225, USA
Crafts acylation reaction include requirement of harsh reaction conditions and super stoichiometric amounts of Lewis acids, low regioselectivity and the formation of unwanted regioisomers. ${ }^{6,7}$ Although other alternative methods have been established over the years comprising of the oxidation of alcohols, ${ }^{8,9}$ Grignard/Barbier reaction followed by oxidation, ${ }^{10}$ and reaction of Grignard reagents with nitriles, ${ }^{10 f}$ these methods do not match the current Green Chemistry requirements due to issues related to safety and economy.

Transition metal-catalyzed oxidative cross-coupling reactions for the direct functionalization of $\mathrm{C}-\mathrm{H}$ bonds with high atomefficiency have emerged as attractive, efficient and straightforward strategies for access to desirable molecules from simple reaction substrates without any pre-modification or pre-functionalization, thereby increasing the efficacy of the anticipated transformations. Therefore, in recent years these cross-coupling strategies have been extensively explored for the direct synthesis of keto compounds by means of selective acylation of the starting materials. These approaches are found to be highly advantageous over classical methods used for the acylation of alkyl, aryl or heteroaryls leading to the formation of desirable acylated compounds because of fewer reaction steps, higher atom-economy, improved selectivity and non-requirement of pre-functionalization of the starting materials. For direct acylation by following the $\mathrm{C}-\mathrm{H}$ activation approach, several reagents including aldehydes, benzyl alcohols, $\alpha$-keto acids, acyl chlorides, etc. have been explored extensively. ${ }^{11-14}$ Amongst these acylating surrogates, aldehydes (aliphatic and aromatic) have received profound 
attention because of their high stability, less toxicity, ease of availability, broad substrate scope and low cost.

In fact, aldehydes consist of an important class of molecules that are found extensively in nature. Amongst the aldehydes, benzaldehyde is one of the most important motifs, which is widely used in food industry as an ingredient in cherry and other natural fruity flavours. Naturally, aldehyde motifs are present in peach, black tea, bitter almond, and apricot kernel. ${ }^{15}$ Benzaldehyde has been reported to act as an antitumour agent for various kinds of tumours occurring in humans ${ }^{16}$ and mice. ${ }^{17}$ The mechanism for the anti-tumour behaviour of benzaldehyde for cell growth inhibition has been well established using human NHIK 3025 cells. ${ }^{18}$ Aldehydes can be formed endogenously by amine oxidases, carbohydrate or ascorbate autoxidation, lipid peroxidation, myeloperoxidase-catalyzed metabolic activation, carbohydrate metabolism or by cytochrome P-450s, etc. ${ }^{19,20}$ In the year 1946, the first review ${ }^{21}$, which was published by Lloyd N. Fergusoy from the University of California, on the synthesis of aromatic aldehydes, covered essential information pertaining to both the direct as well as indirect method for the introduction of the formyl ( $\mathrm{CHO}$ ) group into the aromatic nucleus. It was highlighted in this review that Gattermann and Koch ${ }^{22}$ for the first time prepared aromatic aldehydes via reaction between benzene and its derivatives, $\mathrm{CO}$ and $\mathrm{HCl}$, using anhydrous $\mathrm{AlCl}_{3}$ as a catalyst. Thereafter, this protocol was modified further by Gattermann ${ }^{23}$ himself, where he used cyanide instead of $\mathrm{CO}$ and produced aldimine hydrochloride as an intermediate that was hydrolysed to the aldehyde. In due course, several other methods were established for aldehyde synthesis. Also, meanwhile attempts were made towards utilizing aldehydes for their transformation into valuable compounds. For instance, it was found that benzaldehyde could react with pyruvate and get transformed into a chiral compound $(R)$-phenylacetylcarbinol $[(R)-\mathrm{PAC}]$ with the help of pyruvate decarboxylase (PDC) enzyme (Fig. 1). ${ }^{24,25}$

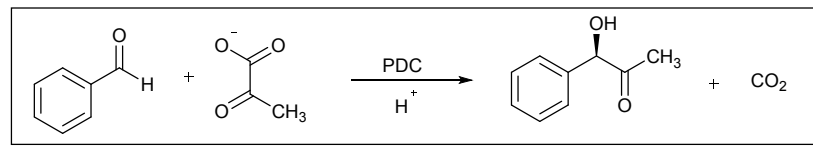

Fig. 1 Transformation of benzaldehyde and pyruvate into (R)-phenylacetylcarbino using pyruvate decarboxylase.

Henceforth, aldehydes were employed as starting materials in important organic reactions such as addition, condensation, hydrogenation, coupling, etc. ${ }^{26-31}$ Over the course of time, aldehydes were also employed in radical acylation and oxidative acylation reactions that result in the direct regioselective formation of new $\mathrm{C}-\mathrm{C}$ and $\mathrm{C}-\mathrm{N}$ bonds. These routes provided better alternatives to anhydridesse acyl halides, $\alpha$-ketoacids and other acylating agents. ${ }^{2}{ }^{2} 340$ विeally, it is well known that green chemistry helps in achieving reduction of waste at source by redesigning existing processes at the molecular level. These acylation reactions add to the credentials of green chemistry. A major breakthrough in the use of aldehydes as acylating agents was achieved when Cheng et al. in 2009 reported the first direct oxidative acylation of a C-H bond applying aromatic aldehydes as acyl equivalents in the presence of a Pd-catalyst. ${ }^{35}$ During mechanistic investigation of the radical induced acylation reactions, it was postulated that the aldehyde moiety gets converted first into an acyl radical (Fig. 2) which then combines to give the corresponding acylated product.

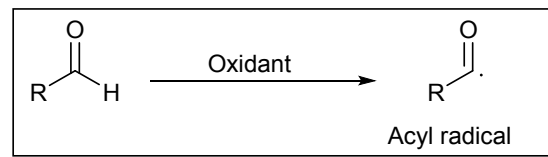

Fig. 2 Acyl radical formation from the aldehydes.

The use of benzaldehydes in radical mediated as well as oxidative cross-coupling reactions was reviewed by Xiao-Feng Wu in 2015. ${ }^{33}$ This mini-review sheds light on recent work in transition metal catalysed acylation of aryls, heteroaryls/heteroarenes. Thereafter, in 2016, Kim and coworkers published a review summarizing the recent progress in oxidative and decarboxylative transition metal-catalysed acylation reactions by $\mathrm{C}-\mathrm{H}$ activation. ${ }^{34}$

\section{Scope of Review}

There is a need to disseminate how wondrously the aldehyde moieties are employed in various acylation reactions using C$\mathrm{H}$ activation and how they succumb to provide a better substitute of the irritating and toxic anhydrides, acyl halides and other acylating reagents. Although there are several reviews on $\mathrm{C}-\mathrm{H}$ bonds activation and transition metalcatalysed reactions, yet, to the best of our knowledge, there is no single review that throws light on the use of aldehydes as magnificent acylation surrogates compiling the acylation of arenes, heteroarenes and alkyls $\left(\mathrm{sp}^{3}, \mathrm{sp}^{2}\right.$ and $\left.\mathrm{sp}\right) \mathrm{C}-\mathrm{H}$ bonds resulting in the synthesis of valuable $\mathrm{C}-\mathrm{X}(\mathrm{X}=\mathrm{C}, \mathrm{O}, \mathrm{N})$ bonds by proficient use of $\mathrm{C}-\mathrm{H}$ activation. This review presents some of the exciting discoveries accomplished during the past few years (2012 to 2020) in the development of novel catalytic protocols, shedding light on some of the latest synthetic tools including flow chemistry and photochemical methodologies. It includes a comprehensive discussion on the mechanistic aspects that will enable the researchers to think creatively and work in this exciting area. This review focusses on using 
greener tools and strategies, given that chemical waste has a disastrous impact on human health as well as on the environment and eco-systems.

\section{Aldehydes in acylation reactions}

\subsection{Acylation of arenes}

In 2012, Kim and his team described the Rh-catalyzed regioselective acylation of secondary benzamides using aromatic aldehydes, which on subsequent intramolecular cyclization afforded 3-hydroxyisoindolin-1-ones (Scheme 1). ${ }^{36}$ Authors have synthesized 21 derivatives of 3hydroxyisoindolin-1-one by reacting several differently substituted benzamides with aldehydes. Benzaldehydes having electron-withdrawing groups such as $\mathrm{NO}_{2}, \mathrm{CF}_{3}$, COOMe, $\mathrm{CN}$, etc. delivered the 3-hydroxyisoindolin-1-ones in high yields. On the other hand, aldehydes carrying the electron-releasing OMe group displayed inferior reactivity. Benzamides having electron-releasing groups delivered high yields in comparison to those bearing electron-withdrawing groups.

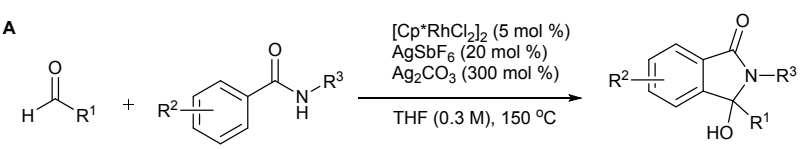

$$
\begin{aligned}
& 20 \text { examples, 30-83\% }
\end{aligned}
$$

B

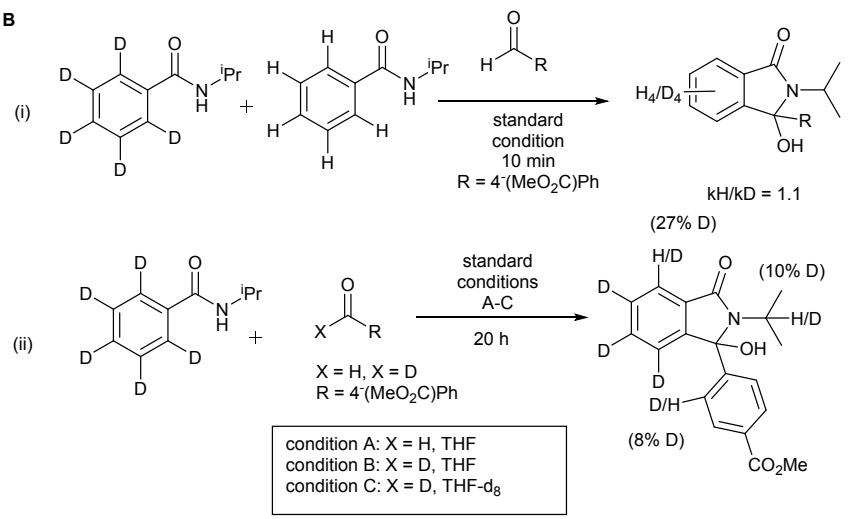

$$
\text { (iii) }
$$

Scheme 1: Rh-catalyzed regioselective $\mathrm{sp}^{2} \mathrm{C}-\mathrm{H}$ acylation of secondary benzamides using aryl aldehydes with intramolecular cyclization and mechanistic studies.

To probe the catalytic reaction pathway for this transformation, authors carried out intermolecular kinetic isotope experiment by treating equimolar amounts of deuterated benzamide and simple benzamide with methyl terephthalaldehydate under standard reaction conditions for
10 min and a $1.1 \mathrm{k}_{\mathrm{H}} / \mathrm{k}_{\mathrm{D}}$ value was observed (Scheme 1B) Cther $_{\text {el }}$ deuterium-labelling control experimentş suggested the râpid and reversible metalation-proto(deutero)demetalation before the cross-coupling reaction. This also suggested that addition of the aldehyde to the cyclo-rhodated intermediate is involved in the rate-limiting step of this conversion. A possible reaction mechanism is depicted in Scheme 2.

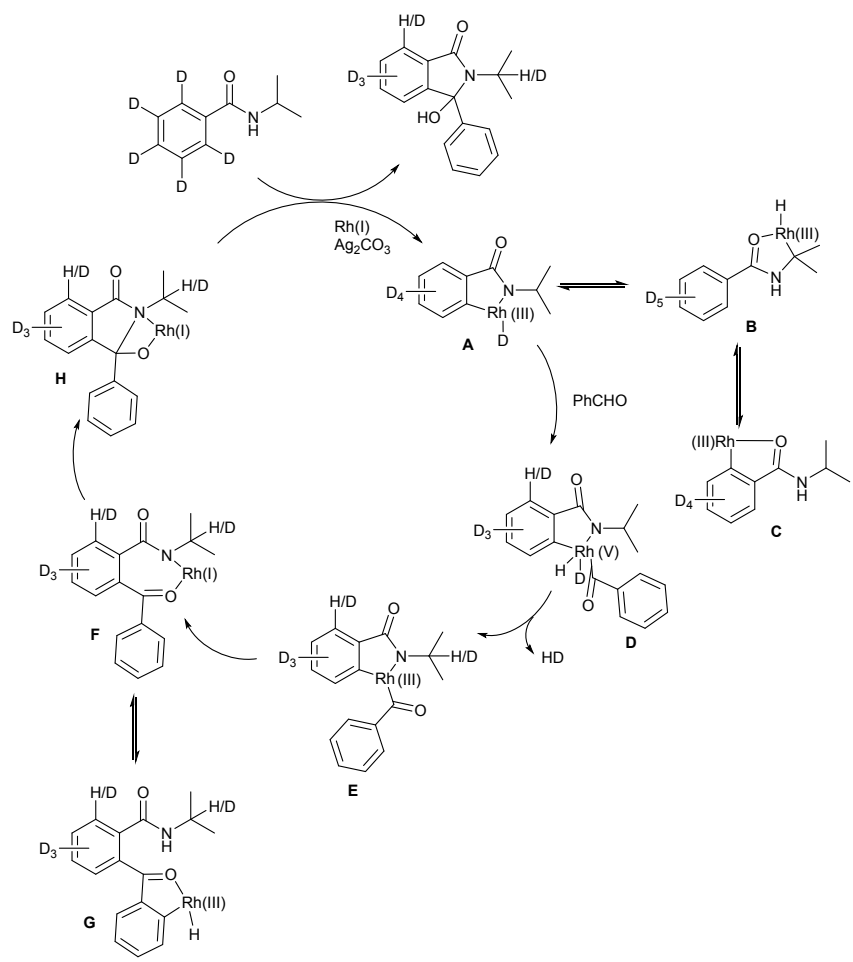

Scheme 2: Plausible reaction mechanism of the Rh-catalyzed regioselective $\mathrm{sp}^{2} \mathrm{C}-\mathrm{H}$ acylation process for the secondary benzamides with aryl aldehydes.

In 2013, Zhang et al. developed a Pd-catalysed protocol for the synthesis of keto-carboxylic acids through an aryl amide directed $\mathrm{C}-\mathrm{H}$ functionalization approach. The reaction proceeded by oxidative coupling between aryl amides and aldehydes using TBHP as oxidant and resulted in imino carboxylic acids, which on subsequent treatment with $\mathrm{HCl}$ solution gave keto carboxylic acids. ${ }^{37}$ The reactions progressed through benzamide directed $o$-acylation followed by ring closing and opening to give keto-carboxylic acids. Both benzamides as well as aldehydes bearing electron-releasing groups and electron-withdrawing groups were compatible for the reaction irrespective of the positions of the functional groups. The authors prepared 19 imino carboxylic acid derivatives in $46-84 \%$ yield and five keto-carboxylic acid derivatives in $50-80 \%$ yield (Scheme 3 ).

Two closely related studies were disclosed by Patel et al. and Wu et al. in 2013 using Pd(II) catalyst and TBHP oxidant for direct o-acylation of 2-arylbenzothiazoles and 2arylbenzoxazoles. In the first study, ${ }^{38}$ the authors reacted 
benzothiazoles or benzoxazoles with aldehydes using $\mathrm{Pd}(\mathrm{OAc})_{2}$ as catalyst and TBHP as oxidant in toluene as solvent (Scheme 4). A set of 38 o-acylated benzothiazoles and benzoxazoles were prepared in moderate to good yields. The developed method was robust and adequate for diverse azoles and aldehydes. The method seemed to be insensitive to the electronic behaviour of the substituents present either on azoles or aldehydes.<smiles>[R][R]C=O</smiles>

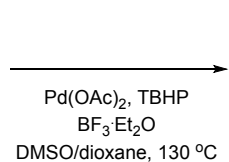<smiles>[R]N=C([R])c1c[R]([R])ccc1C(=O)O</smiles>

19 examples, $46-84 \%$ $\mathrm{R}^{1}=\mathrm{Ph}, 4-\mathrm{OMePh}, 4-\mathrm{MePh}, 4-\mathrm{CIPh}$, $3,4,5-\mathrm{OMePh}$

$\mathrm{R}^{2}=\mathrm{H}, 4-\mathrm{OMe}, 4-\mathrm{F}, 4-\mathrm{Br}, 4-\mathrm{Cl}, 2-\mathrm{OMe}$

2-Me, 3-OMe, 3-Cl

$\mathrm{R}^{3}=\mathrm{OMe}, \mathrm{OBn}, \mathrm{O}-\mathrm{i}-\mathrm{Pr}, \mathrm{O}-\mathrm{t}-\mathrm{Bu}$

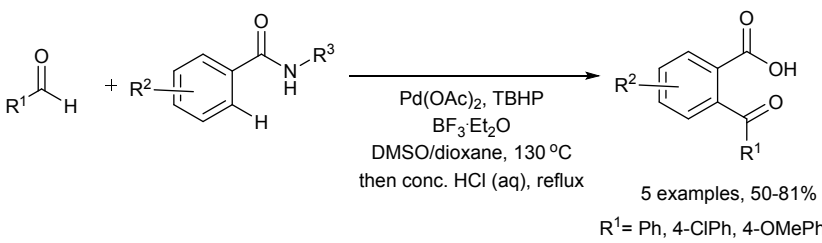

$$
\begin{aligned}
& \mathrm{R}^{2}=4-\mathrm{Cl}, 4-\mathrm{OMe}
\end{aligned}
$$

Scheme 3: Pd-catalyzed synthesis of imino carboxylic acids and ketocarboxylic acids via aryl amide directed $\mathrm{C}-\mathrm{H}$ activation reaction.

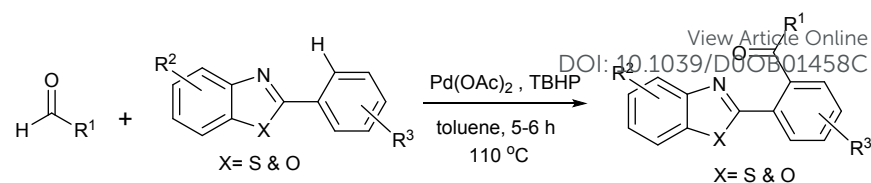

$X=S$

$\mathrm{R}^{1}=\mathrm{Ph}, 4-\mathrm{OMEPh}, 4-\mathrm{OBuPh}, 4-\mathrm{MePH}, 4-\mathrm{PhPh}, 4-\mathrm{CIPh}$, 4- $\mathrm{CO}_{2} \mathrm{MePh}, 4-\mathrm{NO}_{2} \mathrm{Ph}, 3-\mathrm{FPh}, 3-\mathrm{CIPh}, 3-\mathrm{NO}_{2} \mathrm{Ph}, 2-\mathrm{CIPh}$, 3,4-OMePh, 2,6-CIPh, 4-Cl-3- $\mathrm{NO}_{2} \mathrm{Ph}, \beta-$ naphthyl, furanyl, amples, $40-84 \%$ $\mathrm{X}=\mathrm{O}$

$\mathrm{R}^{1}=\mathrm{Ph}, 4-\mathrm{MePh}, 4-\mathrm{PhPh}, 3-\mathrm{ClPh}$ $\mathrm{R}^{2}=\mathrm{H}, 5-\mathrm{Me}$

$\mathrm{R}^{3}=4-\mathrm{Me}, 4-\mathrm{OMe}, 4-\mathrm{Cl}$ $\mathrm{R}^{2}=\mathrm{H}$

$\mathrm{R}^{3}=\mathrm{H}, 4-\mathrm{Me}, 4-\mathrm{OMe}, 4-\mathrm{O}-\mathrm{t}-\mathrm{Bu}, 4-t-\mathrm{Bu}, 4-\mathrm{Cl}, 6-\mathrm{Cl}, 5-\mathrm{F}, 5-\mathrm{Br}$

Scheme 4: $\mathrm{Pd}(\mathrm{II})$-catalyzed direct ortho-acylation of 2-arylbenzothiazoles and 2-arylbenzoxazoles.

In a second study, ${ }^{39}$ the authors reported the 0 -acylation of 2arylbenzoxazoles using aldehydes as coupling partner in the presence of $\mathrm{Pd}(\mathrm{OAc})_{2}$ catalyst, $\mathrm{PPh}_{3}$ as ligand and TBHP as oxidant (Scheme 5). 24 ortho-acylated benzoxazole derivatives were obtained in $37-85 \%$ yield. Benzothiazole and benzo[h]quinoline were efficiently coupled with $p$ chlorobenzaldehyde giving the respective ortho-acylated products in $83 \%$ and $96 \%$ yield after $8 \mathrm{~h}$ at refluxed temperature. Unfortunately, 2-(3methylphenyl)benzimidazole was unable to give the acylated product under the optimized reaction conditions.

Remarkably, 2-arylbenzoxazoles having substituents on the meta-position of the benzene ring exhibited high regioselectivity and acylation achieved at the less crowded ortho- $\mathrm{C}-\mathrm{H}$ bond of the directing group. The steric hindrance at the ortho-position of aromatic aldehydes influenced the reaction efficiency and resulted in a lower yield of the corresponding acylated products. 


\section{ARTICLE}

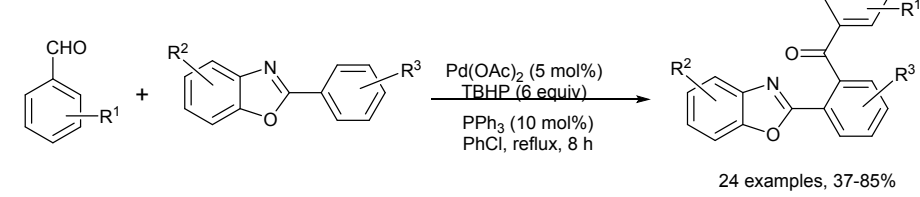

$\mathrm{R}^{1}=\mathrm{H}, 3-\mathrm{OMe}, 3,4-\mathrm{OMe}, 4-\mathrm{Me}, 4-\mathrm{Cl}, 4-\mathrm{Br}, 4-\mathrm{F}$, 2-OMe, 2-Cl, 2,4-Cl, 2-Br, 4-Cl

$\mathrm{R}^{2}=\mathrm{H}, 7-\mathrm{Me}, 5-\mathrm{Cl}$

$\mathrm{R}^{3}=\mathrm{H}, 2-\mathrm{Me}, 3-\mathrm{Me}, 3-\mathrm{OMe}, 3-\mathrm{F}, 3-\mathrm{Cl}, 4-\mathrm{F}$

B
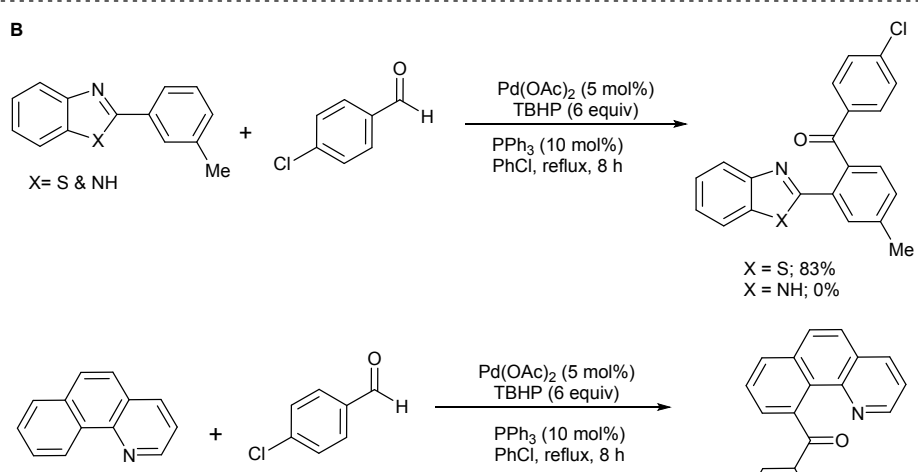
$\mathrm{X}=\mathrm{S} ; 83 \%$
$\mathrm{X}=\mathrm{NH} ; 0 \%$
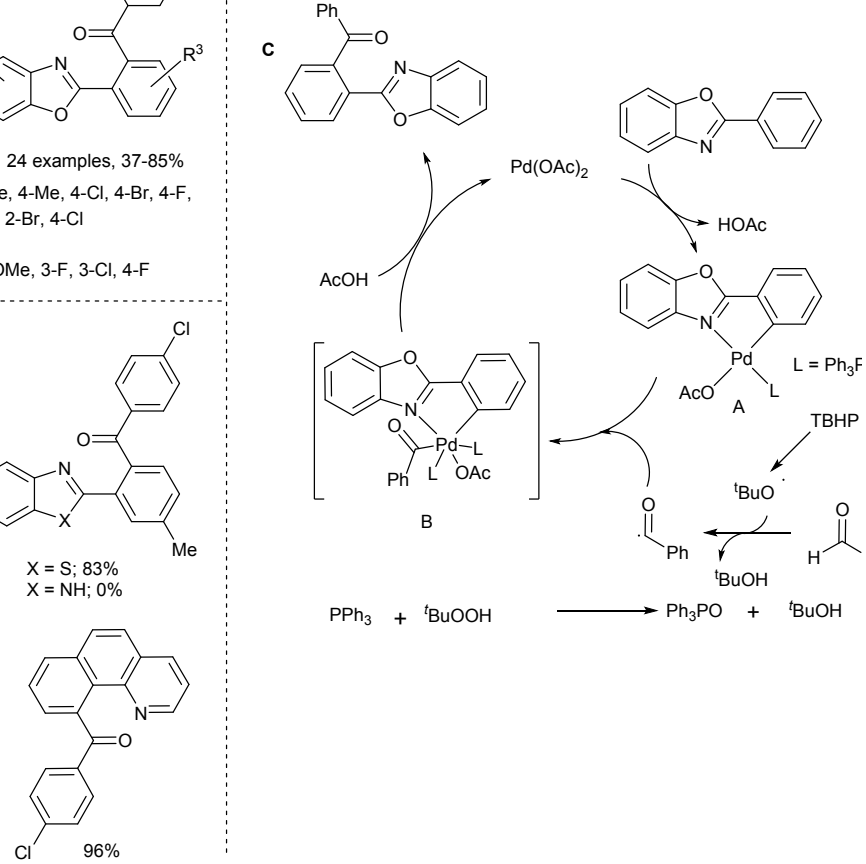

$\mathrm{PPh}_{3}+{ }^{\mathrm{t}} \mathrm{BuOOH}$

$\longrightarrow \mathrm{Ph}_{3} \mathrm{PO}+{ }^{t} \mathrm{BuOH}$

Scheme 5: Pd-catalyzed ortho-acylation of 2-arylbenzoxazoles/ 2-arylbenzothiazoles/2-arylbenzimdazoles and plausible reaction mechanism. experiments were carried out. The observations suggested that the $N$-Boc hydrazone moiety is acting as directing group. The rate of the acylation reaction was found to be significantly faster than that of the hydrolysis step. Scheme 6B also outlines the mechanism of this transformation.
For both the reactions similar reaction pathway was suggested as presented in Scheme 5C. Mechanism starts with cyclopalladation of the 2-arylbenzoxazole or 2arylbenzothiazole to give intermediate $\mathbf{A}$. In the second step, the in-situ generated acyl radical reacts with intermediate $A$ to form either reactive Pd'V or dimeric Pd"II intermediate B. In the last step, reductive elimination resulted 0 -acylated derivatives of 2-arylbenzoxazole and redeveloped $\mathrm{Pd}^{\text {"l }}$ salt to maintain the catalytic cycle.

Kim and his group in 2013 reported the first catalytic acylation protocol to synthesize 1,2-diacylbenzenes from $\mathrm{N}$-Boc hydrazones. ${ }^{40}$ This method involves the $\mathrm{Pd}(\mathrm{II})$-catalysed tandem regioselective acylation of $N$-Boc hydrazones and insitu dissociation of the directing $N$-Boc hydrazone group in the presence of TBHP as oxidant delivering 1,2-diacylbenzenes (Scheme 6). This approach was set up not only for various aldehydes but also for several acetophenones and benzophenone $\mathrm{N}$-Boc hydrazones. Unfortunately, aliphatic and heterocyclic aryl aldehydes were unable to give the coupling products with this catalytic system. To acquire greater understanding of the reaction pathway, various 

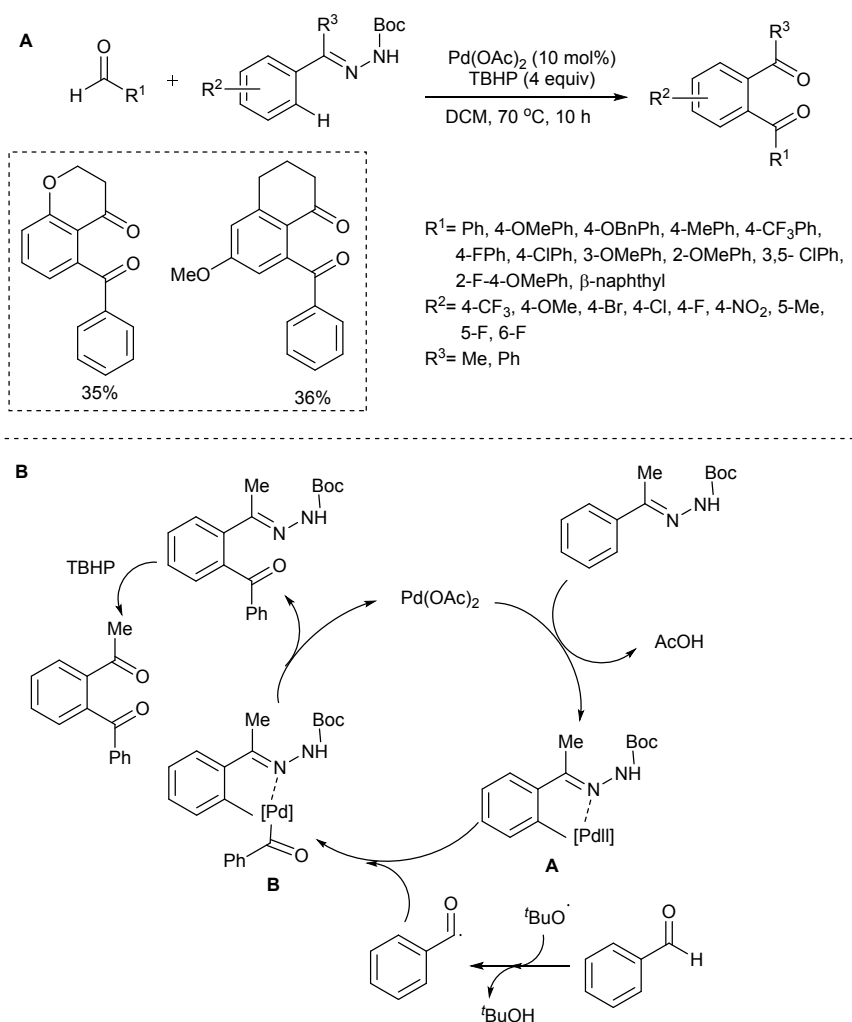

Scheme 6: Pd(II)-catalyzed direct regioselective acylation of N-Boc hydrazones and plausible reaction mechanism.

In 2013, Li et al. reported an azo-group directed selective acylation of symmetrically substituted azobenzenes by aldehydes involving a Pd-catalysed $\mathrm{C}$ - $\mathrm{H}$ activation method. ${ }^{41}$ Using optimized reaction conditions, the scope of various azobenzenes and aldehydes was explored using $\mathrm{Pd}(\mathrm{OAc})_{2}$ and TBHP. Aromatic aldehydes containing strong electronwithdrawing groups such as $\mathrm{CN}, \mathrm{NO}_{2}$ at the para-position of the aryl ring provided higher yields than those containing electron-releasing groups (Me, OMe) at the para-position. Reactions of azobenzene with $\alpha$-naphthaldehyde as well as furan-2-carbaldehyde delivered the products in $86 \% \%_{A}$ and $66 \%$ yield, respectively. Cyclohexanecarbaldehispe B0145Rd propionaldehyde also reacted smoothly to give the corresponding reaction products in 59\% and $64 \%$ yield, respectively. The synthesized acylated azobenzenes were converted into the indazoles using $\mathrm{Zn} / \mathrm{NH}_{4} \mathrm{Cl} / \mathrm{MeOH}$ as reducing system at room temperature in just $5 \mathrm{~min}$ (Scheme 7).

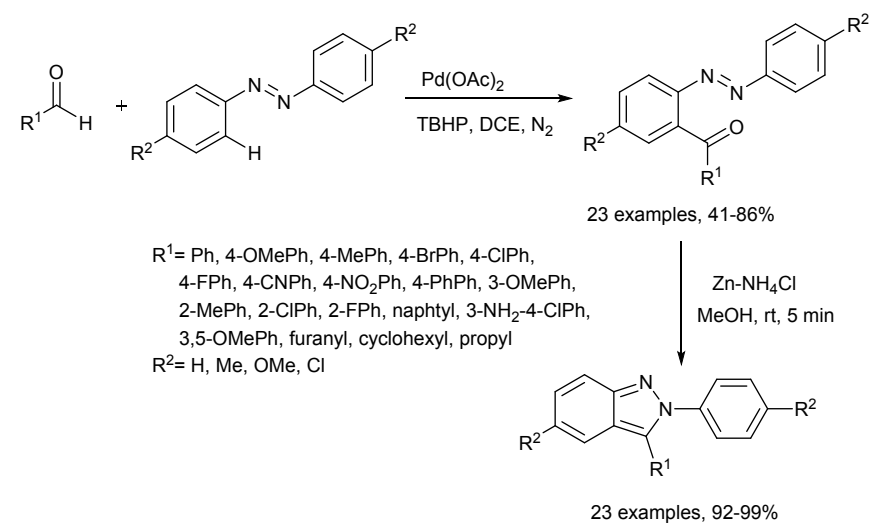

Scheme 7: Pd-catalyzed azo group directed acylation of symmetrically substituted azobenzenes with aldehydes.

Meanwhile, Sharma et al. reported a Pd-catalyzed oxidative $o$ acylation of triflamide-protected benzylamines using aliphatic and aromatic aldehydes via $\mathrm{C}-\mathrm{H}$ activation strategy. It was observed that benzylamines having triflamide as directing group delivered $O$-acyl- $N$-benzyltriflamides with high regioselectivity applying $\mathrm{Pd}(\mathrm{OAc})_{2}$ as catalyst and TBHP as ideal oxidant. They used $\mathrm{ACOH}$ as an additive and the reactions were carried out in the binary solvent system MeCN/DMF (1:1) (Scheme 8A).42 


\section{ARTICLE}

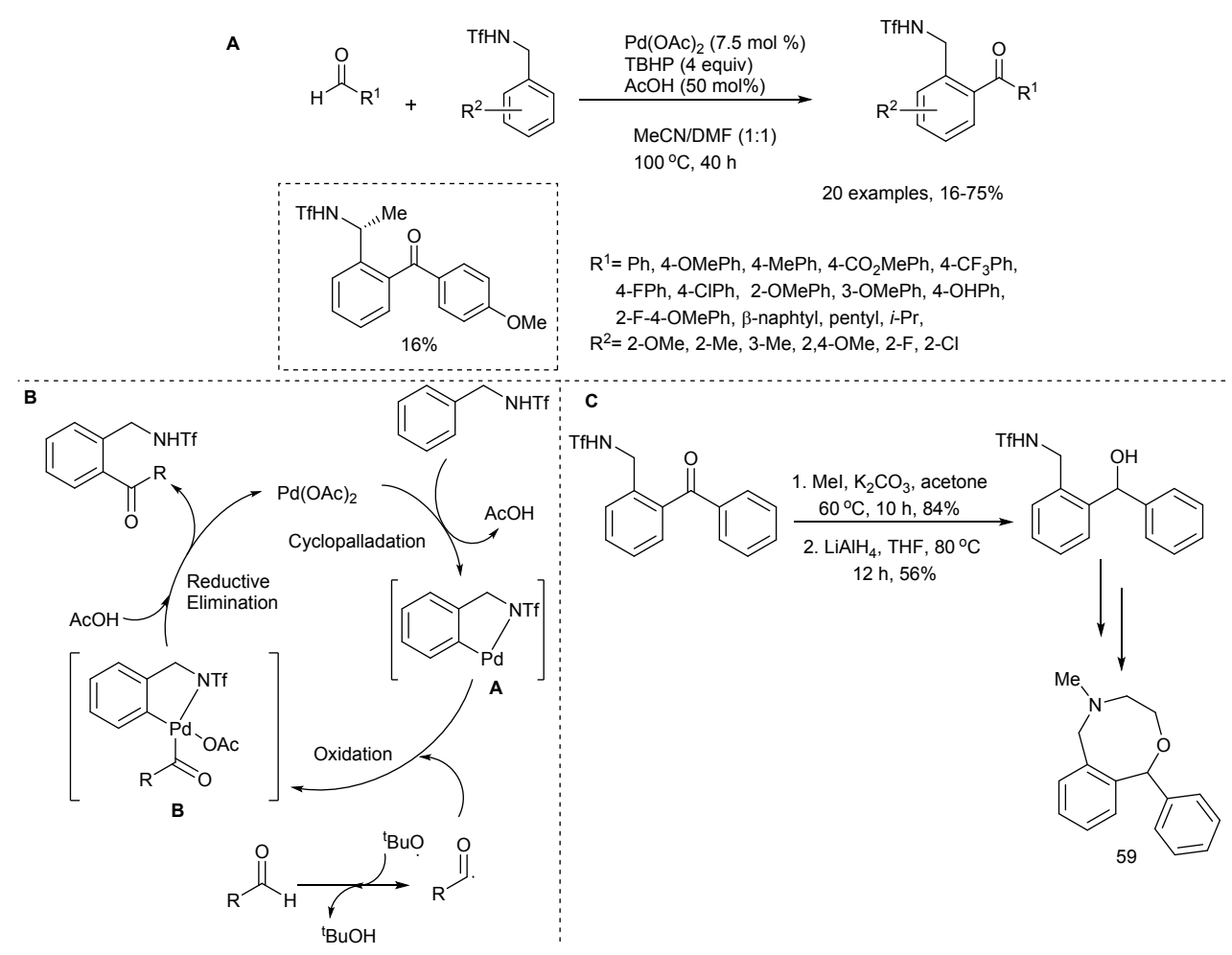

Scheme 8: (A) Pd-catalyzed oxidative acylation of $\mathrm{N}$-benzyltriflamides with aldehdyes via $\mathrm{C}$-H activation; (B) plausible reaction mechanism; (C) transformation of triflamides.

The substrate scope examination revealed that electron poor aromatic aldehydes were less reactive in comparison to electron rich aromatic aldehydes. In order to examine a plausible reaction mechanism for this transformation, the radical scavenger, ascorbic acid, was added in a dosedependent manner and it was found that the reaction proceeds via a radical pathway as shown in Scheme 8B. They have also established that $\mathrm{O}$-acyl- $\mathrm{N}$-benzyltriflamides are effective synthetic precursors for the construction of the analgesic drug nefopam and analogous (Scheme 8C).

Novàk and co-workers reported a Pd-catalysed crossdehydrogenative coupling of anilides with aromatic aldehydes using mild reaction conditions for the selective $o$-acylation of anilides (Scheme 9). ${ }^{43}$ 
A
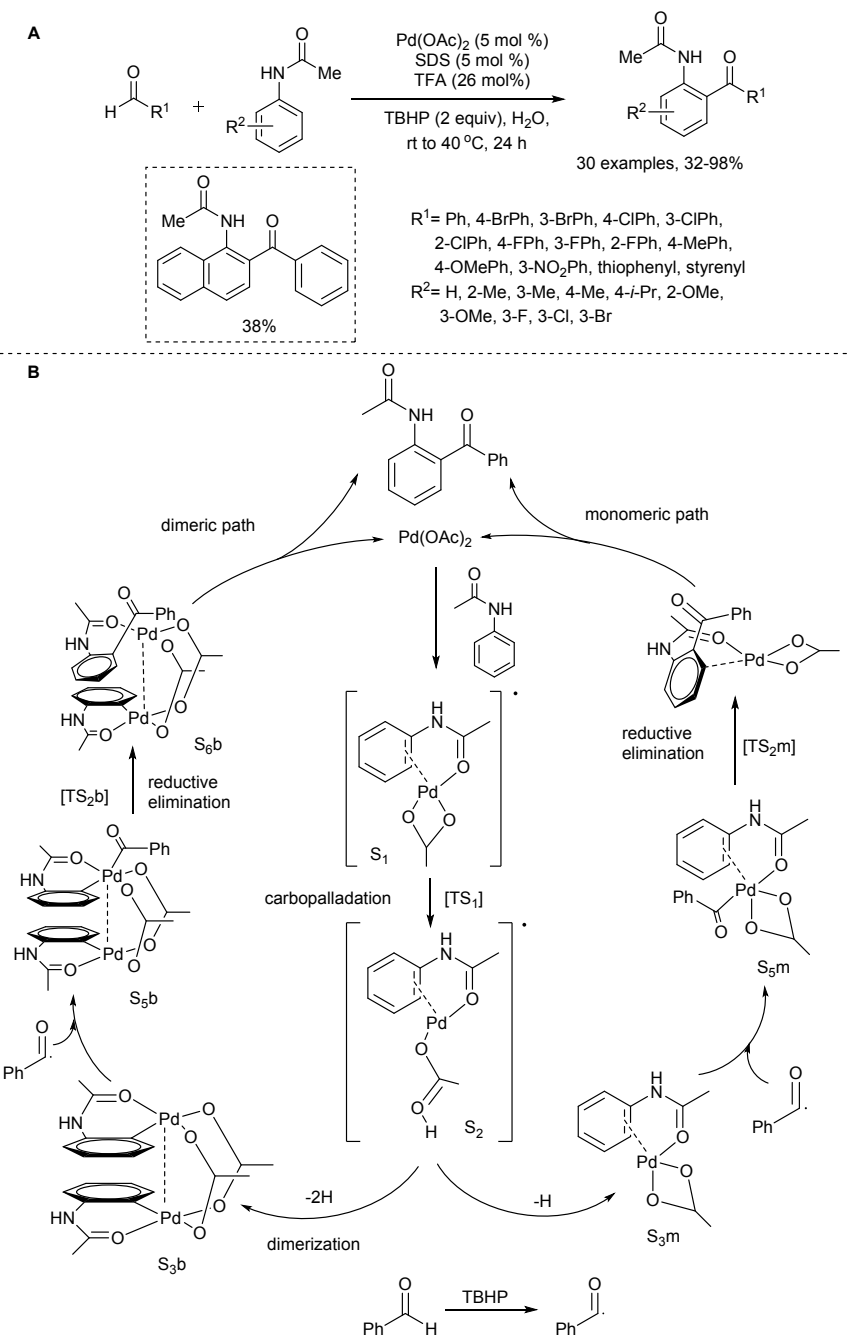

Scheme 9: Pd-catalyzed cross-dehydrogenative coupling between anilides and benzaldehydes, and proposed reaction mechanism.

Remarkably, this reaction was accomplished at $25-40{ }^{\circ} \mathrm{C}$ temperature under aqueous conditions in $24 \mathrm{~h}$. Utilization of the surfactant dodecyl sulphate (SDS) helped to upturn the solubility of the reaction substrates in water, and trifluoroacetic acid (TFA) accelerated the reaction in water. The presence of electron releasing or electron withdrawing groups on the anilide does not affect the reaction outcome and resulted in high yield of the products. Aromatic aldehydes with weak electron-withdrawing groups $(\mathrm{F}, \mathrm{Cl}, \mathrm{Br}$ etc.) provided higher product yield, than those containing electronreleasing groups (Me, OMe). 3-nitrobenzaldehdye delivered the desired product in just $39 \%$ yield. In order to support the hypothesis regarding the probable reaction mechanism, authors have performed quantum mechanical density functional calculations, which suggested the preference of bimetallic catalysis over a monomeric route (Scheme 9B).

In 2014, Kuang and co-workers described the acylation of 2aryl-1,2,3-triazole scaffolds with differently substituted aryl and alkyl aldehydes using $\mathrm{Pd}(\mathrm{OAc})_{2}$ as effective catalyst and
TBHP as oxidant (Scheme 10A). ${ }^{44}$ All the used substrates

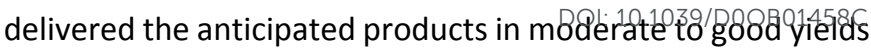
regardless the nature of the substituents. Noticeably, 2-aryl1,2,3-triazole and benzaldehyde both containing strong electron withdrawing groups such as COOMe (on triazole) and $\mathrm{CN}$ (on benzaldehyde) gave the corresponding product in $82 \%$ yield. However, the highest yield (85\%) was obtained in two cases: 1) when unsubstituted 2-aryl-1,2,3-triazole was treated with benzaldehdye and 2) coupling of benzaldehyde bearing a strong withdrawing cyano (CN) group with 2-aryl-1,2,3triazole having strong electron donating methoxy (OMe) group. Interestingly, high regioselectivity was observed with meta-substituted 2-aryl-1,2,3-triazole and acylation at the para-position with respect to the meta-substituent was achieved instead of ortho-position due to steric hindrance.

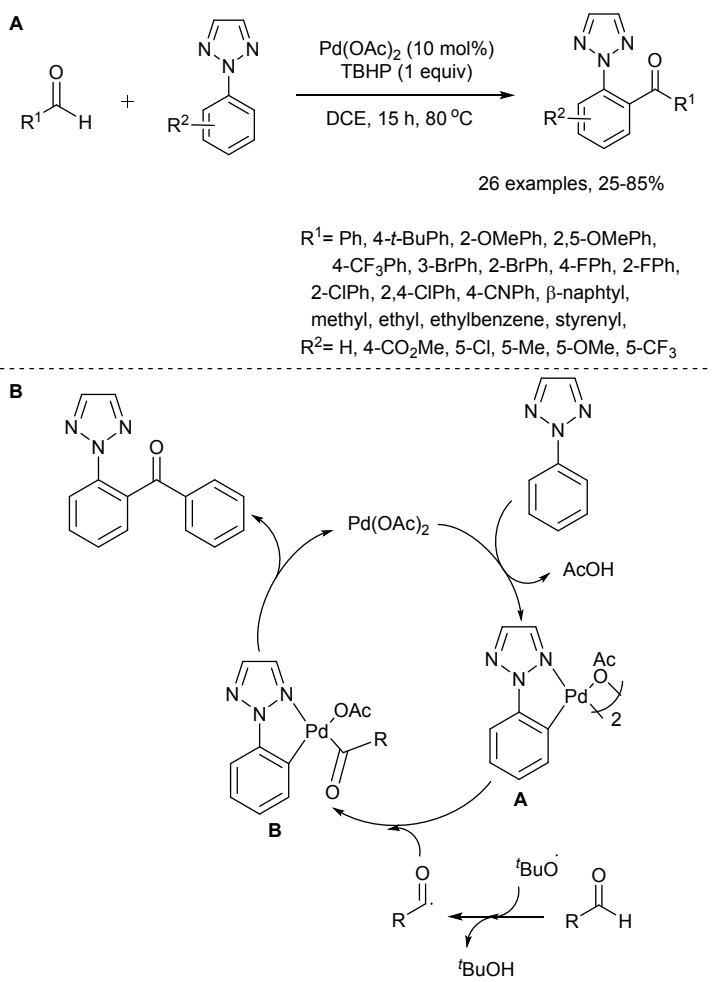

Scheme 10: Pd-catalyzed acylation of 2-aryl-1,2,3-triazole scaffolds with differently substituted aryl and alkyl aldehydes and plausible reaction mechanism.

Based on the available reports and observations, the authors designed a plausible reaction mechanism that starts with the formation of a five membered cyclopalladation intermediate A between 2-aryl-1,2,3-triazole and the Pd-catalyst. Subsequently, the generated benzoyl radical reacts with intermediate $\mathbf{A}$ resulting in conversion of $\mathrm{Pd}(\mathrm{II})$ to the dimeric $\mathrm{Pd}$ (III) or Pd(IV) complex B. Lastly, this complex B undergoes reductive elimination leading to the acylated product and $\mathrm{Pd}(\mathrm{II})$ get regenerated for the subsequent cycle (Scheme 10B). 
In August 2014, Kuang et al. reported the first example of a Pd-catalysed direct ortho-acylation of 2-benzyl-1,2,3-triazoles by aldehydes via $\mathrm{C}-\mathrm{H}$ bond activation in the presence of $\mathrm{Pd}(\mathrm{OAc})_{2}$ as catalyst and TBHP as oxidant. ${ }^{45}$ Using the optimized reaction conditions, the substrate scope with respect to aldehydes as effective acyl source, and 2-benzyl1,2,3-triazoles was explored, and 26 derivatives were prepared with $56-85 \%$ yield. The reaction vienceeded $_{\text {ancer }}$ successfully with substrates having electron ${ }^{3}$ dohating ${ }^{4} 8$ or electron withdrawing groups. However, 2-benzyl-1,2,3triazole bearing a nitro group at the para-position was not found to be reactive and no acylated product was obtained (Scheme 11). The reaction was found to progress following the reaction pathway as shown by Kuang et al. (Scheme 10B).

$$
\begin{aligned}
& \text { 至 } \\
& 26 \text { examples, } 56-85 \%
\end{aligned}
$$

Sun et al. in 2014 introduced azoxy compounds for selective acylation. The authors developed an interesting approach for the selective ortho-acylation of azoxybenzenes using various aromatic, heteroaromatic and aliphatic aldehydes in the presence of $\mathrm{Pd}(\mathrm{TFA})_{2}$ as catalyst and TBHP as oxidant. ${ }^{46}$ They prepared 19 different mono-acylated azoxybenzenes with 23$87 \%$ yield in $24 \mathrm{~h}$ at $60{ }^{\circ} \mathrm{C}$. The presence of mild electronwithdrawing groups $(\mathrm{F}, \mathrm{Cl}, \mathrm{Br})$ at the para-position of the benzaldehydes positively affected the reaction giving higher yields of the mono-acylated derivatives. However, strong electron-withdrawing groups $\left(\mathrm{CN}, \mathrm{NO}_{2}\right)$ had a reverse effect resulting in very poor yields of the corresponding products. Unfortunately, other electron-withdrawing groups like $\mathrm{CF}_{3}$ and $\mathrm{CO}_{2} \mathrm{Me}$ were not suitable for this transformation as no desired products were obtained. Besides the presence of two ortho- $\mathrm{C}-\mathrm{H}$ bonds, the reaction afforded exclusively the monoacylation in the ring directly attached to the $\mathrm{N}=\mathrm{O}$ group (Scheme 12A). The ortho-acylation product was converted into the indazole analogue by a reduction process. The reaction was found to progress through a free radical pathway (Scheme 12B).

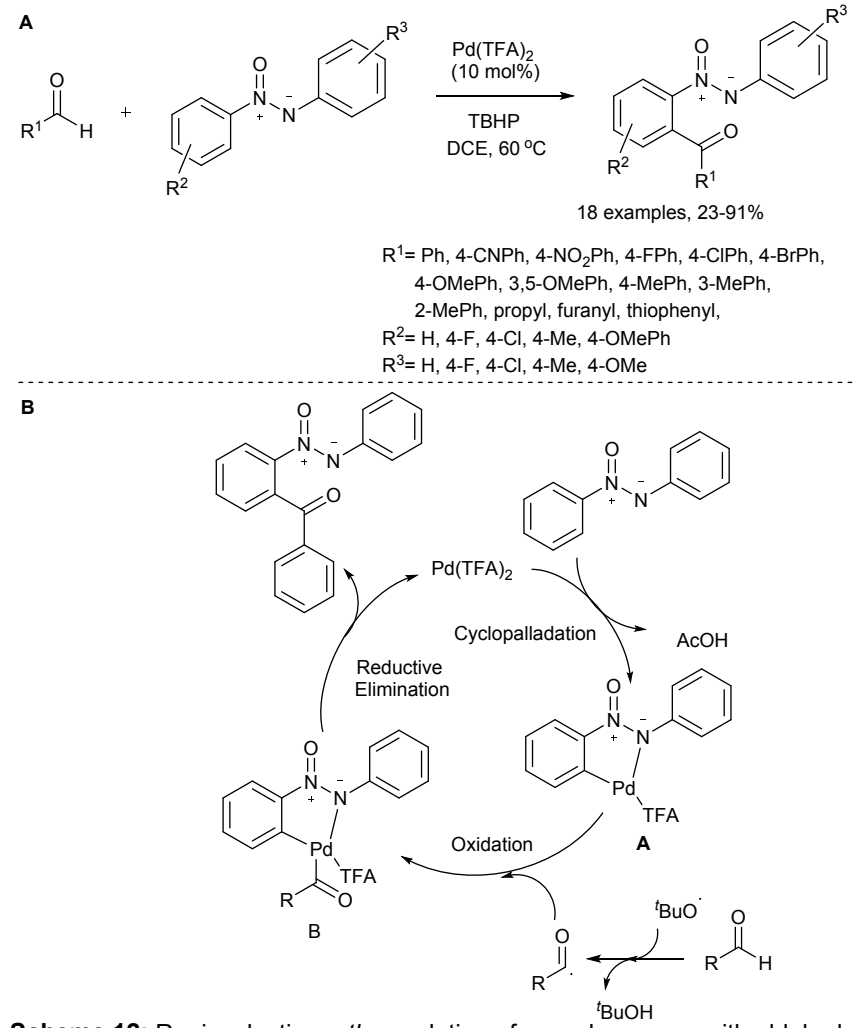

Scheme 12: Regioselective ortho-acylation of azoxybenzenes with aldehydes using $\mathrm{Pd}(\mathrm{TFA})_{2}$ and plausible reaction mechanism.

In 2014, Patel and his team established a strategy for the regioselective ortho $\mathrm{sp}^{2} \mathrm{C}-\mathrm{H}$ acylation of 3,5-diarylisoxazole. ${ }^{47}$ From four $\mathrm{sp}^{2} \mathrm{C}-\mathrm{H}$ bonds and one interior $\mathrm{sp}^{2} \mathrm{C}-\mathrm{H}$ bond, the functionalization occurred at one of the ortho $\mathrm{C}-\mathrm{H}$ bonds near to the $\mathrm{N}$-atom in the presence of $\mathrm{Pd}(\mathrm{OAc})_{2}$ as catalyst and TBHP as oxidant(Scheme 13A). 


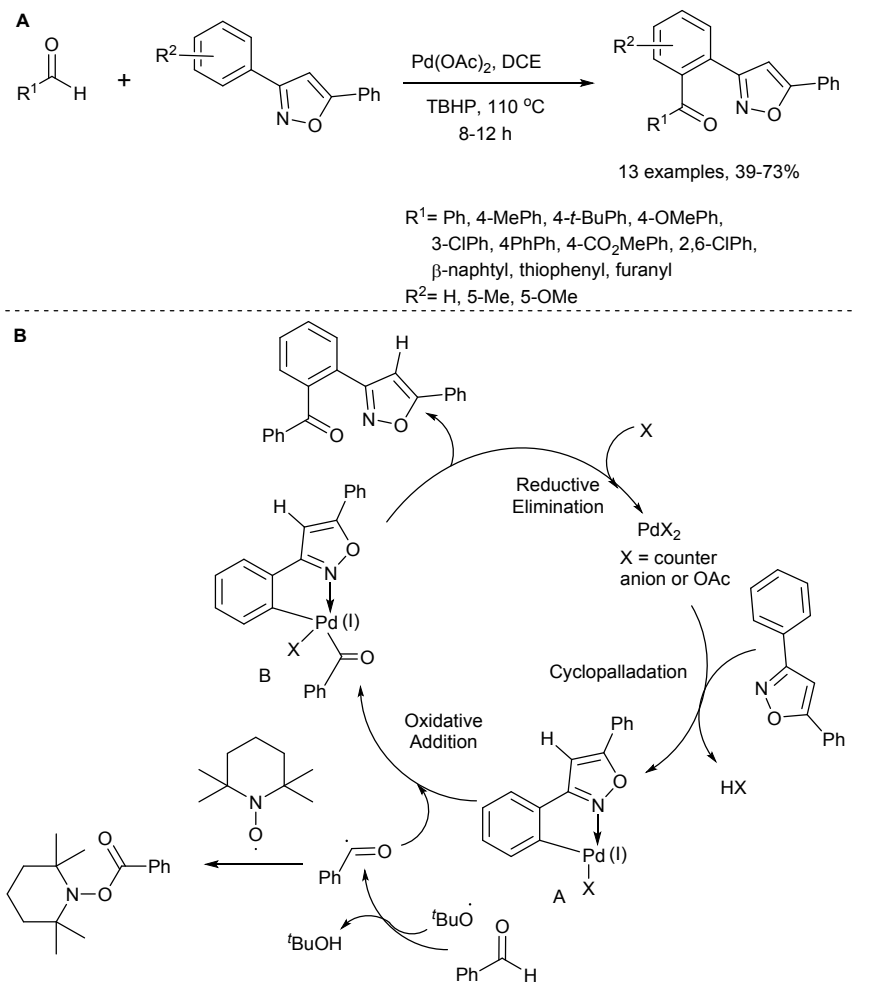

Scheme 13: Pd-catalyzed selective N-directed ortho-acylation of 3,5-diarylisoxazol and proposed reaction mechanism.

Authors reported 13 acylated products with high regioselectivity in $39-73 \%$ yield at $110{ }^{\circ} \mathrm{C}$ after $8-12 \mathrm{~h}$ in dichloroethane (DCE) as solvent. The reaction progressed smoothly with the applied substrates and was found compatible with all kinds of functional groups present on the aldehydes. Nevertheless, the electron-withdrawing groups such as $\mathrm{o}-\mathrm{NO}_{2}, p-\mathrm{Cl}, m-\mathrm{F}$ in 3-aryl ring of 3,5-diarylisoxazole suppressed the product formation completely under these reaction conditions. The reaction mechanism was not thoroughly probed but expected to proceed as outlined in

\section{Scheme 13B.}

In continuation of their work on selective $N$-directed acylation reactions, Patel and co-workers reported a cross dehydrogenative coupling methodology for the selective mono ortho-acylation of the $\mathrm{sp}^{2} \mathrm{C}-\mathrm{H}$ bond of 2,3diarylquinoxalines using aromatic aldehydes. ${ }^{48}$ The authors developed a small library of 23 derivatives employing $\mathrm{Pd}(\mathrm{OAC})_{2}, \mathrm{TBHP}$ and toluene:DCE $(1: 1)$ at $110{ }^{\circ} \mathrm{C}$. Various functional groups were well tolerated on the benzaldehyde and $p$-chlorobenzadehyde provided the highest yield (82\%). Benzaldehydes bearing strong electron-withdrawing groups like $p$-COOMe, $p-\mathrm{NO}_{2}, m-\mathrm{NO}_{2}$ also provided the desired products in good yields. The substrate scope was further extended to substituted 2,3-diarylquinoxaliness icle with benzaldehydes and good yield of the desired products were achieved (Scheme 14).
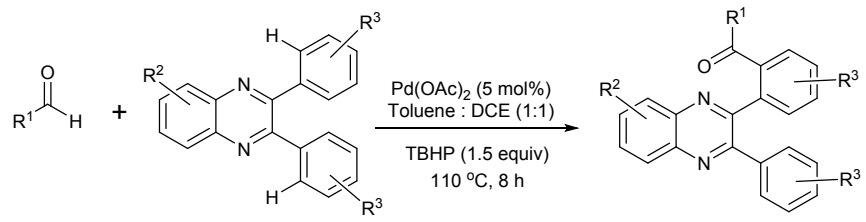

23-examples, $11-82 \%$

$\mathrm{R}^{1}=\mathrm{H}, 4-\mathrm{MePh}, 4-\mathrm{OMePh}, 4-\mathrm{OBuPh}, 4-\mathrm{PhPh}$ 4-CIPh, 4- $\mathrm{NO}_{2} \mathrm{Ph}, 4-\mathrm{CO}_{2} \mathrm{MePh}, 3-\mathrm{CIPh}, 3-\mathrm{FPh}$ 3-NO $\mathrm{NO}_{2} \mathrm{Ph}, 3$.4-OMePh, $\beta$-naphtyl, thiophenyl $\mathrm{R}^{2}=\mathrm{H}, 6,7-\mathrm{Cl}, 6-\mathrm{Me}, 6-\mathrm{Cl}$ $\mathrm{R}^{3}=\mathrm{H}, 4-\mathrm{Me}, 4-\mathrm{Br}, 3-\mathrm{Me}-4-\mathrm{OMe}$

Scheme 14: Cross dehydrogenative coupling for directed mono ortho-acylation of $\mathrm{sp}^{2} \mathrm{C}-\mathrm{H}$ bonds of 2,3-diarylquinoxaline.

Methyl and chloro substituted unsymmetrical 2,3diarylquinoxalines after reaction with benzaldehyde provided inseparable mono-acylated products in a ratio of 5:4 and 5:3, respectively. Furthermore, when the reaction with 2,3diarylquinoxaline having two electron-releasing groups (-Me and -OMe) in one of the aryl ring was performed, mono orthoacylated products were obtained in a 6.7:1 ratio, revealing the favoured oxidative palladation at the more electron rich aryl ring. However, in the presence of bromine in one of the aryl rings, ortho-acylation was accomplished at the unsubstituted aryl ring, resulting in only one product and reconfirming the favoured oxidative palladation of more electron rich aryl ring (Scheme 14).

The reaction conditions applied in regioselective acylation of azobenzenes (Scheme 15) were effectively installed by $\mathrm{Wu}$ and co-workers in 2015 during the acylation of azoxybenzenes by aldehydes using $\mathrm{Pd}(\mathrm{OAC})_{2}$ as catalyst at $80{ }^{\circ} \mathrm{C}$ in the presence of TBHP as oxidant (Scheme 15A). ${ }^{49}$ The authors have prepared a library of derivatives using differently substituted azoxybenzenes and aryl/alkyl aldehydes. However, in comparison to Sun's protocol ${ }^{46}$, aliphatic aldehydes gave inferior yields and heterocyclic aldehydes could not be applied for this transformation, which shows the significance of the reaction temperature. The authors also performed some control experiments to investigate the reaction mechanism. When the reaction was carried out in the presence of the radical scavenger 2,2,6,6tetramethylpiperidyl-1-oxyl (TEMPO) no acylation product was obtained revealing a free radical pathway (Scheme 15B). The probable reaction route for this conversion is shown in Scheme 15C. 


\section{ARTICLE}

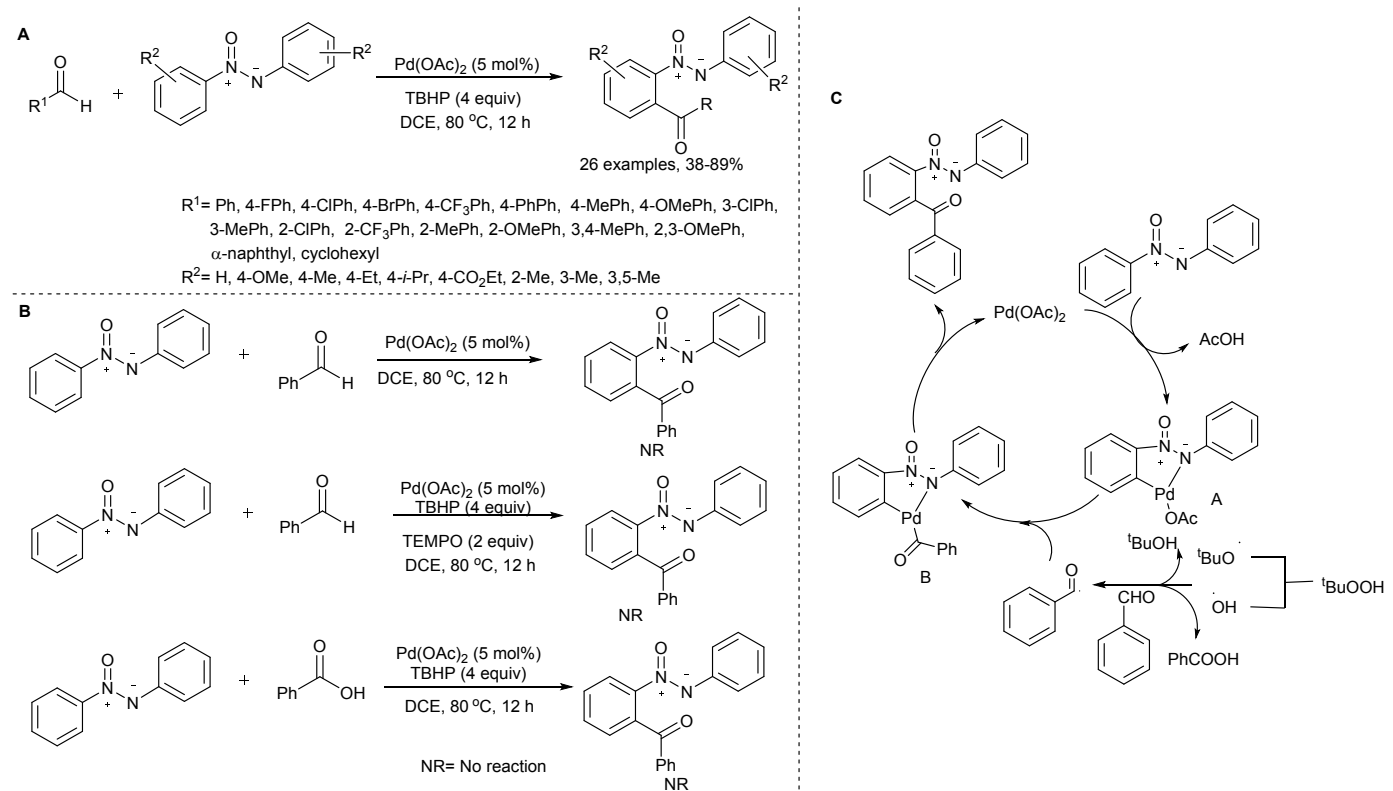

Scheme 15: (A) Regioselective ortho-acylation of azoxybenzenes with aldehydes; (B) Control experiments; (C) plausible reaction mechanism.

In 2015 Xiao et al., successfully carried out the acylation of the aryl ring of acetophenone $O$-methyl oxime with aromatic aldehydes using almost similar reaction conditions as was used by Novàk's and co-workers as given in Scheme $9 .{ }^{50}$ In this case reactions were carried out at $50{ }^{\circ} \mathrm{C}$ for $12 \mathrm{~h}$ and the targeted products were achieved in $53-80 \%$ yields. The authors extended the application of the reaction conditions

for the acylation of the aryl ring of 2-phenylpyridines, diphenyldiazenes, aromatic azo-compounds and other aryl ketone oximes with aromatic aldehydes (Scheme 16A-D). The reactions proceeded effectively in all these cases and electron-releasing or electron-withdrawing groups were compatible under standard reaction conditions. $\mathrm{R}^{1}=\mathrm{Ph}, 4-\mathrm{MePh}, 4-\mathrm{OMePh}, 4-\mathrm{FPh}, 4-\mathrm{ClPh}$ 4-BrPh, 4-t-BuPh, 2-CIPh, $\beta$-naphtyl $\mathrm{R}^{2}=\mathrm{H}, \mathrm{Me}, \mathrm{C}_{2} \mathrm{H}_{5}$

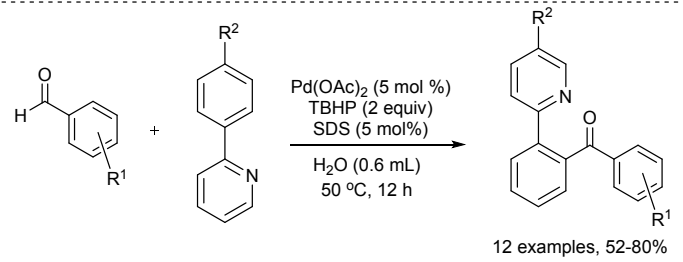

$\mathrm{R}^{1}=\mathrm{H}, 4-\mathrm{Me}-4-\mathrm{OMe}, 4-\mathrm{F}, 4-\mathrm{Cl}$, 4-Br, 4-t-Bu, 2-Cl, 3-Me $\mathrm{R}^{2}=\mathrm{Me}, \mathrm{OMe}, \mathrm{Cl}$<smiles>[R]c1ccc(C(=O)c2ccccc2/N=N\Nc2ccccc2)cc1</smiles>
$\mathrm{R}^{1}=\mathrm{H}, 4-\mathrm{Me}, 4-\mathrm{OMe}, 4-\mathrm{F}, 4-\mathrm{Cl}$ 4-Br, 2-Cl, 3-Me<smiles>[R]C(=O)c1ccc([R])cc1C([R])=NOC</smiles>

(1)

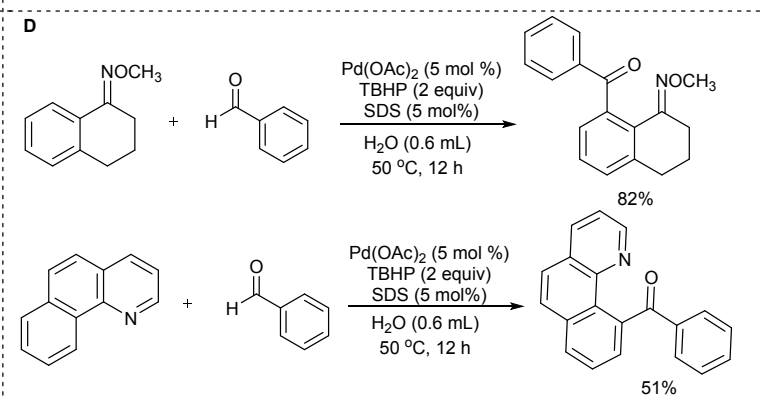

Scheme 16: Pd-catalyzed acylation of aryl ring (A) acetophenone O-methyl oximes; (B) 2-phenylpyridines; (C) diphenyldiazenes; (D) aryl ketone oxime and aza phenanthrene with aromatic aldehydes. 


\section{ARTICLE}

Yi's group in 2015 described the synthesis of orthoacylphenols by performing an oxidative $\mathrm{C}-\mathrm{H}$ coupling reaction between phenols and aldehydes using the cationic ruthenium hydride complex $\left[\left(\mathrm{C}_{6} \mathrm{H}_{6}\right)\left(\mathrm{PCy}_{3}\right)(\mathrm{CO}) \mathrm{RuH}\right]^{+} \mathrm{BF}_{4}{ }^{-}$as an effective catalyst in the absence of metal oxidant. ${ }^{51}$ The reaction progressed significantly with the applied phenols and aldehydes comprising electron donating and electron withdrawing groups, and resulted in the formation of 26 ortho-acylphenol derivatives in $35-78 \%$ yield. Besides the cationic ruthenium hydride complex, the reaction involved the use of $\mathrm{K}_{2} \mathrm{CO}_{3}$ as base and $\mathrm{PPh}_{3}$ as additive in chlorobenzene solvent for the smooth transformation at 110 ${ }^{\circ} \mathrm{C}$ (Scheme 17). Interestingly, the coupling of phenols with $\alpha, \beta$-unsaturated aldehydes under the optimized reaction conditions resulted in flavonoids. The authors prepared 20 flavonoid derivatives successfully with $23-88 \%$ yield having various functional groups. The chemoselectivity of the developed protocol was explored by treating estrone with cyclohexanecarbaldehyde and 4-chlorobenzaldehdye and the corresponding coupling products were obtained in a 1:2 ratio.

$$
\text { }
$$<smiles>Oc1cccc2ccccc12</smiles><smiles>[R]C=O</smiles>

\section{$\left[\left(\mathrm{C}_{6} \mathrm{H}_{6}\right)\left(\mathrm{PCy}_{3}\right)(\mathrm{CO}) \mathrm{RuH}^{+} \mathrm{BF}_{4}^{-}\right.$ 8-20}

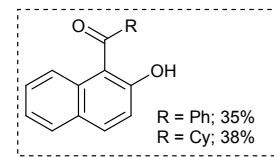

$$
\mathrm{R}^{1}=
$$

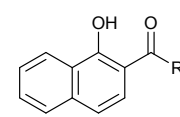
6 examples, $33-61 \%$ $\mathrm{Ph}, 4-\mathrm{FPh}$, Et, cyclohexy 3-cyclohexenyl, $\mathrm{CH}(\mathrm{Me}) \mathrm{Ph}$

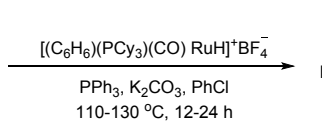
$110-130^{\circ} \mathrm{C}, 12-24 \mathrm{~h}$

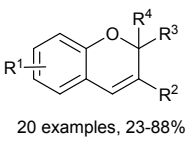
$\mathrm{R}^{1}=7-\mathrm{OMe}$ $\mathrm{R}^{2}=\mathrm{H}, \mathrm{Me}, n$-hexyl $\mathrm{R}^{3}=\mathrm{H}, \mathrm{Ph}, n-\mathrm{Pr}, \mathrm{Et}, 4-\mathrm{FPh}$

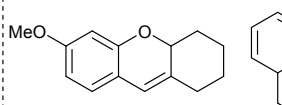

$53 \%$

$\mathrm{R}^{2}=\mathrm{H}, \mathrm{R}^{3}=n-\mathrm{Pr} ; 40 \%$ $\mathrm{R}^{3}=\mathrm{H}, \mathrm{Ph}$,
$\mathrm{R}^{4}=\mathrm{H}, \mathrm{Ph}$
In the same year Wu et al. reported a study for the direct ortho-acylation of 2-phenoxypyridines with aldehydes to produce a series of novel aryl ketones in the presence of $\mathrm{Pd}(\mathrm{OAc})_{2}$ as catalyst, TBHP as oxidant and chlorobenzene as solvent (Scheme 18). ${ }^{52}$ In order to gain an insight into the reaction mechanism, authors performed intramolecular and intermolecular kinetic isotope effect studies. The results of experiments showed that the ortho $\mathrm{C}-\mathrm{H}$ bond cleavage of 2phenoxypyridines does not participate in the rate determining steps of the reaction. The binding of 2-phenoxypyridines with the palladium ion was considered as the crucial ratedetermining step for the acylation. Furthermore, the effect of various radical scavengers on the reactivity was determined to probe either the reaction was following an ionic pathway or proceeding via a radical pathway. The results of experiments strongly supported the radical pathway. In addition to the above studies, some other control experiments were also performed by carrying out the reaction between 2-phenoxypyridine palladacycle (A) with different benzaldehydes in the presence and absence of TBHP. Based on all these experiments, a plausible mechanism was proposed as shown in Scheme 18B. The authors also demonstrated the synthetic utility of this protocol by synthesizing (2-hydroxyphenyl)(phenyl)methanones and 1hydroxy-9H-fluoren-9-ones. 
A

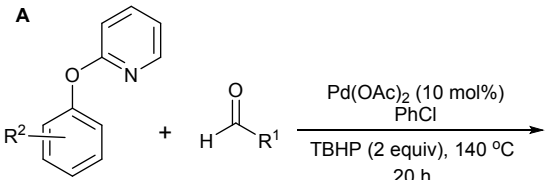

$20 \mathrm{~h}$

\section{2 examples, 3-94\%}

$\mathrm{R}^{1}=\mathrm{Ph}, 4-\mathrm{MePh}, 4-\mathrm{OMePh}, 4-\mathrm{NO}_{2} \mathrm{Ph}, 4-\mathrm{CF}_{3} \mathrm{Ph}$, 4-AcPh, 4-FPh, 4-CIPh, 4-BrPh, 4-IPh, 2-FPh, 3-FPh, 3-CIPh, 3-BrPh, 3-CHOPh, 3,5-MePh, 2,5-MePh, 3,5-OMePh, 5-OMePh, 3,4,5-OMePh

$\alpha$-naphthyl
$\mathrm{R}^{2}=\mathrm{H}, 5-\mathrm{Me}, 5-\mathrm{OMe}, 5-\mathrm{NO}_{2}, 5-\mathrm{F}, 5-\mathrm{Cl}, 5-\mathrm{Br}, 5-\mathrm{I}$<smiles>O=C(c1ccccc1)c1ccc2ccccc2c1Oc1ccccn1</smiles>

$94 \%$
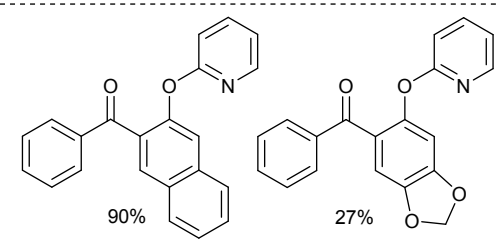

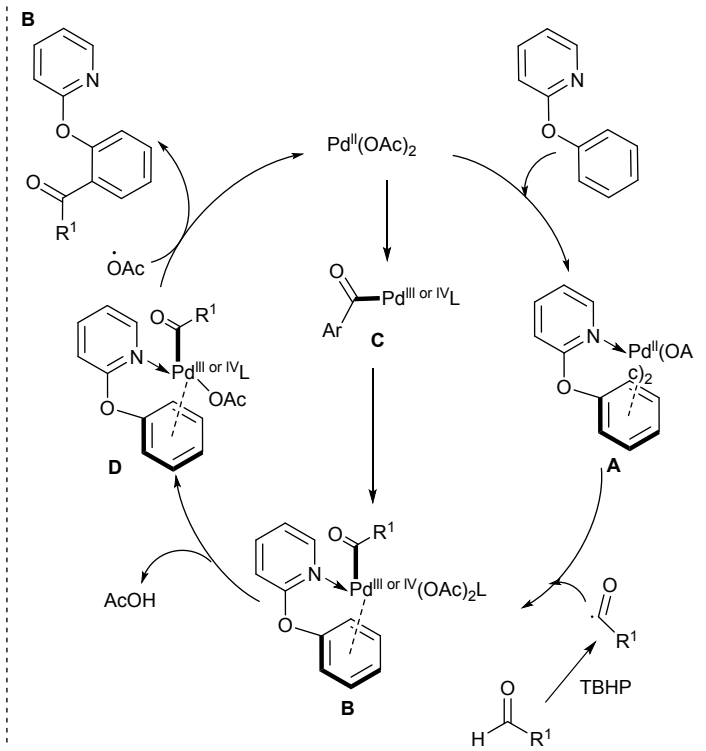

Scheme 18: Direct ortho-acylation of 2-phenoxypyridines with aldehydes and proposed reaction mechanism.

Triphathi et al. in 2015 reported a metal-free one pot radical approach for the cross coupling between aryl diazonium tetrafluoroborates and aldehydes to access the synthesis of diaryl ketones. ${ }^{53}$ A library of 20 derivatives was established by coupling differently substituted aromatic aldehydes with various derivatives of aryl diazonium tetrafluoroborate using di-tert-butylperoxide (DTBP) as a radical initiator. The presence of electron-releasing ( $\mathrm{Me}, \mathrm{OMe}$ ) groups as well as electron-withdrawing $\left(\mathrm{F}, \mathrm{Cl}, \mathrm{NO}_{2}, \mathrm{COMe}\right)$ groups on aromatic aldehydes was well tolerated under the developed conditions and afforded the corresponding products in $72-95 \%$ yield.
Heterocyclic aldehydes such as furan-2-carboxyaldehyde and thiophen-2-carboxyaldedye provided the respective products in $65 \%$ and $88 \%$ yield. Bulkier aromatic aldehydes, $\alpha$ naphthaldehyde and $\beta$ - naphthaldehyde provided the $89 \%$ and $79 \%$ yield, respectively. Aryl diazonium tetrafluoroborate having electron-withdrawing $(\mathrm{F}, \mathrm{Br})$ groups resulted higher product yields than that of containing electron-releasing (Me) group (Scheme 19A). Based on experimental data and literature precedents, authors described a plausible reaction mechanism for this transformation (Scheme 19B). 


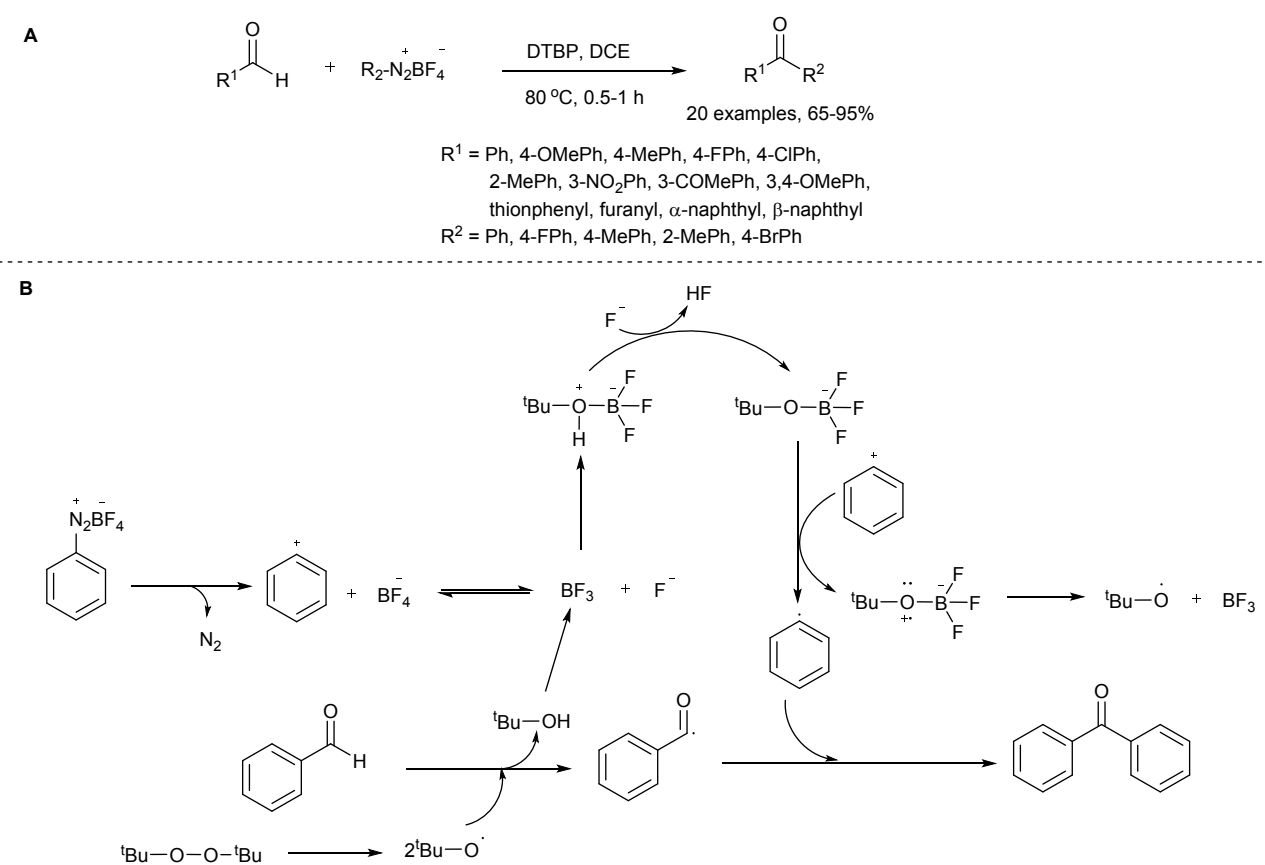

Scheme 19: (A) Metal-free cross coupling between aryl diazonium tetrafluoroborates and aldehydes to the synthesis of diaryl ketones; (B) plausible reaction mechanism.

In early 2016, Jiao and co-workers reported the $\mathrm{N}$ hydroxyphthalimide (NHPI) and palladium co-catalyzed oxidative acylation of acetophenone o-methyl oxime using aldehydes via selective $\mathrm{C}-\mathrm{H}$ functionalization. In this protocol molecular oxygen was used as terminal oxidant for $\mathrm{C}-\mathrm{H}$ acylation. ${ }^{54} \mathrm{~A}$ wide range of $\mathrm{o}$-methyl oximes and aldehydes (alkyl/aryl) was explored and various derivatives were prepared bearing electron withdrawing and releasing groups at $80^{\circ} \mathrm{C}$ within $24 \mathrm{~h}$ in 1,4-dioxane as solvent (Scheme 20A). The developed acylation reaction conditions were also applied for benzo[h]quinolone, 1-phenylpyrazole, 2phenylpyridine and 2-phenoxypyridine and the corresponding targeted products were acquired in moderate to good yields (Scheme 20B). Unfortunately, azobenzene and acetanilide provided inferior yields of the acylated products and phenyl $\mathrm{N}, \mathrm{N}$-dimethylcarbamate was found to be unreactive under these reaction conditions. The removal of the directing group using $\mathrm{HCl}$ /dioxane and subsequent intramolecular aldolization in the presence of $\mathrm{NaOH} / \mathrm{DMSO}$ converted the oxime ether into the isoindoline (Scheme 20C). 


\section{ARTICLE}

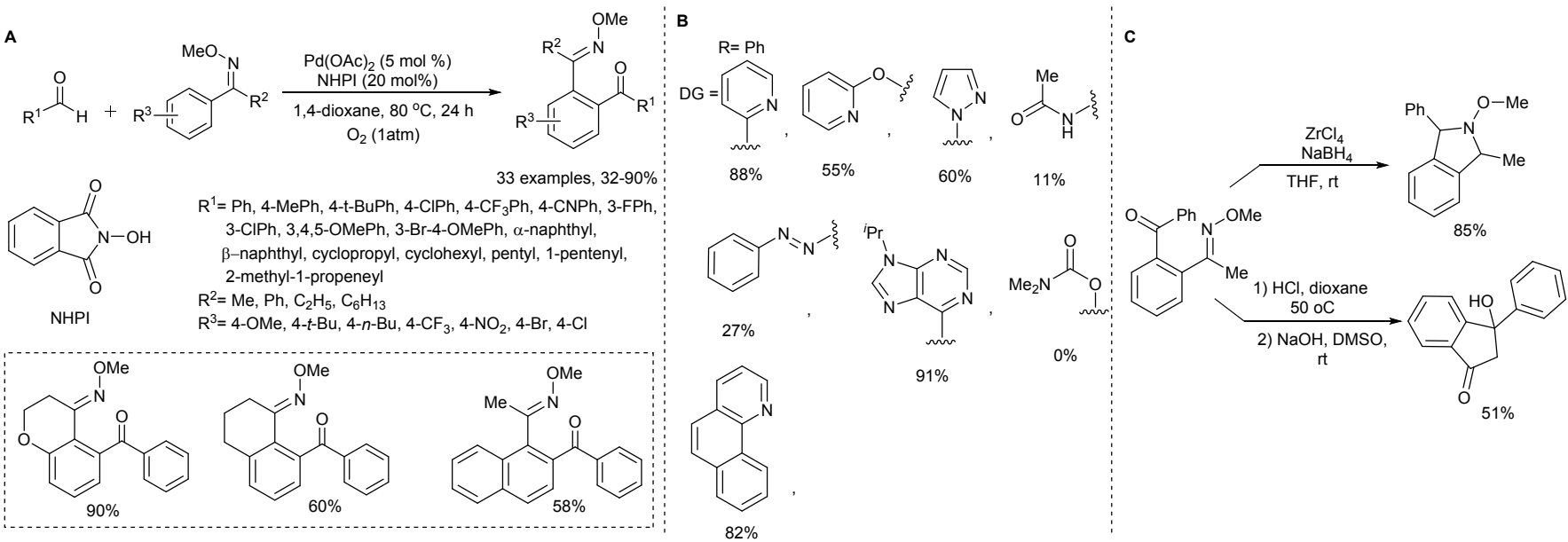

Scheme 20: NHPI and palladium co-catalyzed aryl C-H bond aerobic oxidative acylation in presence of various directing group with aryl/alkyl aldehydes and conversion of acylation product into isoindoline and 3-hydroxy-3-phenylindanone.

Zhao and Jiang in 2016 reported a proficient method for the selective acylation of 1,4-disubstituted 1,2,3-triazoles applying the 1,2,3-triazole moiety as directing group using aromatic aldehydes as acyl transfer agent in presence of Pdcatalyst (Scheme 21A). ${ }^{55}$ The best reaction conditions were used to prepare 27 derivatives in 55-92\% yield after $24 \mathrm{~h}$ of reaction at $120{ }^{\circ} \mathrm{C}$. Reaction proceeded with almost equal efficacy in case of aldehydes as well as 1,4-disubstituted 1,2,3triazoles. However, aldehydes with strong electron withdrawing groups $\left(\mathrm{NO}_{2}, \mathrm{MeS}=\mathrm{O}\right)$ afforded relatively lower yields. Further the authors carried out several experiments to gain insight into the reaction mechanism. The reaction between 4-phenyl-1-( $p$-tolyl)-1H-1,2,3-triazole and benzaldehyde in the presence of the free radical scavenger TEMPO gave only traces of the desirable compound demonstrating a radical pathway. Moreover, the intermolecular kinetic isotope effect $\left(k_{H} / k_{D}\right)$ was also determined and was found to be 6.3 , suggesting that the $\mathrm{et}$ cleavage of the $\mathrm{C}-\mathrm{H}$ bond may be the rate-limiting step (Scheme 21B). Based on outcomes of these experiments, a plausible reaction mechanism was proposed as outlined in Scheme 21C. 


\section{ARTICLE}

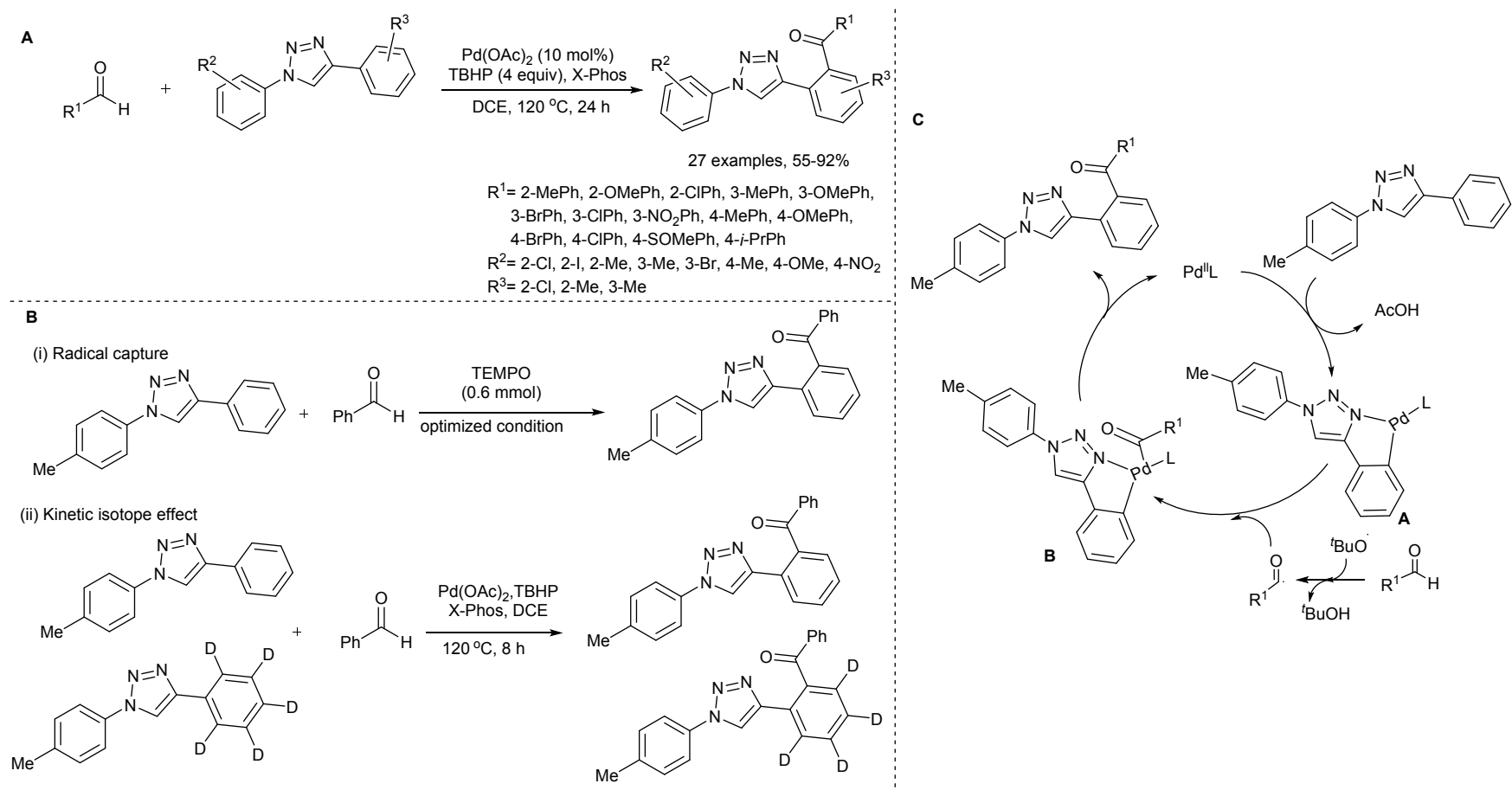

Scheme 21: (A) Regioselective acylation of 1,4-disubstituted 1,2,3-triazoles with aromatic aldehydes; (B) control experiments; (C) plausible reaction mechanism.

In contradiction of directing-group assisted direct acylation, in 2016, Suchand and Satyanarayan described an environmentally benign protocol for the Pd-catalysed direct acylation of an aryl system starting from simple and commercially available iodo arenes and aldehydes (alkyl/aryl), leading to the production of aryl-aryl and alkyl-aryl ketones (Scheme 22A). ${ }^{56}$ In total, 69 derivatives could be prepared in $45-89 \%$ yield using of $\mathrm{Pd}(\mathrm{OAc})_{2}$ as catalyst, $\mathrm{Ag}_{2} \mathrm{O}$ as additive and $70 \%$ aqueous solution of TBHP as oxidant after $12 \mathrm{~h}$ at 120 ${ }^{\circ} \mathrm{C}$, revealing a broad substrate scope and generality of the developed method. However, $p$-nitrobenzaldehyde could not result in the corresponding product but reaction was found to be compatible with $m$-nitroiodobenzene. The reaction was favorable with furan-2-carboxaldehyde, but was unsuccessful with pyridinecarboxaldehyde and thiophenecarboxaldehyde. Furthermore, product formation could not be observed with bromo arene implying that the more reactive iodo arenes are necessary for the achievement of this transformation. To further demonstrate the synthetic utility of this newly developed protocol, it was extended to the synthesis of benzofuranones by selective reduction of the keto group with $\mathrm{NaBH}_{4}$, followed by in-situ intramolecular nucleophilic attack of the hydroxyl group to the ester group of selected acylated compound to afford the corresponding benzofuranones (Scheme 22B). This approach was also used for the preparation of the antispasmodic pitofenone a combined drug in Spasmalon. Pitofenone was successfully prepared in just two steps using this protocol (Scheme 22C). 


\section{ARTICLE}

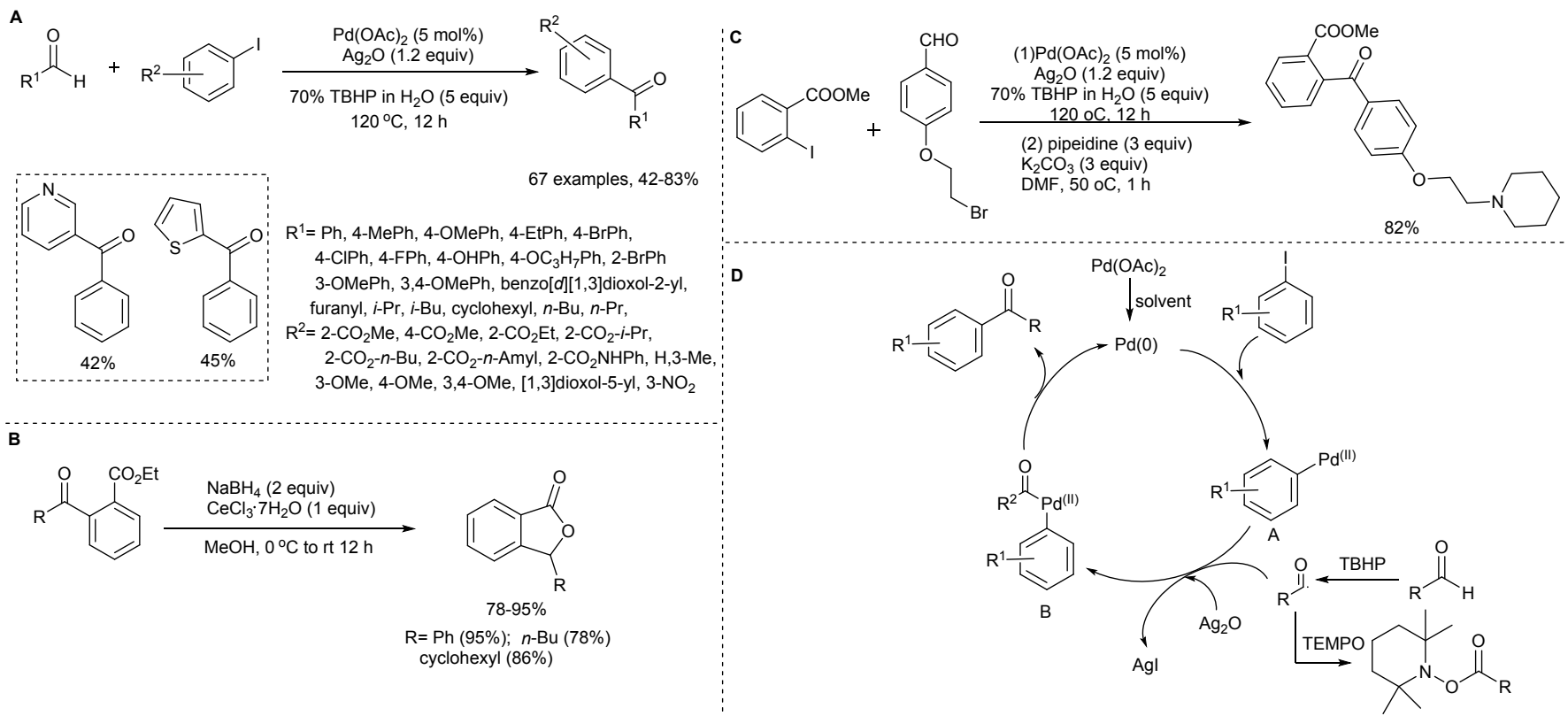

Scheme 22: (A) Pd-catalyzed direct acylation of iodo arenes with aldehydes (alkyl/aryl) leading to the aryl-aryl and alkyl-aryl ketones; (B) Conversion to benzofuranones by selective reduction of keto group; $(C)$ conversion to pitofenone; (D) plausible reaction mechanism.

To investigate the reaction mechanism, the authors anticipated that the reaction may progress through the development of an acyl radical of aldehyde due to TBHP. This hypothesis was proven by performing the reaction in the presence of TEMPO under standard conditions, as no product formation was observed whereas the aldehyde radicaltrapped ester was obtained in $95 \%$ yield. A plausible reaction pathway for this transformation is shown (Scheme 22D).

In 2017, Xiahng et al. established a protocol for direct $\mathrm{C}-\mathrm{H}$ functionalization of aldehyde via photoredox, nickel, and hydrogen atom transfer catalysis in a synergistic approach. ${ }^{57}$ This simple and efficient protocol transforms a wide variety of commercially available aldehydes with aryl or alkyl bromides into the desired ketones in excellent yield (Scheme 23A). Aryl bromides containing electron-withdrawing groups such as $\mathrm{CO}_{2} \mathrm{Me}, \mathrm{CN}, \mathrm{CF}_{3}, \mathrm{SO}_{2} \mathrm{Me}$ delivered the slightly higher product yield in comparison to those containing electron-releasing $\mathrm{Me}$, OMe groups. Monocyclic as well as bicyclic aromatics were also coupled effectively with tert-butyl-4formylpiperidine-1-carboxylate to furnish the respective products in good to excellent yields. Noticeably, vinyl bromides and alkyl bromides were also delivered the corresponding acylated products in good yields. Next, the scope of aldehydes was also investigated by coupling a wide range of aliphatic and aromatic aldehydes with 5-bromo-2(trifluoromethyl)pyridine and the desired products were obtained in good to excellent yields. A triple catalytic activation mechanism was proposed for this transformation (Scheme 23B). In the proposed mechanism, the photocatalyst $\operatorname{Ir}\left[\mathrm{dF}\left(\mathrm{CF}_{3}\right) \mathrm{ppy}\right]_{2}(\mathrm{dtbbpy}) \mathrm{PF}_{6}$ was excited into ${ }^{*} \operatorname{Ir}\left[\mathrm{dF}\left(\mathrm{CF}_{3}\right) \mathrm{ppy}\right]_{2}(\mathrm{dtbbpy})^{+}$in presence of visible light. The excited ${ }^{*} \operatorname{Ir}(\mathrm{III})$ affected the oxidation of quinuclidine to form radical cation and reduced $\operatorname{Ir}(\mathrm{II})$ complex. The formed radical cation then participates in hydrogen-atom transfer to generate the corresponding acyl radical. Subsequently, oxidative addition of aryl bromide to $\mathrm{L}_{n} \mathrm{Ni}(0)$ species delivers the aryl-Ni(II) species, which is converted into acyl-Ni(III) complex. After reductive elimination, the desired ketone product is obtained along with $\mathrm{Ni}(\mathrm{I})$ species. This is one of the crucial step where both nickel and photoredox catalytic cycles would simultaneously turn over via single electron transfer from the reduced $\operatorname{Ir}(I I)$ species to the $\mathrm{Ni}(I)$. Lastly, the quinuclidine catalyst is generated with the help of inorganic base via deprotonation of quinuclidinium ion. 


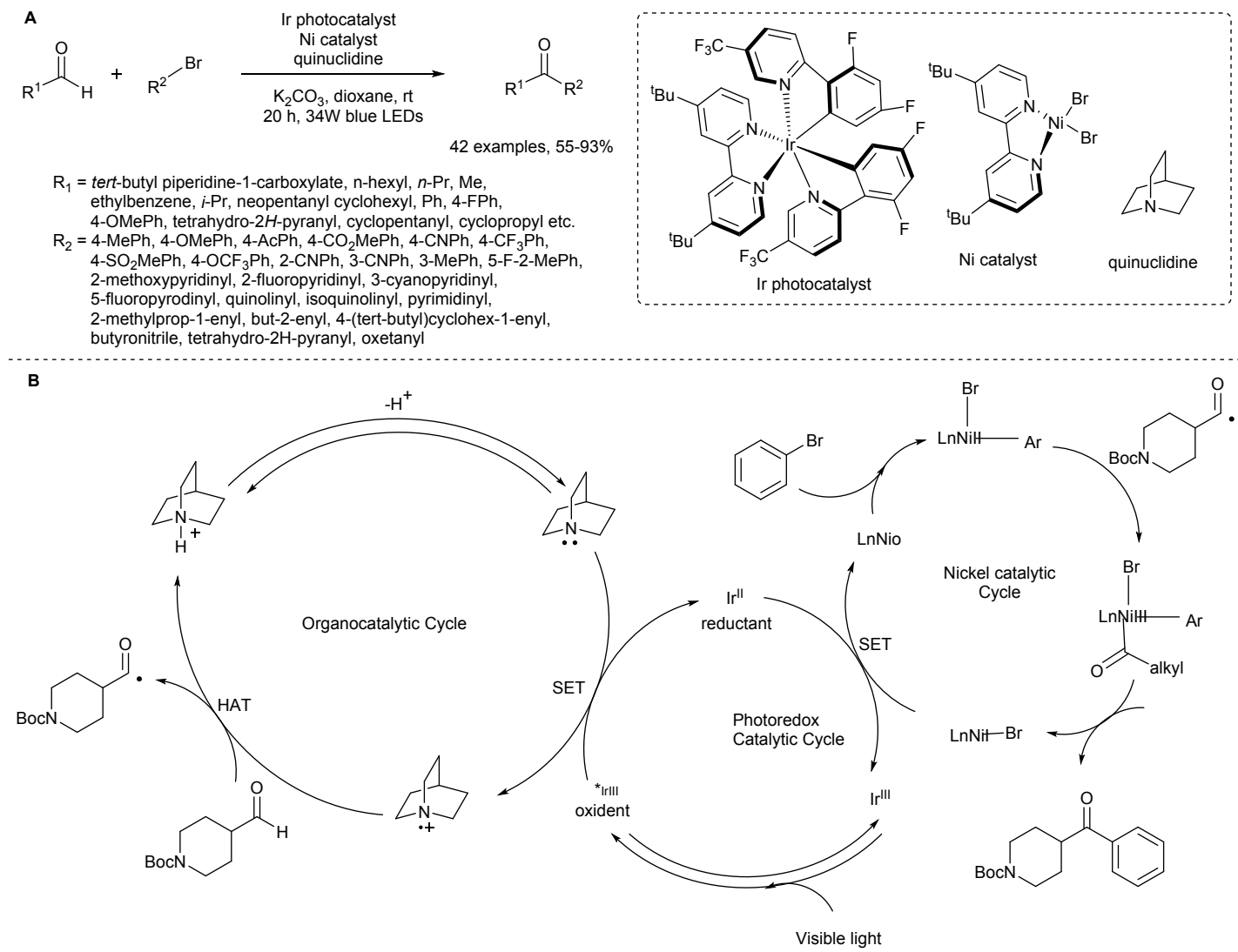

Scheme 23: (A) C-H functionalization of aldehyde via photoredox, nickel, and hydrogen atom transfer catalysis; (B) plausible reaction mechanism.

Newman and co-workers accomplished the direct intramolecular coupling between organotriflates and aldehydes using an innovative catalytic system comprising of $\mathrm{NiO}$ precatalyst, a phosphine based ligand and a base in 2017 (Scheme 24A). ${ }^{58}$ This catalytic reaction pathway provided a ready access to a relatively large number of ketone-containing compounds and prove to be superior to the conventional Friedel-Crafts reaction (FCRs). Unlike the FCRs, it did not pose any selectivity or reactivity related complexities. Both electron donating, withdrawing and bulkier sterically hindered hypothesis- were well tolerated on both the coupling partners. Interestingly, the aliphatic aldehydes were difficult to couple as they invariably lead to the formation of Tishchenko-type side products in presence of TMP. However, as the authors tried to switch to the quinuclidine motif, they successfully managed to obtain desired ketones. Besides, complex biologically active molecules could also be synthesized and derivatized. It was striking to note that the protocol also afforded benzothiophenes in good yield that showed a non-traditional/conventional disconnection for acquiring gateway to the synthetic precursor to raloxifene which is a significant estrogen receptor modulator. The most notable aspect of this protocol was that it lied within the premises of sustainable synthesis by not involving the use of any directing group (DG) that prevented waste generation and also eliminated the need for stoichiometric activation or intramolecular reactivity. It was anticipated by the authors that the mechanism primarily proceeded through a Heck type mechanism involving the role of $\pi$ bond of aldehyde moiety in the insertion-elimination stage. 


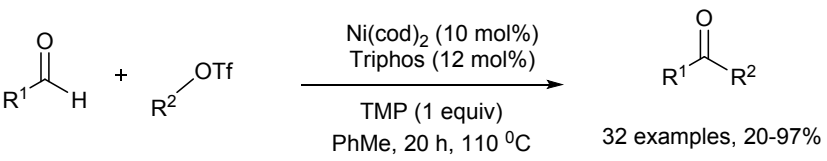

$$
\begin{aligned}
& \mathrm{R}^{1}=\mathrm{Ph}, 2-\mathrm{MePh}, 4-\mathrm{CNPh}, 3-\mathrm{FPh}, 2,3-\mathrm{OMePh} \text {, pyridinyl, } \\
& \text { thiophenyl, benzothiophenyl, furanyl, 3-hydroxyPh, } \\
& \text { indiolyl, 4-CIPh, cyclohexyl, ethylbenzene, n-pentane, } \\
& \text { 1-benzylpiperidinyl, tert-butyl } 1 H \text {-indolyl-1-carboxylate } \\
& \text { 6-methoxy-b-naphthyl, etc. } \\
& \mathrm{R}^{2}=\mathrm{Ph}, 4-\mathrm{OMePh}, 4-\mathrm{COMePh} \text {, pyridinyl, 4-CNPh, 4-FPh, etc. }
\end{aligned}
$$

Scheme 24: Ni-catalyzed direct intramolecular coupling between organotriflates and aldehydes.

In 2019 Chu et al. reported Pd(II)-catalyzed late stage ortho C$\mathrm{H}$ bond acylation of anilines with aromatic aldehydes using 3methoxy-2-pyridinyl as removable directing group. ${ }^{59} \mathrm{~A}$ wide substrate scope of differently substituted aryl aldehydes and $N$-protected anilines was explored to synthesize 26 monoacylated derivatives of aniline using $\mathrm{Pd}(\mathrm{OAc})_{2}$ as catalyst and TBHP as oxidant (Scheme 25A). However, in few cases along with monoacylated aniline formation diacylated product was observed. Aromatic aldehydes bearing electronreleasing as well as electron-donating groups reacted smoothly to give corresponding acylated products in good yields under optimized reaction conditions. Scope of substituted $N$-protected anilines was determined by coupling with benzaldehyde and aniline having electron releasing OMe group provided slightly better result in comparison to anilines having electron donating $\mathrm{F}, \mathrm{Cl}$ and $\mathrm{Br}$ groups. To elucidate whether reaction is proceeding through radical pathway or not radical trapping experiments were carried out using BHT (butylated hydroxytoulene), DPE (1,2-diphenylethylene) and TEMPO as free radical quencher. The results of the experiments revealed that a radical species could be involved in reaction. Furthermore, investigation of kinetic isotope effect indicates that the $\mathrm{Pd}$-catalyzed ortho $\mathrm{C}-\mathrm{H}$ bond cleavage of aniline is not involved in rate-determining steps. On the basis of the results of these experiments a plausible reaction mechanism was given by authors (Scheme 25A).

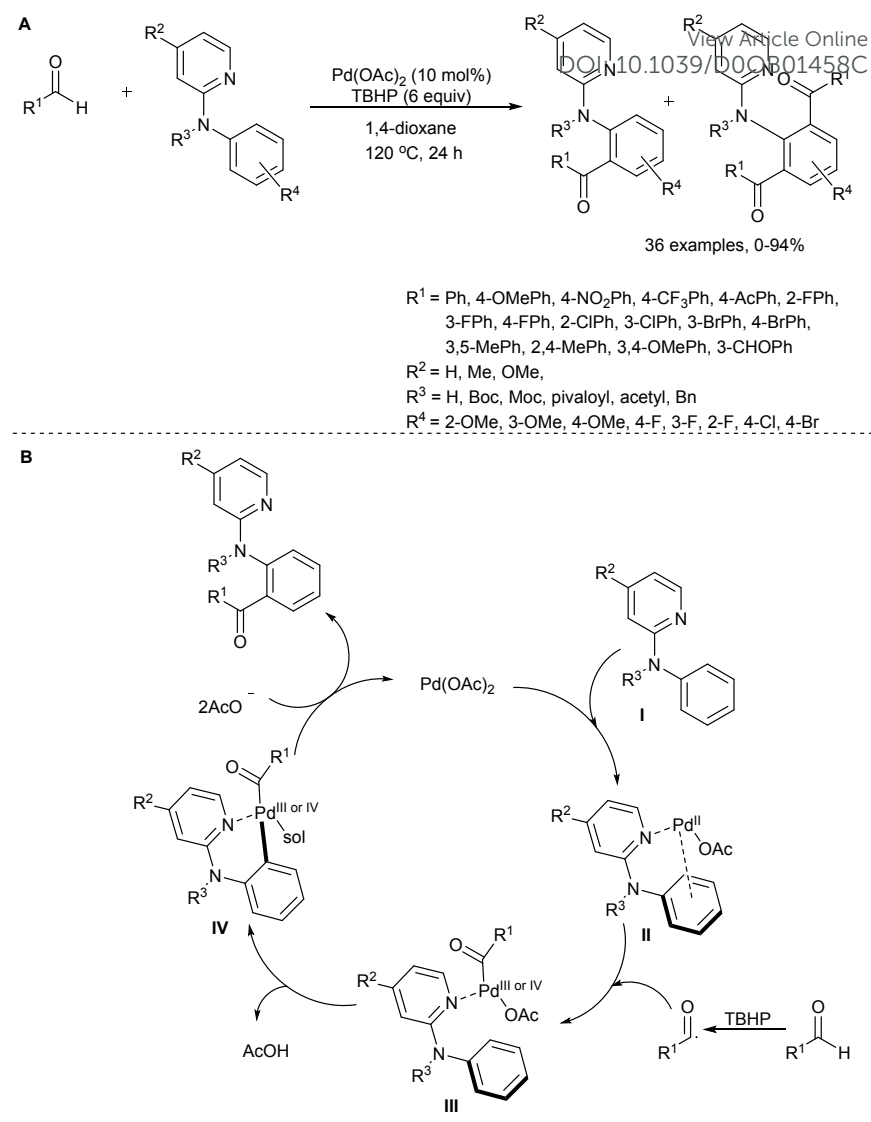

Scheme 25: (A) Pd(II)-catalyzed late stage ortho $\mathrm{C}-\mathrm{H}$ bond acylation of anilines with aromatic aldehydes; (B) plausible reaction mechanism.

In 2020, Panda and his group reported direct $\mathrm{o}$-acylation of $\mathrm{N}$ methoxysulfonamides with aromatic aldehydes in the presence of $\mathrm{Pd}(\mathrm{OAc})_{2}$ as catalyst and TBHP as oxidant. ${ }^{60}$ In this transformation sulfonamide served as directing group. The scope of various $\mathrm{N}$-methoxysulfonamides was investigated with aromatic aldehydes by synthesizing 22 o-acylated derivatives of $\mathrm{N}$-methoxysulfonamides in $31-68 \%$ yields (Scheme 26A). Aryl aldehydes as well as $\mathrm{N}$ methoxysulfonamides having electron-releasing groups or electron-withdrawing groups reacted smoothly and delivered the good yields of corresponding products. However, aliphatic aldehydes such as heptanal and nonanal yielded the desired products in poor yields. Unfortunately, in case of $-\mathrm{NO}_{2}$ group reaction failed due to the deactivation of the ring and starting material was recovered.

To design the reaction mechanism some control experiments such as deuterium exchange and kinetic isotope effect were carried out (Scheme 26B). Deuterium exchange experiment revealed that the initial cleavage of ortho $\mathrm{C}-\mathrm{H}$ bond of $\mathrm{N}$ methoxysulfonamide produces aryl-Pd intermediate involving a reversible process. Kinetic isotope effect suggested that intial cleavage of $\mathrm{C}-\mathrm{H}$ bond is a rate-limiting step. On the basis of these experiments and literature precedents a plausible reaction mechanism was proposed as shown in scheme $\mathbf{2 6 C}$. 


\section{ARTICLE}

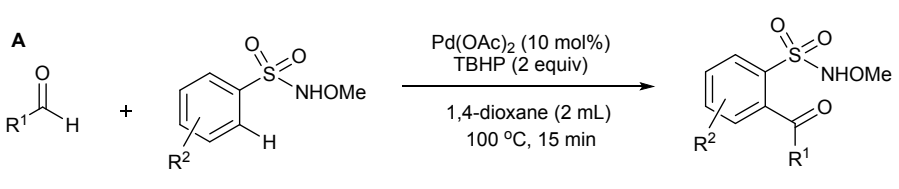

20 examples, $28-68 \%$

$\mathrm{R}^{1}=\mathrm{Ph}, 4-\mathrm{MePh}$, 4-CIPh, 4-BrPh, 4-FPh, 4- $\mathrm{NO}_{2} \mathrm{Ph}, 2-\mathrm{BrPh}$ 4-CNPh, 4- $\mathrm{CO}_{2} \mathrm{MePh}, n$-hexyl, $n$-octyl, styrenyl

$\mathrm{R}^{2}=\mathrm{H}, 4-\mathrm{Me}, 4-\mathrm{Et}, 4-\mathrm{Cl}, 4-\mathrm{Br}, 4-\mathrm{OMe}, 3,4-\mathrm{OMe}, 3,4-\mathrm{Me}$, $3,4-\mathrm{Cl}, 4-\mathrm{NO}_{2}$

\section{B Control experiments}

a) Deuterium exchange experiment
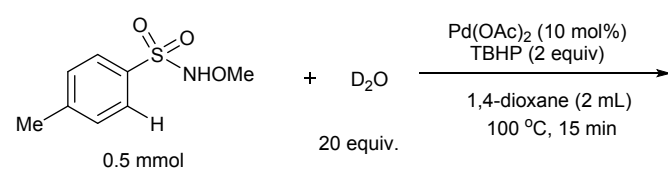

b) Kinetic Isotops Effect (KIE)<smiles>CONS(=O)(=O)c1ccccc1</smiles>

$0.25 \mathrm{mmol}$
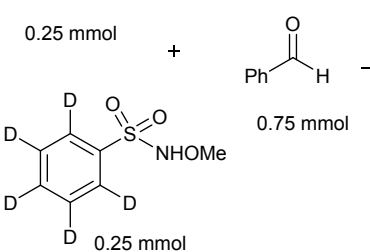

$\mathrm{Pd}(\mathrm{OAc})_{2}(10 \mathrm{~mol} \%)$ TBHP (2 equiv)

1,4-dioxane $(2 \mathrm{~mL})$

$100^{\circ} \mathrm{C}, 15 \mathrm{~min}$

$\mathrm{kH} / \mathrm{kD}=3.3$

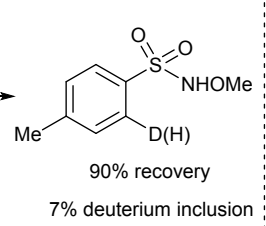

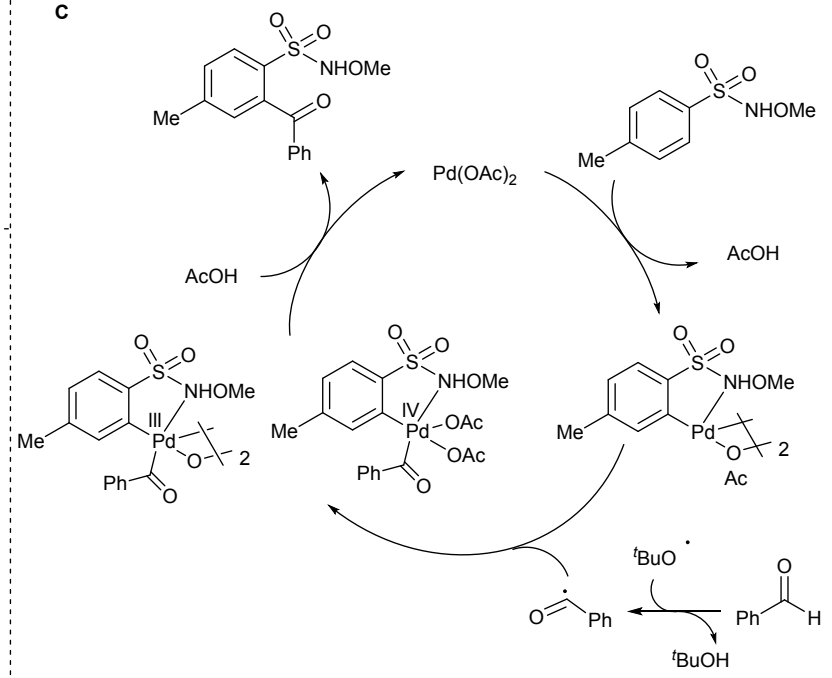

C

Scheme 26: (A) Pd-catalyzed direct o-acylation of $\mathrm{N}$-methoxysulfonamides with aromatic aldehydes; (B) control experiments; (C) proposed reaction mechanism.

In quest for exploring the efficacy of photoredox catalysis in $\mathrm{C}-\mathrm{H}$ activation, König and team in 2019 designed a photocatalytic pathway involving $\mathrm{Ni}$ based catalyst and achieved the dual catalytic benzoylation of aryl bromides. ${ }^{61}$ This unique pathway involved the efficient and smart amalgamation the concepts of photochemistry (395 nm LED as photoirradiation source) and nickel-catalysis $\mathrm{Ni}(\mathrm{dmbpy}) \mathrm{Br}_{2}$. The investigation was initiated by targeting the coupling of 4 chlorobenzaldehydes and 4-bromobenzonitriles. The results of the screening experiment revealed acetone as the optimal solvent, $\mathrm{Ni}(\mathrm{dmbpy}) \mathrm{Br}_{2}$ as the most efficient precatalyst and $\mathrm{Na}_{2} \mathrm{CO}_{3}$ as the preferred base. Thereafter, as the scope of the reaction was examined, it was found that the electron deficient substrates rendered the desired benzophenones in good to excellent yields. In particular, the halogenated ketone moieties were obtained in moderate to good yields. Also the heteroaryl ketones could be synthesized in moderate yield (Scheme 27A). Notably, 2-bromo-4-(trifluoromethyl)pyridine and 2-bromobenzothiazole could render substantial amount of product. Benzaldehyde also permitted the benzoylation of bromobenzene and electron rich bromides in good yield. Additionally, the scope of 4-bromobenzonitrile as the coupling partner was also explored. While most of the benzaldehydes showed good reactivity including the fluorinated benzaldehydes, yet 4-hydroxybenzaldehyde and 4-aminobenzaldehyde could not react to furnish the desired ketone. Based on various computations and experimental studies, a plausible mechanistic pathway was proposed (Scheme 27B). During the photoredox catalytic cycle, the first step involved the absorption of photon by benzophenone (BP) which led to the generation of a triplet state BP*. This in turn facilitated the abstraction of hydrogen atom from aldehyde, leading to the formation of both the acyl radical as well as the radical $\mathrm{BP}-\mathrm{H}$. The acyl radical was trapped by the generated $\mathrm{Ni}$ (II) species B formed via the oxidative addition of the $\mathrm{Ni}(0)$ complex $\mathbf{A}$ into the aryl bromide. The so formed $\mathrm{Ni}$ (III) species 
C was anticipated to form benzophenone BP and complex D via reductive elimination. The catalytic cycle was finally completed through the single electron transfer from BP-H to the $\mathrm{Ni}(\mathrm{I})$ bromide $\mathrm{D}$, that furnished $\mathrm{Ni}(0)$ complex $\mathrm{A}$ and $\mathrm{BP}$ (ground state).

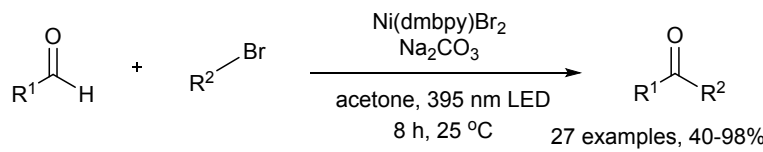

$\mathrm{R}^{1}=\mathrm{Ph}, 4-\mathrm{CNPh}, 4-\mathrm{CO}_{2} \mathrm{MePh}, 2-\mathrm{CNPh}$ 4-CF $\mathrm{CF}_{3} \mathrm{Ph}$, 4- ${ }^{\mathrm{B}} \mathrm{BuOPh}$, 4-MePh, 4- ${ }^{-} \mathrm{BuPh}, 4-\mathrm{CF}_{3} \mathrm{OPh}$, 3-FPh, 3- $\mathrm{CF}_{3} \mathrm{Ph}, 4-\mathrm{BzOPh}$

$\mathrm{R}^{2}=\mathrm{Ph}, 4-\mathrm{OMePh},{ }^{-}{ }^{-} \mathrm{BuPh}, 4-\mathrm{CNPh}, 4-\mathrm{CF}_{3} \mathrm{OPh}, 4-\mathrm{ClPh}$, 4- $\mathrm{CF}_{3} \mathrm{Ph}, 4-\mathrm{FPh}, 4-\mathrm{CF}_{3} \mathrm{SO}_{2} \mathrm{Ph}, 3,5-\mathrm{CF}_{3} \mathrm{Ph}, 4-{ }^{\mathrm{t}} \mathrm{BuCO} \mathrm{CO}_{2} \mathrm{Ph}$ pyridinyl, pyrimidinyl, 2-methylbenzo[d]thiazolyl, 6-chloropyridinyl

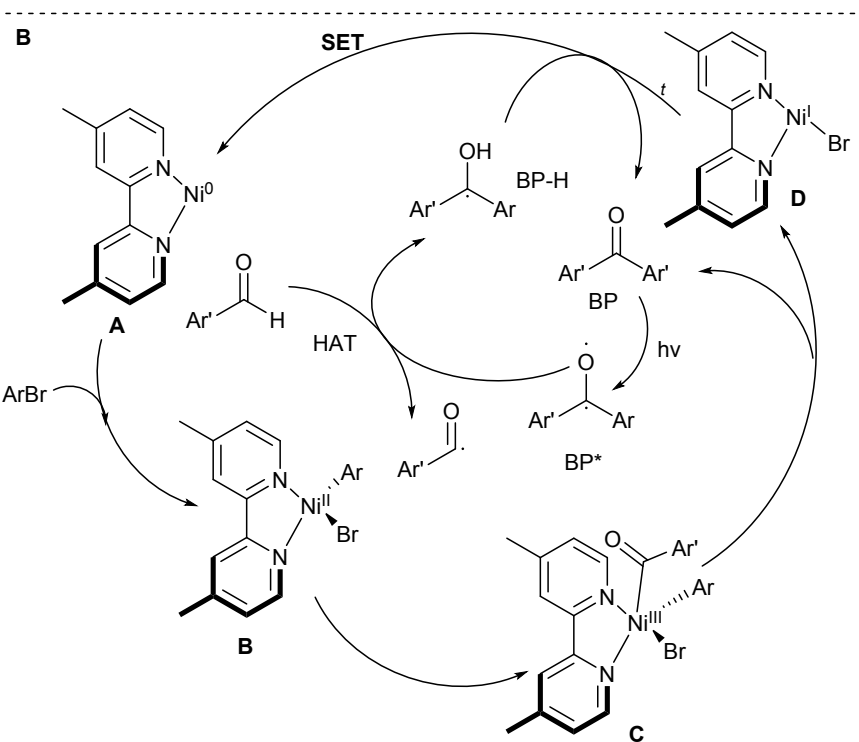

Scheme 27: (A) Ni-catalyzed photocatalytic dual benzoylation of aryl bromides; (B) proposed reaction mechanism.

\subsection{Acylation of alkyls}

\subsubsection{Acylation of $s p^{3}$ carbons}

Rovis and co-workers (2012) employed a dual-catalysis strategy for the asymmetric $\mathrm{sp}^{3} \alpha$-acylation of $1,2,3,4-$ tetrahydroisoquinoline using aldehydes as acylating agents. $\mathrm{A}$ chiral $\mathrm{N}$-heterocyclic carbene (NHC) in combination with photocatalyst $\left[\mathrm{Ru}(\mathrm{bpy})_{3}\right]^{3+}$ was used in the presence of $\mathrm{m}$ dinitrobenzene ( $m$-DNB) under blue light irradiation. ${ }^{62}$ Various aldehydes were reacted with substituted $N$-aryl-1,2,3,4tetrahydroisoquinolines and 16 derivatives were prepared in 51-94\% yield at ambient temperature (Scheme 28A). Authors projected a catalytic cycle which involves irradiation of $\left[\mathrm{Ru}(\mathrm{bpy})_{3}\right]^{2+}$ (III) using blue light resulting in excited $\left[\mathrm{Ru}(\mathrm{bpy})_{3}\right]^{* 2+}$ (II) which generated a powerful oxidant $\left[\mathrm{Ru}(\mathrm{bpy})_{3}\right]^{3+}(\mathrm{I}) .{ }^{63}$ Afterwards, single electron oxidation of the tetrahydroisoquinoline followed by hydrogen abstraction resulted in iminium ion $\mathbf{A}$ and recovering of $\left[\mathrm{Ru}(\mathrm{bpy})_{3}\right]^{2+}$ (III). On the other hand, interaction between NHC and aldehyde generated the nucleophilic Breslow intermediate $\mathbf{B}$, which then captured iminium ion $\mathbf{A}$ to form a new intermediate $\mathbf{C}$. Elimination of the $\mathrm{NHC}$ from intermediate $\mathrm{C}$ provided $\alpha$-amino ketone $\mathbf{D}$ and allowed NHC $\mathbf{E}$ to re-enter in catalytic cycle again (Scheme 28B). 


\section{ARTICLE}

A
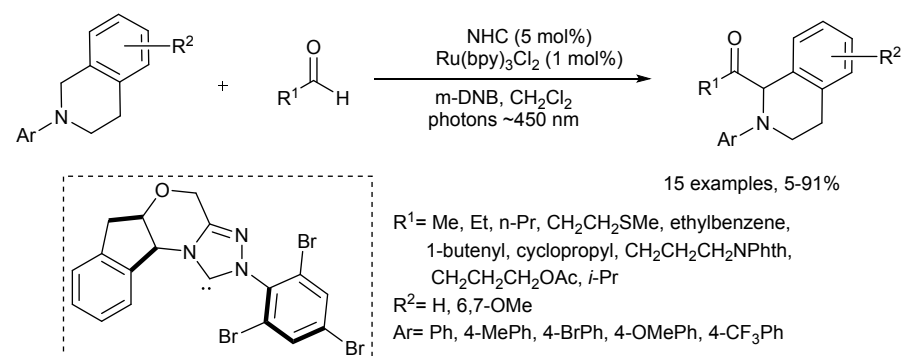

$\mathrm{R}^{1}=\mathrm{Me}, \mathrm{Et}, \mathrm{n}-\mathrm{Pr}, \mathrm{CH}_{2} \mathrm{CH}_{2} \mathrm{SMe}$, ethylbenzene, 1-butenyl, cyclopropyl, $\mathrm{CH}_{2} \mathrm{CH}_{2} \mathrm{CH}_{2} \mathrm{NPhth}$,

$\mathrm{CH}_{2} \mathrm{CH}_{2} \mathrm{CH}_{2} \mathrm{OAc}, i-\mathrm{Pr}$

$\mathrm{R}^{2}=\mathrm{H}, 6,7-\mathrm{OMe}$

$\mathrm{NHC}$

$\mathrm{Ar}=\mathrm{Ph}, 4-\mathrm{MePh}, 4-\mathrm{BrPh}, 4-\mathrm{OMePh}, 4-\mathrm{CF}_{3} \mathrm{Ph}$

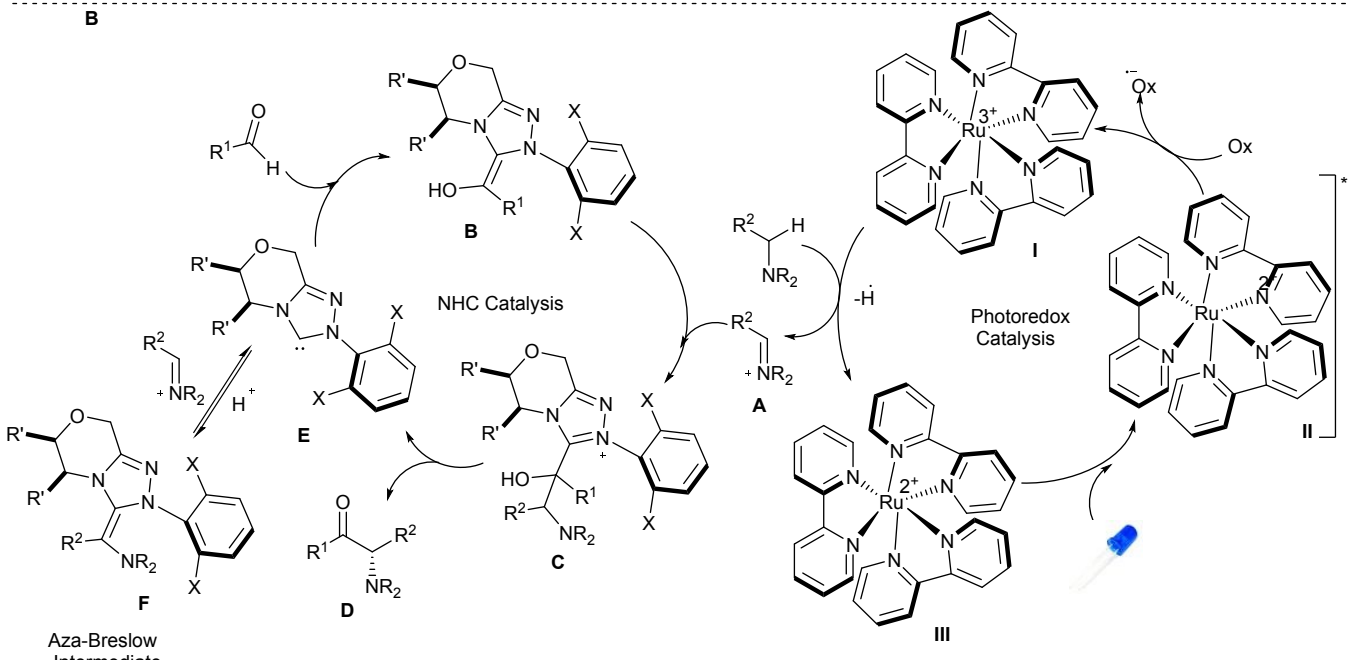

Intermediate

Scheme 28: Photocatalyzed asymmetric $\mathrm{sp}^{3}$-acylation of tertiary amines and proposed catalytic cycle

Suresh and co-workers developed a intermolecular tandem Cu-catalyzed $O$-arylation-oxidative acylation protocol between 2,4-dihydro-3H-pyrazol-3-ones and $O$-halo aryl carboxaldehydes to synthesize chromone fused pyrazoles using air as an ideal oxidant. ${ }^{64}$ The reactions were carried out taking $0.5 \mathrm{mmol}$ of 2,4-dihydro-3H-pyrazol-3-ones, $0.6 \mathrm{mmol}$ of $o$-halo aryl carboxaldehydes in the presence of Cul as catalyst, 1,10-phenanthroline as ligand, $\mathrm{K}_{2} \mathrm{CO}_{3}$ as base at 120 ${ }^{\circ} \mathrm{C}$ in DMSO as solvent. The reaction was used to prepare 25 chromone fused pyrazoles in moderate to good yields presetting countable tolerance towards diverse substituents in substrate. During the initial screening of substrates 2bromobenzaldehdye provided better results than 2chlorobenzaldehdye and 2-iodobenzaldehdye, suggesting that bromo group as a better leaving group for this transformation. Afterwards, the scope of various differently substituted 2-bromobenzaldehydes was explored and it was found that electron donating groups on 2bromobenzaldehyde were well accepted and provided the resultant products in good yield. However, an electronwithdrawing group such as fluorine gave the corresponding chromone fused pyrazole in moderate yield. Tetracyclic chromone fused pyrazole was obtained in $66 \%$ yield with 1bromo-2-naphthaldehdye on the other hand the reaction of $N$-Boc pyrazolone with 2-bromobenzaldehdye failed to deliver product. Moreover, this methodology was not found suitable in the case of heteroaromatic aldehyde like 2chloronicotinaldehdye (Scheme 29A). 


\section{ARTICLE}<smiles>[Y]C1=NN([CH])C(=[OH+])C1</smiles><smiles>[X]c1ccccc1C=O</smiles>

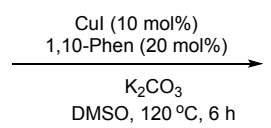
$\mathrm{X}=\mathrm{Br}, \mathrm{Cl}, \mathrm{I}$<smiles>Cc1nn(-c2ccccc2)c2oc3cc4c(cc3c(=O)c12)OCO4</smiles>
$\mathrm{Ph} \quad 51 \%$<smiles>Cc1nn(-c2ccccc2)c2oc3c(ccc4ccccc43)c(=O)c12</smiles><smiles>O=c1c(-c2ccccc2)nn([O+])c2oc3cc4ooc4cc3c12</smiles>
$\mathrm{Ph}^{\mathrm{N}}{ }_{51 \%}$ B

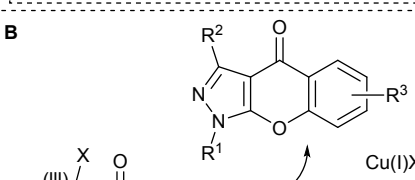<smiles></smiles><smiles>[X]c1ccccc1C=O</smiles><smiles>[X]C(C)(C)c1ccccc1COCCC</smiles>

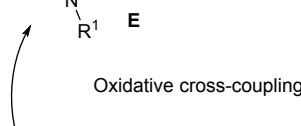

Oxidative cross-coupling<smiles>[X][Ge]1(C)OC=Cc2ccccc2O1</smiles>
O-Arylation
27 examples, $25-74 \%$

$\mathrm{R}^{1}=\mathrm{Ph}, 3-\mathrm{NO}_{2} \mathrm{Ph}, \mathrm{Me}$, benzy $\mathrm{R}^{2}=\mathrm{Me}, \mathrm{Ph}, n-\mathrm{Pr}, t-\mathrm{Bu}, \mathrm{CF}_{3}$ $\mathrm{R}^{3}=\mathrm{H}, 7-\mathrm{Me}, 6-\mathrm{OMe}, 6-\mathrm{F}, 6-\mathrm{B}$ 8-Cl, 5-Cl, 7-F-6-OMe

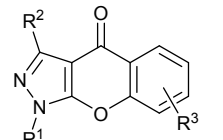

$\mathrm{R}^{1}$ :

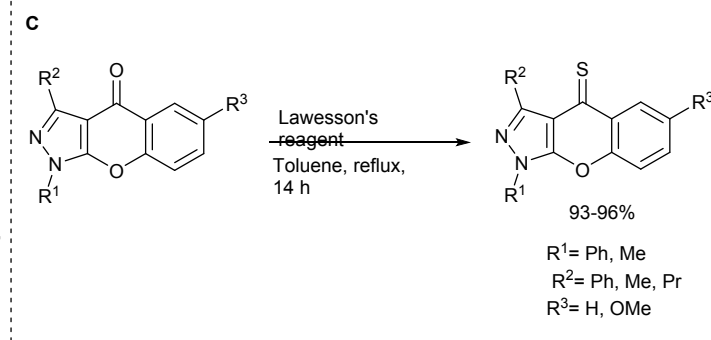

D

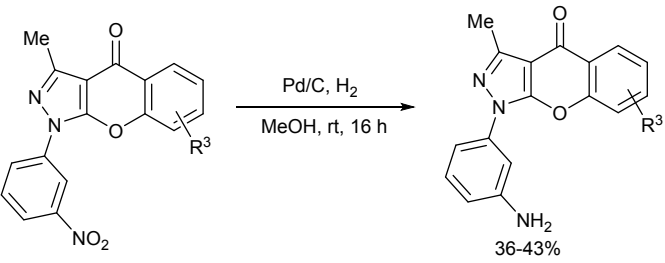

$\mathrm{R}^{3}=\mathrm{H}, 6-\mathrm{OMe},[1,3]$ dioxoly

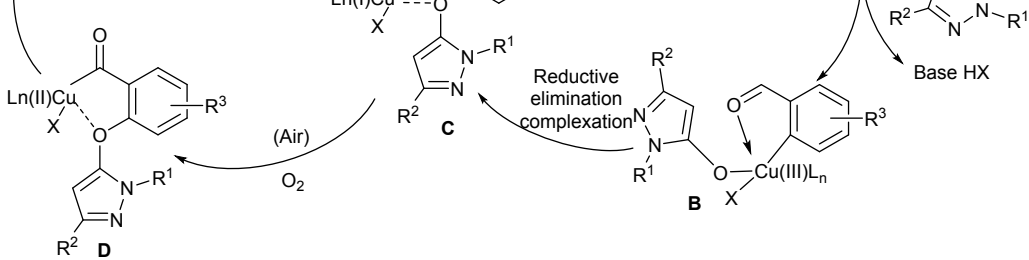

Scheme 29: (A) Cu-catalyzed ortho-arylation-oxidative acylation of 2,4-dihydro-3H-pyrazol-3-ones with ortho-halo aryl carboxaldehydes; (B) Plausible reaction mechanism; (C) Thionation of few chromone fused pyrazoles; (D) conversion of chromone fused pyrazoles into an $\mathrm{A}_{2}$-subtype selective adenosine receptor antagonist and its derivatives.

Based on the literature report and control experiments, a plausible mechanism was proposed for this methodology (Scheme 29B). The applicability of the developed method was also checked for the gram scale and the targeted product was obtained in $68 \%$ yield. Moreover, some synthesized compounds were also treated with Lawesson's reagent and the thione derivative was obtained in 93\% yield (Scheme $29 \mathrm{C}$ ). The method had also been extended to synthesize an A2subtype selective adenosine receptor antagonist and its derivatives (Scheme 29D). 


\section{ARTICLE}

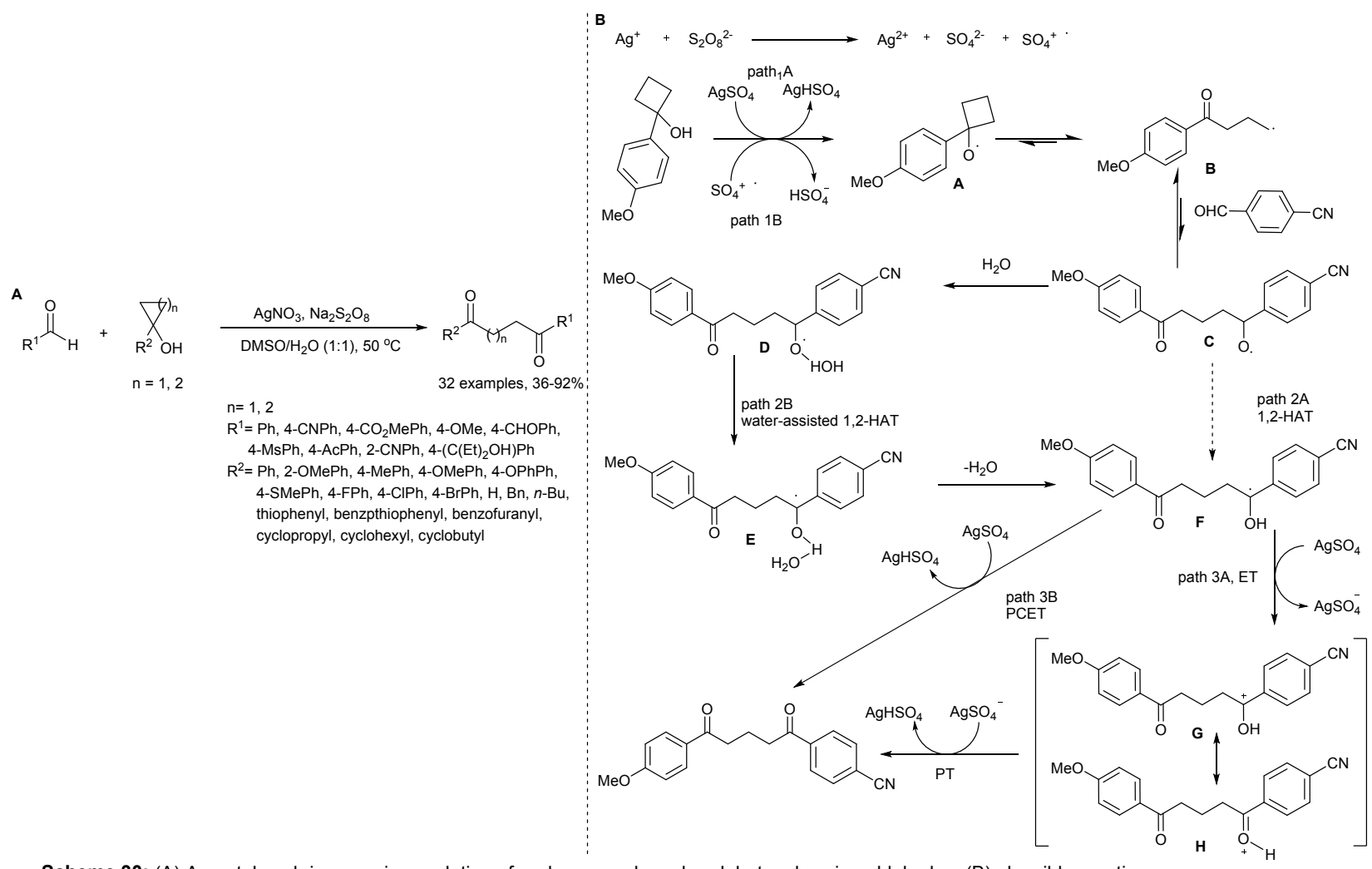

Scheme 30: (A) Ag-catalyzed ring opening acylation of cyclopropanols and cyclobutanols using aldehydes; (B) plausible reaction mechanism.

Che et al. in 2018, described Ag-catalyzed ring opening acylation of cyclopropanols and cyclobutanols through intermolecular oxidative radical addition of aromatic aldehydes using mild and neutral reaction conditions. ${ }^{65}$ 1-(4Methoxyphenyl)cyclobutan-1-ol and p-cynobenzaldehydye were chosen as model reaction substrates to evaluate the reaction parameters. Using the optimized reaction conditions, the substrate scope with respect to cyclopropanols, cyclobutanols and aromatic aldehydes was explored and 32 derivatives were prepared in $36-92 \%$ yield at $50{ }^{\circ} \mathrm{C}$ (Scheme 30A). The reactions proceeded smoothly with the applied substrates bearing distinct functional groups of varying electronic behaviour. To investigate the reaction mechanism, the reaction between model reaction substrates 1-(4methoxyphenyl)cyclobutan-1-ol and $p$-cyanobenzaldehdye was carried out using TEMPO under standard reaction conditions and a mixture of products was obtained without any acylated product. The results of control experiments ruled out the formation of any possible acyl radical. Based on these outcomes and earlier reports, a probable mechanism was proposed as displayed in scheme 30B.

\subsubsection{Acylation of $s p^{2}$ carbons}

In 2013, Wang et al. developed an efficient and novel approach for the synthesis of $\alpha, \beta$-unsaturated keto compounds by $\mathrm{Cu}$-catalysed direct oxidative coupling reaction of alkenes and aldehydes with high atom economy. ${ }^{66}$ For the successful transformation of alkenes and aldehydes into the desirable $\alpha, \beta$-unsaturated keto compounds, the authors carried out the reactions using $\mathrm{CuCl}_{2}$ as most suitable catalyst and TBHP as oxidant under nitrogen atmosphere. All the employed aldehydes and alkenes underwent coupling reaction effectively under the used reaction conditions irrespective of the positions and electron behaviour of substituents present either on the aromatic aldehydes or the alkenes resulting in 18 derivatives in $30-80 \%$ yield (Scheme 31A). Authors investigated the possible mechanism by performing the reaction in the presence of radical trapping 
substance 2,6-di-tert-butyl-4-methylphenol (BHT) under standard reaction conditions, and the reaction found to follow a free radical pathway as shown in scheme 31B. DOI: 10.1039/D0OB01458C

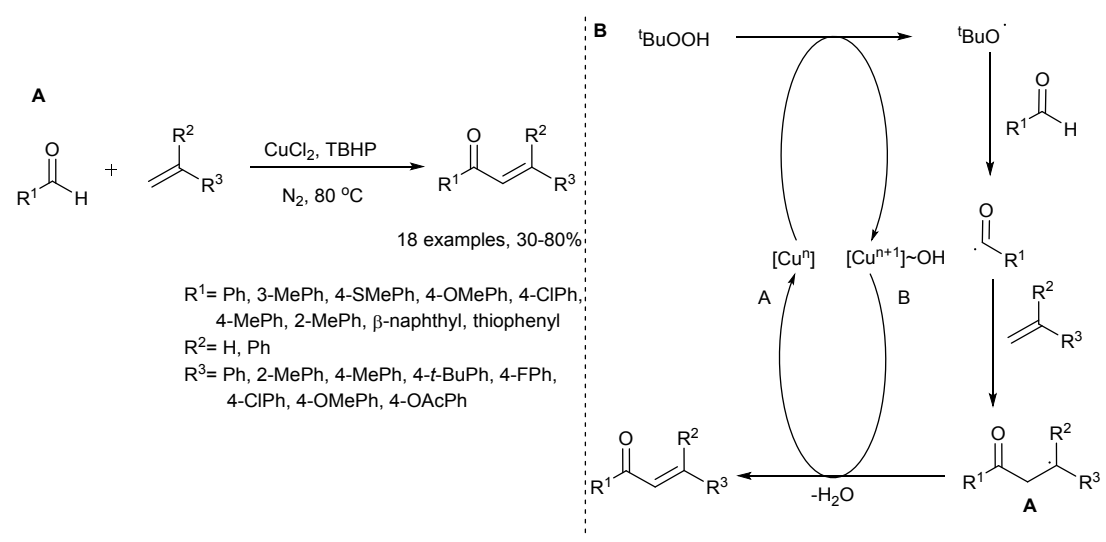

Scheme 31: (A) Cu-catalyzed direct oxidative coupling between alkenes and aldehydes; (B) plausible reaction mechanism.

In 2015, Li and co-workers developed a Fe-catalysed protocol for the acylation of terminal alkenes which undergoes subsequent intramolecular oxygenation in a tandem manner to deliver functionalized 2,3-dihydrofurans having a quaternary carbon. ${ }^{67}$ The method bears a few salient features, which include the insertion of carbonyl substituents and a quaternary carbon containing various functional groups like alkyl, aryl and esters. To check the applicability of the newly developed method several aldehydes (aromatic and aliphatic) were treated with a variety of terminal alkenes in the presence of $\mathrm{FeCl}_{2}$ as catalyst, di-tert-butylperoxide (DTBP) as oxidant and chlorobenzene as solvent under nitrogen atmosphere. The authors prepared 17 different acylated- oxygenated products in $22-65 \%$ yield after $1 \mathrm{~h}$ of reaction at 50 ${ }^{\circ} \mathrm{C}$ (Scheme 32A).

Olefinic $\beta$-diketones and olefinic $\beta$-ketone esters smoothly reacted with benzaldehydes to provide theresultant dihydrofurans in moderate yields. However, the presence of a $\mathrm{SO}_{2} \mathrm{Ph}$ group on the alkene suppressed the reaction with benzaldehyde and the desired product was not observed. Moreover, the scope of aldehydes was also studied and both aromatic as well as aliphatic aldehydes reacted effectively under the optimized reaction conditions and afforded the products in moderate to good yields. However, in the case of cyclohexane carboxaldehdye and pivaldehyde, decarbonylation products were obtained. 


\section{ARTICLE}

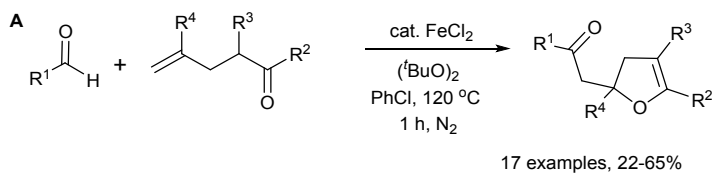

$\mathrm{R}^{1}=\mathrm{Ph}$, cyclopropyl, $t-\mathrm{Bu}, 4-\mathrm{MePh}, 4-\mathrm{OMePh}, 4-\mathrm{BrPh}$, thiopheyl $\mathrm{R}^{2}=\mathrm{Ph}, 4-\mathrm{MePh}, 4-\mathrm{OMePh}, 4-\mathrm{CIPh}, \alpha-$ naphthyl

$\mathrm{R}^{3}=\mathrm{COPh},(\mathrm{CO})-4-\mathrm{MePh},(\mathrm{CO})-4-\mathrm{OMePh},(\mathrm{CO})-4-\mathrm{CIPh}, \mathrm{CO}_{2} \mathrm{Me}, \mathrm{CO}_{2} \mathrm{Et}, \mathrm{Me}$ $\mathrm{R}^{4}=\mathrm{CO}_{2} \mathrm{Me}, \mathrm{CO}_{2} \mathrm{Bn}, \mathrm{Ph}, \mathrm{Me}$
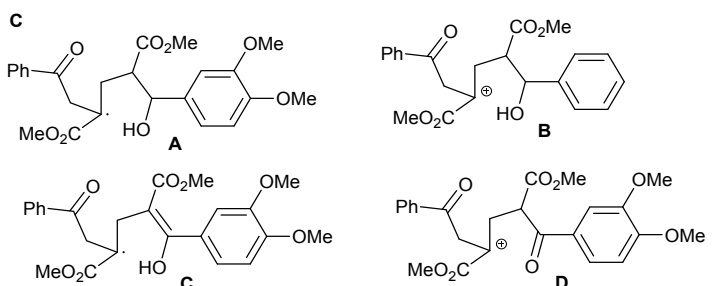<smiles>C=C(CC(C(=O)[CH+]C(=O)c1ccccc1)C(=O)c1ccccc1)C(=O)c1ccccc1</smiles>

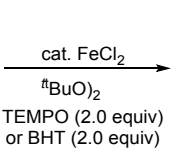<smiles>CC(=O)CC1(C(C)=O)CC(C(=O)c2ccccc2)=C(c2ccccc2)O1</smiles><smiles>C=C(CC(C(=O)OC)C(=O)c1ccc(OC)c(OC)c1)C(C)=O</smiles><smiles>COc1ccc(C2=C(C(C)=O)CC(CC(C)=O)(C(C)=O)O2)cc1OC</smiles>

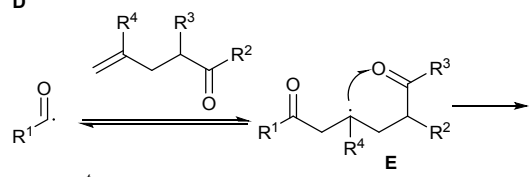<smiles>[R]C(=O)CC1([R])CC([R])C([R])O1</smiles>
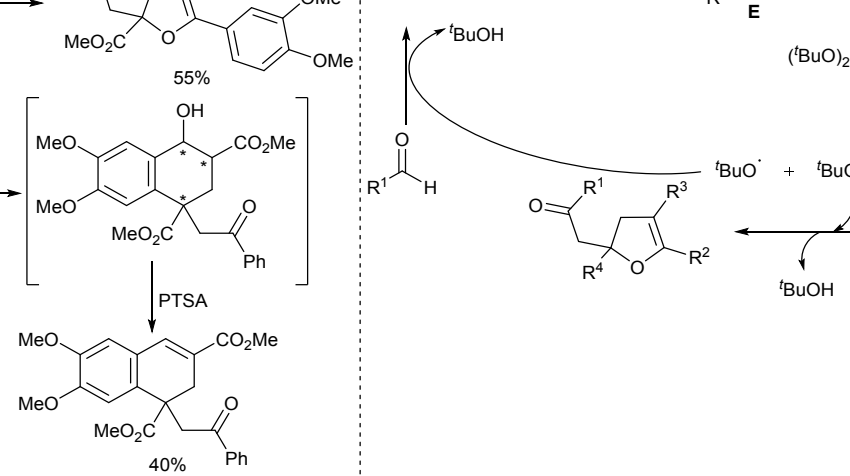

Scheme 32: (A) Fe-catalyzed tandem acylation of terminal alkenes; (B, C) comtrol experiments and (D) plausible reaction mechanism.

To get an insight in the reaction mechanism, few control experiments were performed under standard conditions (Scheme 32B). The use of radical scavengers TEMPO and BHT totally suppressed product formation and the alkene was recovered quantitatively supporting the addition of an acyl radical to the $\mathrm{C}=\mathrm{C}$ bond in the initial step. The reaction of benzaldehyde with the olefinic ketone resulted in the preferred dihydrofuran in 55\% yield. An alkene having a hydroxyl group instead of a carbonyl group delivered a tetrahydronaphthalene as the major product, which on subsequent dehydration gave dihydronaphthalene. However, required the tetrahydrofuran product could not be obtained via possible intermediates $\mathbf{A}$ and $\mathbf{B}$. Based on these results, it wasclear that the formation of the dihydrofuran was not possible through the possible intermediate $\mathbf{C}$ or $\mathbf{D}$ (Scheme 32C). Based on the observations of experiments and literature reports, a tentative reaction mechanism was established (Scheme 32D).
The idea of visible light mediated dual photoredox organocatalysis for the direct aldehyde $\mathrm{Csp}^{2} \mathrm{C}-\mathrm{H}$ functionalization was also fruitfully utilized by Liu et al. ${ }^{68}$ The protocol led to the generation of acyl radical species that either underwent addition to electrophilic alkenes or participated in the $\mathrm{Ni}$-catalysed cross coupling reactions, allowing the synthesis of a diverse range of unsymmetrical ketones, present predominantly in various organic building blocks. During the initial trials, benzaldehyde and 2cyclohexeneone were chosen as the model substrates for the purpose of optimization and delightfully, moderate yields of the desirable adduct could be formed. In order to investigate the ability of quinuclidine as the HAT catalyst, a series of experiments were performed using a number of co-catalysts. Also, a few photoredox catalysts were tested amongst which $\left.\left[\operatorname{Ir}\left[\mathrm{dF}_{3}\right) \text { ppy }\right]_{2}(\mathrm{dtbbpy})\right] P F$ where $(\mathrm{dF}=3,5$-diFluoro; ppy $=2$ phenylpyridine; dtbbpy $=4,4^{\prime}$-ditert-butyl-2,2'-bipyridine) complex emerged to be a material of choice. Amongst the various tested solvents, acetonitrile (MeCN) prove to be the most favourable one resulting in high product yield. The 
control experiments significantly re-inforced the need of both catalyst as well as visible light to mediate this transformation. Henceforth, the authors engaged themselves in the mission of evaluating the scope of the reaction by subjecting a diversity of aldehydes and found the aliphatic linear as well as branched chain aldehydes to be more reactive and affording the desired products smoothly in moderate to good yields as compared to the aromatic aldehydes (Scheme 33A). It was striking to note that in case of the weaker benzylic $\mathrm{Csp}^{3} \mathrm{C}-\mathrm{H}$ bonds, selective $\mathrm{Csp}^{2} \mathrm{C}-\mathrm{H}$ activation could be achieved. Surprisingly, the branched aldehyde motifs yielded trace amounts of decarbonylated product.

The protocol was also applicable for an expansive range of olefin acceptor as evident from the obtained results. $\alpha, \beta$ unsaturated ketones resulted in quantitative yields and electron withdrawing substituents such as sulphones were well tolerated. However, in case of acrolein addition, the conversion was rather low. Also, wondrously, the cyclohexanecarboxyl radical was unable to open cyclopropane ring and starting material could be procured as such as it remained totally unreactive. Furthermore, to add to the credentials, this strategy could also be extended to cooperative catalysis with $\mathrm{Ni}$ catalysed cross coupling between the generated acyl radical and organohalides (Scheme 33B).

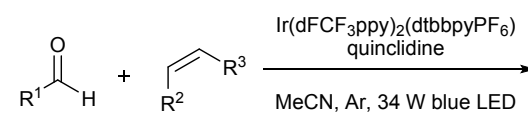

$12 \mathrm{~h}$

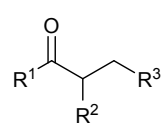

20 examples, $31-99 \%$
$\mathrm{R}^{1}=\mathrm{Ph}, 4-\mathrm{BrPh}$, ethylbenzene, cyclohexyl, cyclopentyl, $n$-hexyl, ethyl, i $\mathrm{Pr},{ }^{i} \mathrm{Bu}, \mathrm{CH}_{2} \mathrm{CH}\left(\mathrm{CH}_{3}\right) \mathrm{Ph}, \mathrm{CHEt}_{2}$, etc.

$\mathrm{R}^{2}=\mathrm{CO}_{2} \mathrm{Me}, \mathrm{H}, \mathrm{Me}$

$\mathrm{R}^{3}=\mathrm{CO}_{2} \mathrm{Me}, \mathrm{H}, \mathrm{CO}_{2} \mathrm{Et}, \mathrm{CO}_{2}{ }^{t} \mathrm{Bu}, \mathrm{COCH}_{2} \mathrm{Me}, \mathrm{COMe}, \mathrm{SO}_{2} \mathrm{Ph}, \mathrm{CN}$

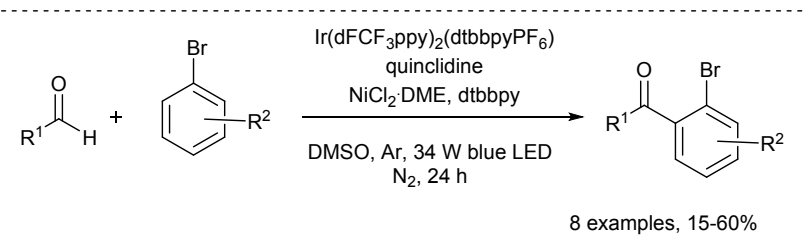

$\mathrm{R}^{1}=\mathrm{Ph}$, ethylbenzene, cyclohexyl, cyclopentyl, $n$-hexyl, ethyl, $\mathrm{CH}_{2} \mathrm{CH}\left(\mathrm{CH}_{3}\right) \mathrm{Ph}, \mathrm{CHEt}_{2}$

$\mathrm{R}^{2}=2-\mathrm{CN}, 4-\mathrm{AC}$

Scheme 33: Ir catalyzed aldehyde $\mathrm{Csp}_{2} \mathrm{C}-\mathrm{H}$ functionalization of $(\mathrm{A})$ alkenes and $(B)$ arylhalides using aldehdyes.

Kokotos and co-workers developed a green photo organocatalytic route for the $\mathrm{C}-\mathrm{H}$ activation of aldehydes which led to the selective hydroacylation of electron deprived alkenes. ${ }^{69}$ For accomplishing this, phenylglyoxalic acid was utilized as the photocatalyst and household bulbs for the purpose of photo irradiation. The authors began their investigation by questioning whether theph photocatalyst could provide the desired solution and in this endeavour they tested a wide range of photoinitiators in the model reaction between cyclohexaldehyde and diethyl maleate. Amongst all the tested photocatalytic sources, phenylglyoxalic led to higher product yield with excellent selectivity. On further experimentation, it was found that the reaction could also take place in water and sunlight, but in the absence of either of these, the reaction failed to proceed. After optimizing the reaction conditions, the authors examined the scope of substrates and found that while the branched aldehydes led to higher product yield and selectivity, linear aliphatic aldehydes also rendered single product with good to excellent yield (Scheme 34A). Thereafter, alkenes and aliphatic esters were also screened. Despite showing a wide generality, the protocol failed in case of amides of maleic acid and other esters such as methyl acrylate, methyl crotonate, and $\mathrm{N}$-phenyl maleimide due to polymerization issues. Also, when dibenzyl fumarate was subjected to the similar reaction conditions, the product was obtained in lower yield.

To probe the reaction mechanism, fluorescence quenching studies and UV-Visible experiments were performed. Through the results of the fluorescence test, it was interpreted that the acyl radical was not generated directly by the excited phenylglyoxylic acid, unlike what had been observed in case of literature precedents. However, in case of esters of maleic acid (diethyl maleate and fumarate) quenching of phenylglyoxylic acid was observed. On the basis of various mechanistic studies, a mechanism was proposed (Scheme 34B). The irradiation led to the excitation of phenylglyoxalic acid which formed an exciplex (inferred as a radical ion pair) with diethyl maleate via a photoinduced electron transfer (PET) process. The exciplex was found to be in equilibrium with another ion pair generated between $\mathrm{PhCOCOOH}$ and water. In absence of a HAT donor aldehyde, photodecomposition occurred, quickly leading to the formation of benzaldehyde. On the other hand, when the HAT donor (aldehyde) was present, a HAT process with the aldehyde furnished the acyl and $\mathrm{PhCOCOOH}$ radical which slowly underwent decomposition to form benzaldehyde. The fluorescence quenching test also affirmed that the HAT process could not be initiated by the phenylglyoxalic acid on its own. This could also be the reason behind the difference in selectivity exhibited by other photointiators and phenylglyoxalic acid. The authors reached to the conclusion that exciplex formation between phenylglyoxylic acid and dialkyl maleate is mandatory for this reaction. 


\section{ARTICLE}

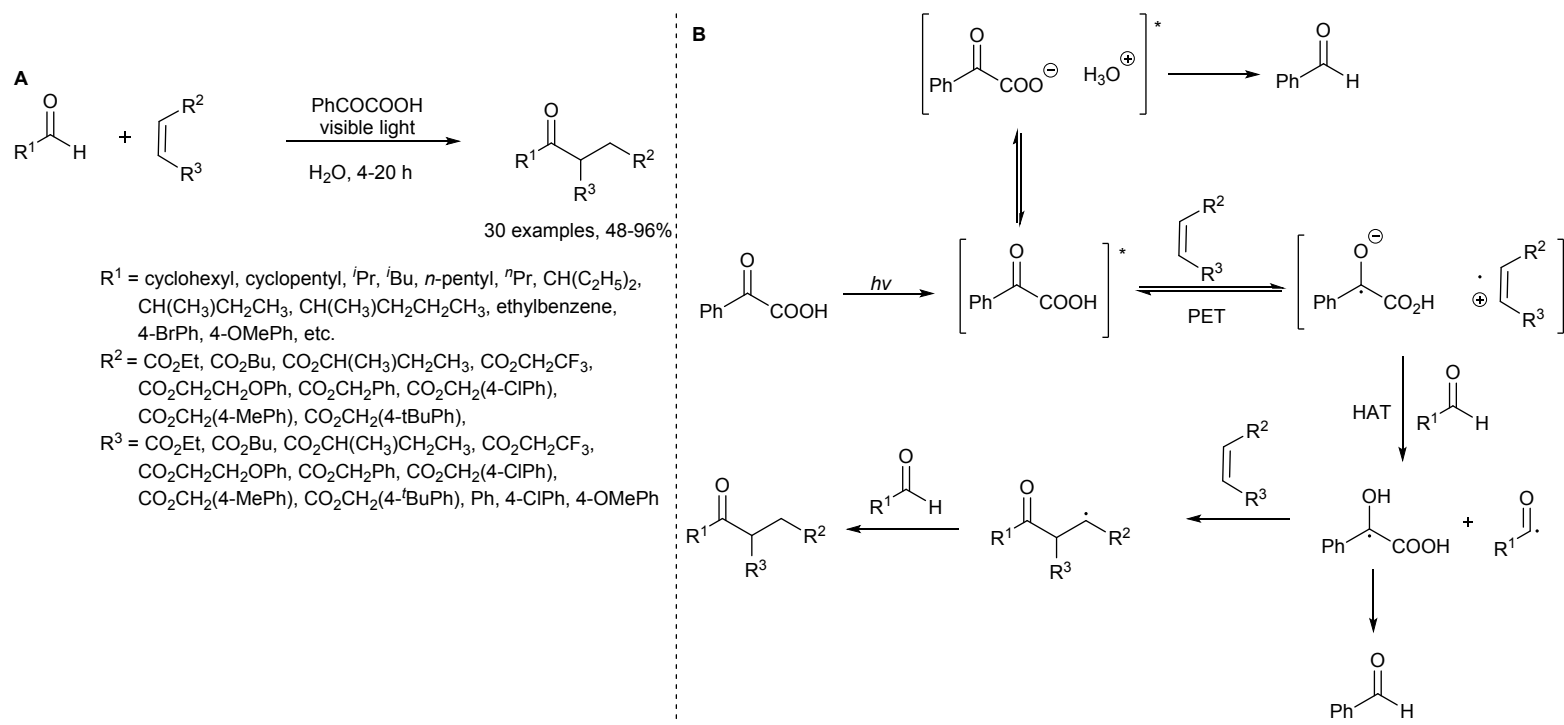

Scheme 34: (A) Photocatalytic hydroacylation of alkenes with aldehdyes; (B) proposed reaction mechanism.

Taking into account the fascinating advantages of photocatalysis, Yadav and team designed a promising metal free, photocatalytic one-pot route to obtain chalcones via radical denitrative benzoylation of $\beta$-nitrostyrenes..$^{70}$ Visible light was utilized as the energy source, $N$-hydroxyphthalimide (NHPI) as the reusable photocatalyst and acetonitrile was chosen as the green solvent. The primary reason for employing NHPI as the catalyst was that it could readily generate benzoyl radical photochemically from benzaldehyde and this in turn could cross couple with $\beta$-nitrostyrene to furnish chalcones. Sequentially, a number of control experiments were performed that delineated the significance of employing visible light and NHPI to afford the target chalcone compounds. After establishing the optimal conditions for this visible light mediated synthesis, the generality of the protocol was explored and it was found that a broad range of $\beta$-nitrostyrenes and benzaldehydes containing diverse electron donating as well as withdrawing substituents could be applied that demonstrated impressive tolerance (Scheme 35A). It was further appealing to note that a choleretic drug named "metochalcone" could also be obtained using similar reaction conditions by the team of researchers. The protocol followed a radical mechanistic pathway which was confirmed via the addition of TEMPO (2,2,6,6-tetramethyl-1- piperidinyloxyl) -a radical scavenger that quenched the reaction completely. The formation of benzoyl-TEMPO adduct was confirmed by HRMS.

To further gain an insight into the reaction mechanism, electron paramagnetic resonance experiments were also carried out, which also confirmed the involvement of radical species in the reaction (Scheme 35B). Additionally, a kinetic isotope experiment was also conducted, which gave a $\mathrm{K}_{H} / \mathrm{K}_{\mathrm{D}}$ ratio of 5.2, indicating the aldehydic $\mathrm{C}-\mathrm{H}$ bond activation. Apart from this, an on/off experiment was also carried out which signified the role of visible light in this process. Based on various mechanistic studies and previous literature reports, a plausible mechanism was proposed (Scheme 35C). As demonstrated, under visible light irradiation wherein 7 Watt LED was used under inert $\mathrm{N}_{2}$ atmosphere, a radical was formed by the migration of $\mathrm{H}$ atom of NDPI from $\mathrm{O}$ of the $\mathrm{CO}$ group of imide. The hydrogen transfer from the aldehyde moiety formed acyl radical along with the radical species $\mathbf{B}$. The acyl radical therefore underwent reaction with (E)- $\beta$ nitrostyrene to generate the benzylic radical, which eliminated the $\mathrm{NO}_{2}$ radical to form the targeted product. Thereafter, the $\mathrm{NO}_{2}$ radical abstracted $\mathrm{H}$ atom from $\mathrm{B}$ in order to regenerate NHPI that could further sustain the catalytic cycle. 


\section{ARTICLE}

A

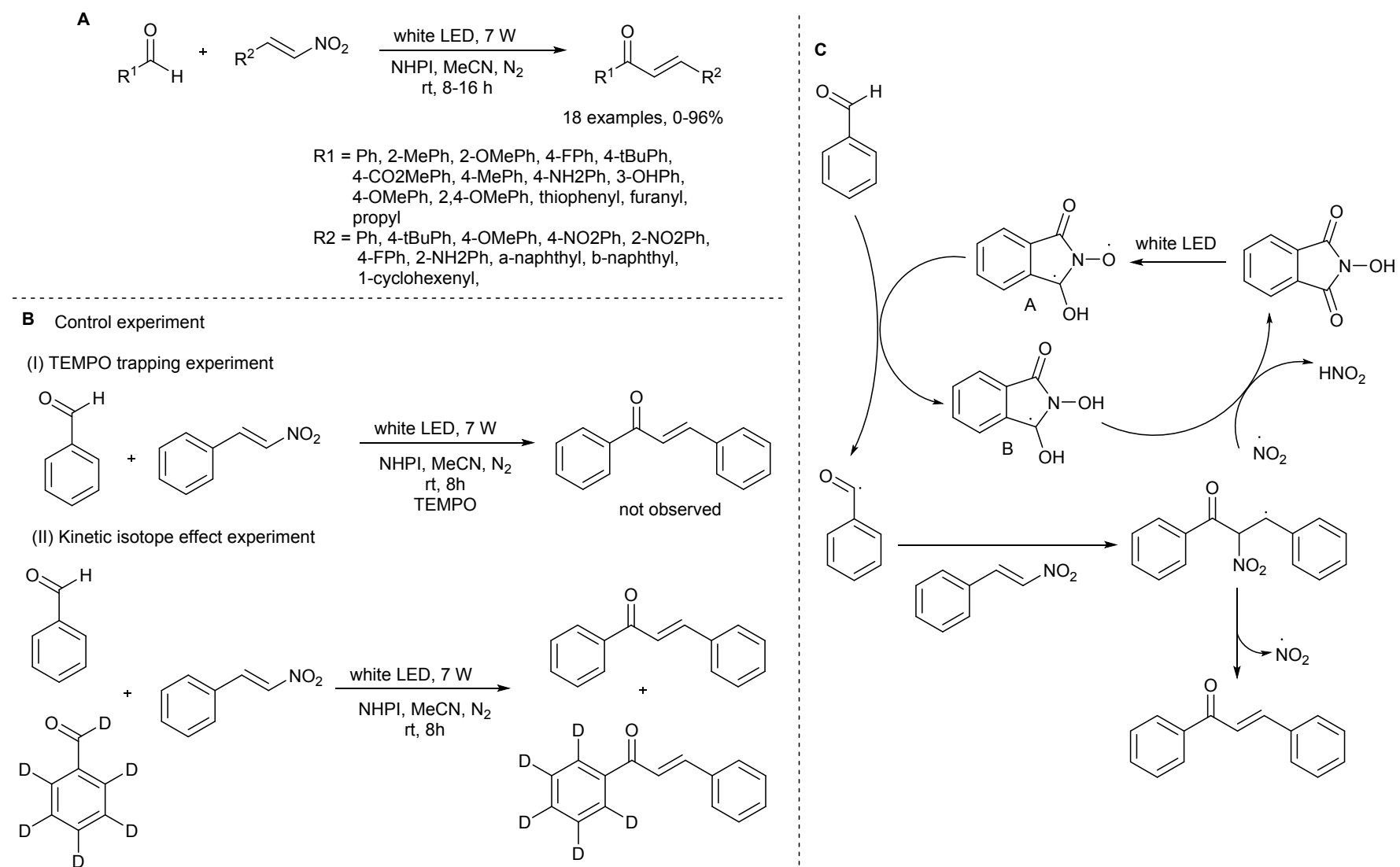

Scheme 35: (A) photocatalytic one-pot benzoylation of $\beta$-nitrostyrenes using aldehdyes; (B) control experiments; (C) plausible reaction mechanism.

Encouraged by this idea as well as the splendid results encountered in case of sustainable photochemical transformations, Jr. and co-workers set out in the task of performing epoxyacylation and hydroacylation of olefins under visible light driven conditions employing methylene blue as the photoredox catalyst and persulphate $\left(\mathrm{K}_{2} \mathrm{~S}_{2} \mathrm{O}_{8}\right)$ as the oxidizing agent. ${ }^{71}$ They utilized a single set of reagents for two diverse set of transformations. While performing the optimization, the authors found that nearly $35 \%$ of the epoxyketone moiety could be obtained using $2.5 \mathrm{~mol} \%$ of methylene blue as photocatalyst, $1.0 \mathrm{~mol} \mathrm{~K}_{2} \mathrm{CO}_{3}$ as the base and 2.0 equiv of $\mathrm{K}_{2} \mathrm{~S}_{2} \mathrm{O}_{8}$ under $100 \mathrm{~W}$ irradiation. An increase in product yield to $92 \%$ was observed on decreasing the amount of base employed for this protocol. A set of control experiments revealed the indispensable need of all the reagents as well as light to render the desired moiety with good conversion percentage. The generality of the protocol was investigated wherein a broad spectrum of aldehydes and olefins were subjected to the optimized conditions (Scheme 36A). Much to the delight of the researchers, the protocol showed great efficacy in furnishing the target compounds possessing either electron donating or withdrawing groups in good to excellent yields. Aliphatic aldehydes and styrene particularly reacted very well and yielded the target product in good yield.

This strategy was also extended to benzaldehydes and nonconjugated olefins and again both electron donating and electron withdrawing substituents were well tolerated. Unfortunately, aliphatic aldehydes failed to give good results. Sytrenes also when subjected to the hydroacylation gave the corresponding epoxyketone in only traces. The results clearly suggested that only non-conjugated long chain olefins can participate in this transformation (Scheme 36B). Again a plausible mechanism was proposed. A triplet state electron 
acceptor $\mathrm{MB}^{*}$ was generated via the photoexcitation of methylene blue using a household lamp (100 W), which engaged in a single electron transfer (SET) with hydroperoxide anion produced from the persulphate alkaline hydrolysis that afforded the hydroperoxyl radical and methylene blue radical. Thereafter, through a hydrogen atom transfer (HAT) between benzaldehyde and hydroperoxyl radical, an acyl radical was produced, which added to the styrene molecule to generate radical $\mathbf{A}$. This further provided an access $_{n}$ to peroxide (B) by combining with hydroxyperoxy was generated in the first step during SET. In the final step, the targeted epoxyketone molecule was produced via the elimination of $\mathrm{OH}^{-}$from $\mathbf{B}$ under alkaline conditions. Methylene blue was regenerated via oxidation either aerially or in presence of persulphate (Scheme 36C). Similar mechanism was also proposed for the acylation reaction.
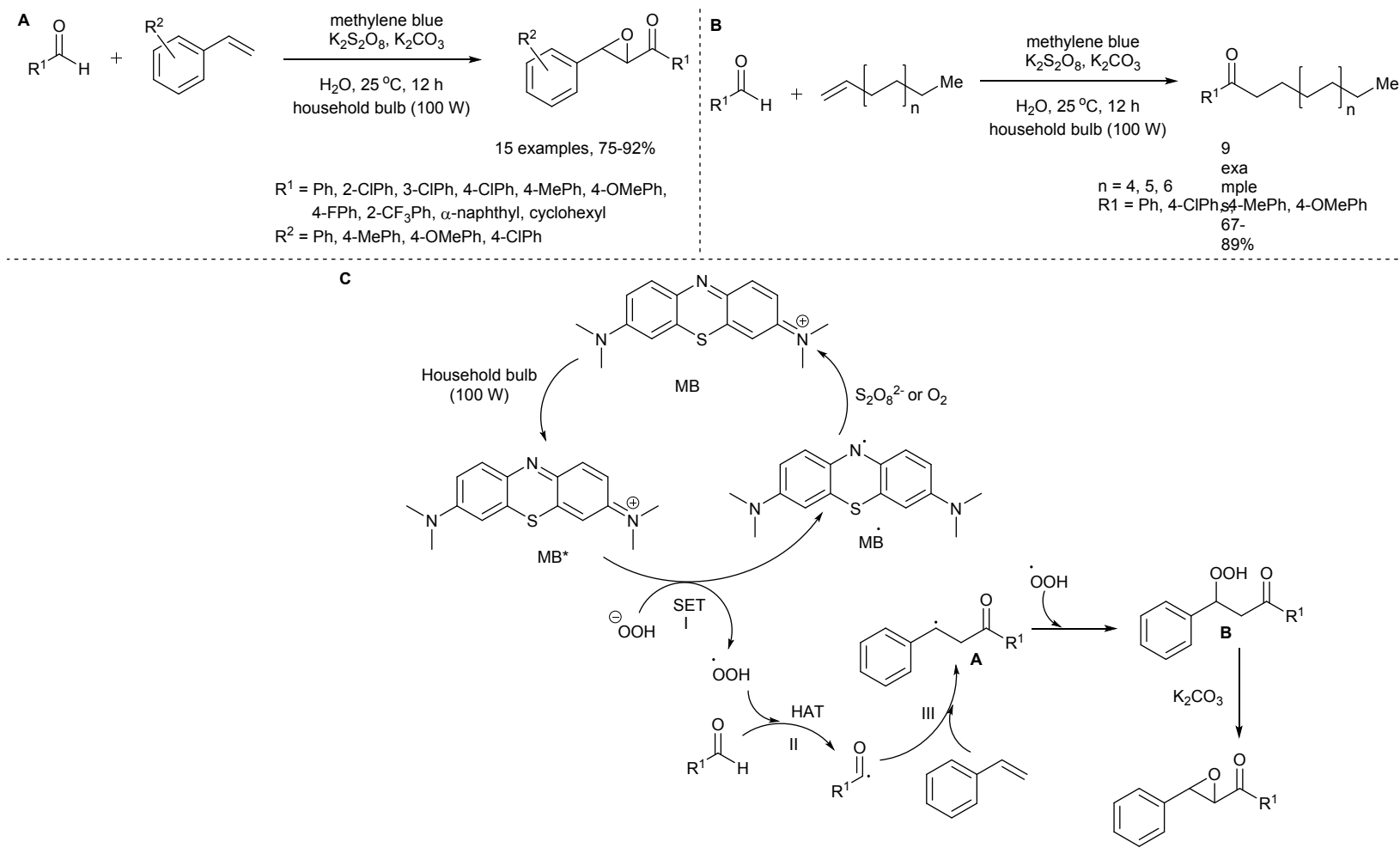

Scheme 36: (A) Epoxyacylation and (B) hydroacylation of olefins under visible light driven conditions usingmethylene blue as the photoredox catalyst; (C) proposed reaction mechanism.

Recently in 2019, Fe-catalyzed acyl-azidation of alkenes to synthesize unsymmetrical $\beta$-azido ketones has been reported by $\mathrm{Ge}$ et al. under mild reaction conditions. Aromatic and aliphatic aldehydes were used as acyl radical precursors, azidotrimethylsilane ( $\mathrm{TMSN}_{3}$ ) as azido source, and TBHP as an oxidant in this transformation (Scheme 37A). ${ }^{72}$ The effects of various parameters including metal catalyst, solvent, additives and temperature was studied taking styrene and benzaldehyde as model substrates and $\mathrm{TMSN}_{3}$ as azido source to achieve the best reaction conditions. Interestingly, best product yield was obtained when styrene $(0.5 \mathrm{mmol})$ was treated with benzaldehyde $(2.5 \mathrm{mmol})$ in the presence of $\mathrm{Fe}$ (OTf) ${ }_{3}$ ( 2 mol\%) catalyst and TBHP (1.25 mmol) oxidant using $\mathrm{TMSN}_{3}(1.25 \mathrm{mmol})$ after $24 \mathrm{~h}$ at room temperature.

Having the optimized reaction conditions in hand, initially the authors investigated the scope of alkenes, $o_{-}, m$ - and $p$ substituted styrenes (vinylarenes) with benzaldehyde delivering products in moderate to good yields. Styrenes having alkyl substituents performed better than those carrying halogens. Interestingly, vinylarenes containing an ester or a free carboxylic group at the para-position also reacted effectively under the optimized reaction conditions providing moderate yields of the products. Moreover, heterocyclic compounds, $\alpha, \beta$-unsaturated carbonyl compounds and conjugated dienes also resulted in the corresponding azido ketones in moderate yields on treatment with benzaldehyde and $\mathrm{TMSN}_{3}$. Subsequently, the scope of aromatic aldehydes, aliphatic aldehydes and $\alpha, \beta$-unsaturated aldehydes was investigated. Aryl aldehydes having either electron-releasing or electron-withdrawing groups reacted smoothly with moderate to good yields; however, electronreleasing groups were found to be more efficient than electron-withdrawing groups.Few preliminary experiments were executed to investigate the reaction pathway and, depending on these studies, a plausible reaction mechanism 
for this acyl-azidation reaction was proposed as outlined in scheme 37B.

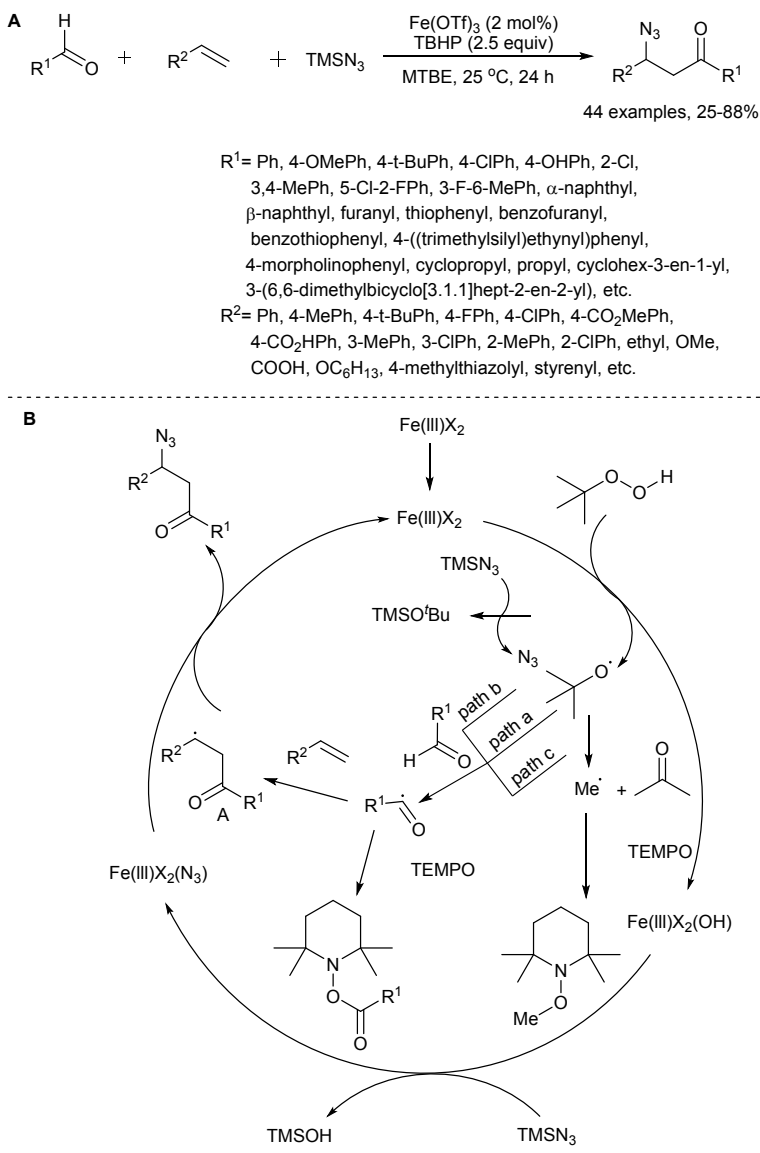

Scheme 37: Iron catalyzed acyl-azidation of alkene and plausible reaction mechanism.

\subsubsection{Acylation of sp carbons}

In 2014, Li and co-workers disclosed a metal-free protocol for the acylation of $N$-arylacrylamides with aldehdyes followed by an intramolecular cyclization to synthesize 3acylspiro[4,5]trienones. ${ }^{73}$ The flexibility of reaction was demonstrated by the synthesis of 28 3-acylspiro[4,5]trienones in good to excellent yields. Reactions were performed between several electron-rich and electron-deficient $N$ arylacrylamides and aldehydes (aromatic and aliphatic) using TBHP as optimum free-radical initiator oxidant without any catalyst under optimized reaction conditions giving the respective products in 66-94\% yield. Extensive screening of $N$ arylacrylamides suggested that several groups including OMe, $\mathrm{Me}, \mathrm{CN}$ on the aryl ring of the terminal alkyne were well tolerated, and electron-releasing groups showed better reactivity in comparison to electron-withdrawing groups. $\mathrm{N}$ arylacrylamides bearing substituents like $o-\mathrm{Me} / \mathrm{I}, m$-Me on the aryl ring of nitrogen also performed well affording the good product yields. Moreover, the presence of a OMe or $\mathrm{F}$ group at the para-position of the $N$-aryl ring delivered the respective 3-acylspiro[4,5]trienone in $81 \%$ and $74 \%$, xield The

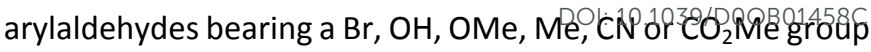
on the aryl ring were also found compatible with the optimal reaction conditions and the reactivity order was found to be para>meta>ortho. Moreover, aliphatic aldehydes could be easily reacted using the optimized reaction conditions, resulting in thecorresponding spiro[4,5]trienones in good yields (Scheme 38A).

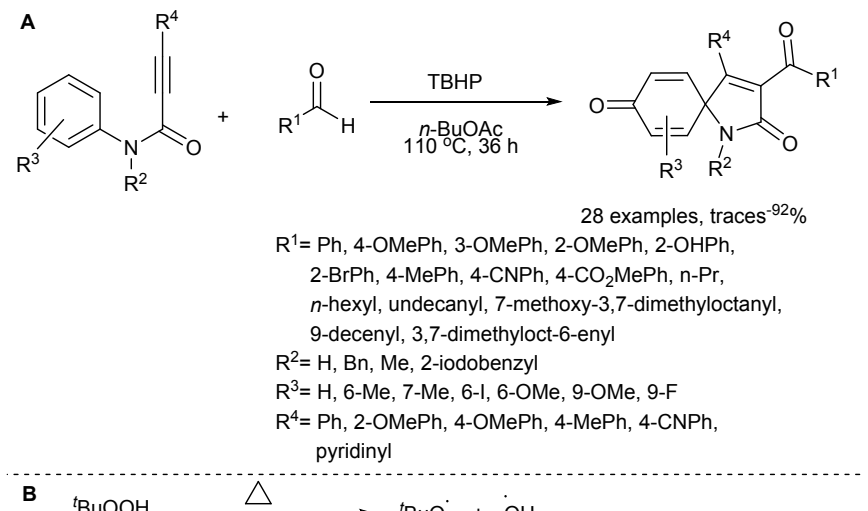

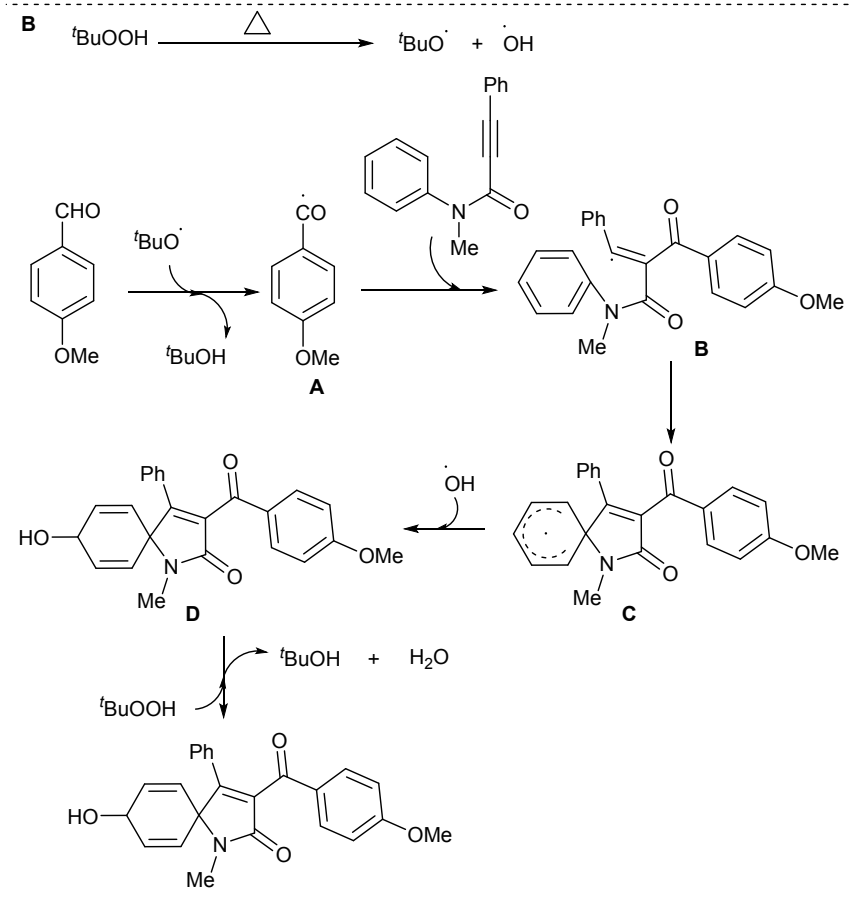

Scheme 38: (A) Acylation of N-arylacrylamides with aldehdyes followed by an intramolecular cyclization; (B) plausible reaction mechanism.

On the basis of control experiments and literature support, the authors designed a plausible reaction mechanism (Scheme 38B). The mechanism involves the formation of carbonyl radical $\mathbf{A}$ from the aldehyde through a singleelectron transfer (SET) process in the presence of TBHP. Subsequent acylation of the alkyne with carbonyl radical $\mathbf{A}$ resulted in vinyl radical $\mathbf{B}$, which on selective ipsocarbocyclization produced radical intermediate $\mathbf{C}$. This 
intermediate $\mathbf{C}$, after selective addition of $\mathrm{OH}$ radical, afforded another intermediate D. Lastly, intermediate D on the oxidation in presence of TBHP, delivered the preferred 3acylspiro[4,5]trienone.

In 2015, Wu and co-workers also revealed a metal-free tandem acylation of alkynoates with aldehydes followed by an intramolecular cyclization resulting in 3-acyl-4-arylcoumarins. The reaction proceeded under metal-free conditions in the presence of tetrabutylammonium bromide (TBAB) as additive and $\mathrm{K}_{2} \mathrm{~S}_{2} \mathrm{O}_{8}$ as oxidant for the selective synthesis of biologically attractive 3 -acylcoumarins. ${ }^{74}$ Under the optimized reaction conditions, various differently substituted aldehydes and aryl alkynoates could be coupled in a metal-free acylation/cyclization process to obtain the 3-acylcoumarins in moderate to good yields. Aromatic aldehydes having electronreleasing groups at the para-position of the aromatic rings coupled more efficiently than those containing electronwithdrawing groups. Although, ortho- and meta-substituted benzaldehydes were also appropriate for this conversion but a slight decrease in yields was found. Moreover, alkyl and cyclic aldehydes also provided coumarin derivatives in moderate yields.

Similarly, the aryl alkynoates with either electron-rich substituents or electron-poor substituents at the paraposition of the phenoxy ring reacted well and products were obtained in good yields. However, in the presence of the strong electron-withdrawing $\mathrm{CF}_{3}$-group on the phenoxy ring, only $38 \%$ yield was obtained whereas, no product was formed for the ortho-substituted system. Furthermore, aryl alkynoate with a methyl group at the meta-position of the phenoxy ring resulted in a mixture of two regioisomers in a 1.6:1 ratio. However, the presence of a methoxy group at the metaposition delivered only one isomer in $76 \%$ yield (Scheme 39 ).

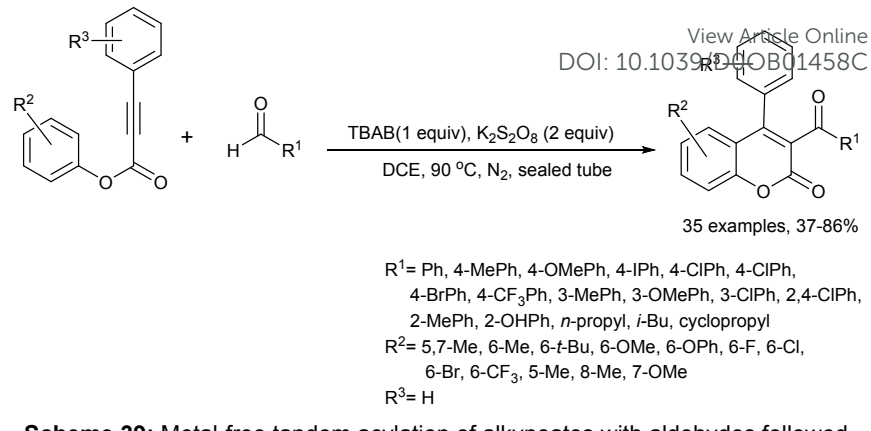

Scheme 39: Metal-free tandem acylation of alkynoates with aldehydes followed by an intramolecular cyclization.

To gain insight in the reaction mechanism for this newly developed protocol, the authors performed some control experiments. The intramolecular and intermolecular kinetic isotope, effects were measured using deuterium labeled substrates in competing experiments and the $k_{H} / k_{D}$ values were found to be 0.9 and 1.3 , respectively. The observed low $\mathrm{k}_{\mathrm{H}} / \mathrm{k}_{\mathrm{D}}$ suggested that the $\mathrm{C}-\mathrm{H}$ bond cleavage is not the ratelimiting step in this transformation. Moreover, when the reactions were carried out in the presence of the free radical scavengers TEMPO or BHT, no product formation was observed and the adduct of $p$-tolualdehdye with TEMPO or $\mathrm{BHT}$ was observed, suggesting a free radical pathway of the reaction (Scheme 40A). In accordance with the observations of the control experiments, a plausible mechanism following the free radical pathway was proposed (Scheme 40B). Initially bis(tertrabutylammonium) peroxysulfate is generated by the reaction between peroxysulfate and TBAB, which get converted into the tetrabutylammonium sulfate radical anion at high temperature. This radical reacted with $p$ methylbenzaldehyde to give an acyl radical A. Subsequently, the selective addition of acyl radical $\mathbf{A}$ to the $\alpha$-position of the $\mathbf{C}=\mathbf{O}$ bond in alkynoate $\mathbf{Y}$, resulted in the vinyl radical $\mathbf{B}$. This intermediate $\mathbf{B}$ then cyclized to the arene and formed another radical intermediate $\mathbf{C}$. Next, a single-electron transfer from intermediate $\mathbf{C}$ to another sulfate radical could give cation $\mathbf{D}$. This cation $\mathbf{D}$ upon deprotonation by the formed sulfate dianion provided the 3-acylcoumarin derivative and another bisulfate anion. 


\section{ARTICLE}

A

(a)

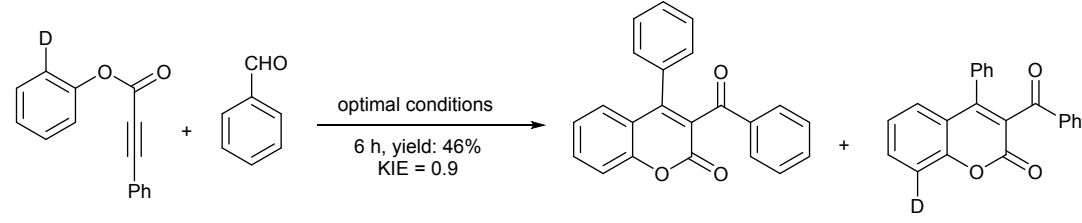

(b)

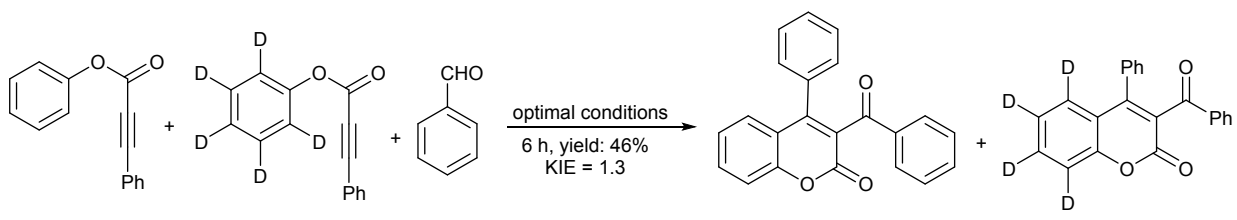

(c)
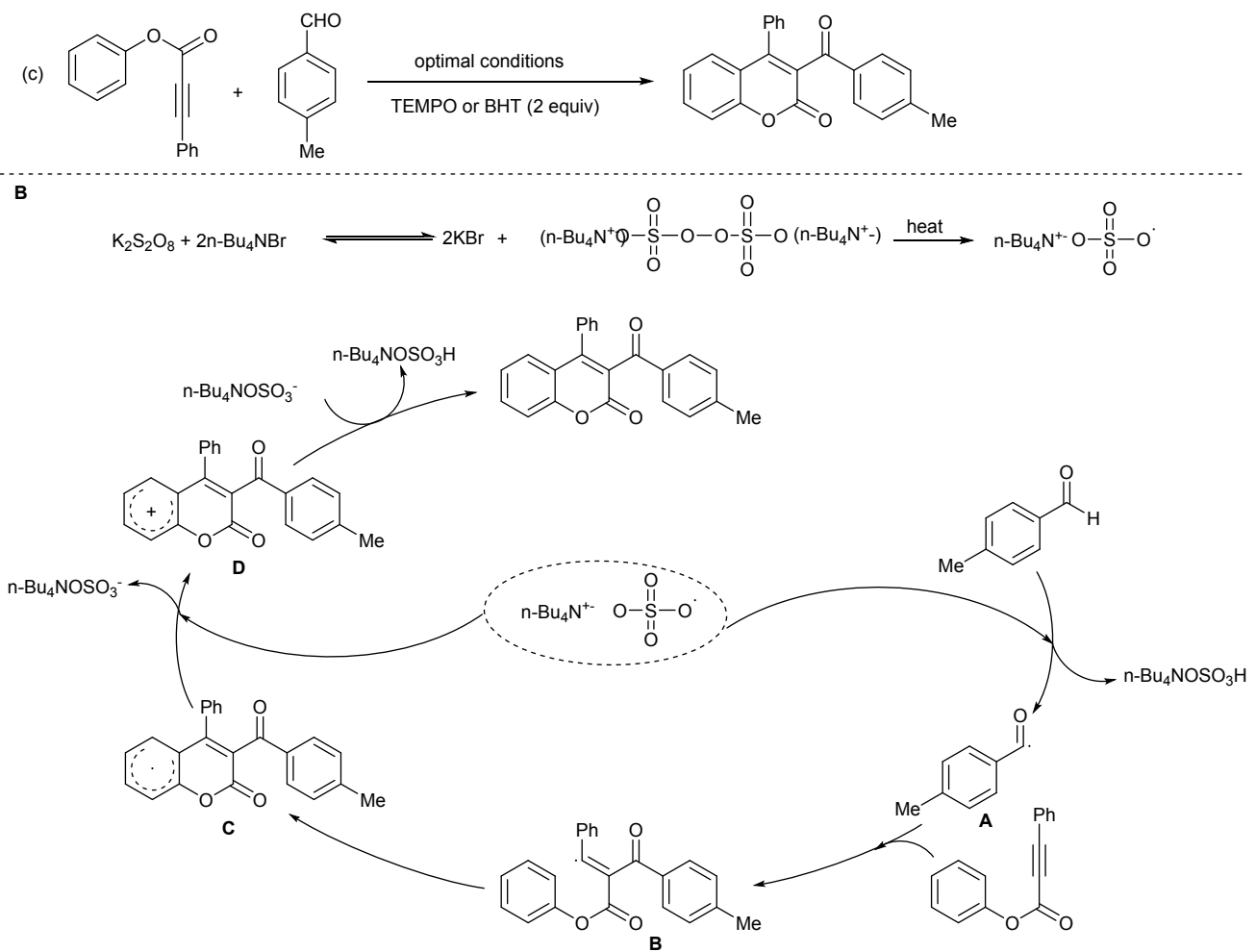

Scheme 40: (A) Control experiments; (B) plausible reaction mechanism.

\subsection{Acylation of heteroarenes/heteroaryls}

Heterocyclic compounds represent the largest and one of the most vital classes of organic compounds used in many biological fields due to their importance for the treatment of multiple illnesses and building blocks for industries. Presently, several heterocyclic compounds are known and due to the enormous synthetic research as well as their synthetic utility the number of heterocyclic molecules is increasing rapidly day-by-day. Heterocyclic compounds play a significant role in almost all fields of science such as medicinal chemistry, biochemistry and synthetic chemistry, and are widely distributed in natural products, biomolecules and other bioactive molecules. Heterocyclic scaffolds are major constituents of biological molecules such as DNA, RNA, vitamins, enzymes, chlorophyll, haemoglobin and many more. Therefore, pharmacists and organic chemists have been making extensive efforts for the formation and functionalization of heterocyclic molecules through developing versatile, atom- and step-economical efficient synthetic strategies. In this direction, Zhou and co-workers (2012) explored the first Rh-catalysed regioselective oxidative 
C2-acylation of the ubiquitous indole ( $N, N$-dimethyl- $1 H$ indole-1-carboxamide) by coupling with aryl/alkyl aldehydes involving direct $\mathrm{sp}^{2} \mathrm{C}-\mathrm{H}$ bond cleavage and $\mathrm{C}-\mathrm{C}$ bond formation strategy. ${ }^{75}$ The scope of $\mathrm{N}$-protected indoles was explored with various aldehydes using $\mathrm{Cp} * \mathrm{Rh}(\mathrm{MeCN})_{3}\left(\mathrm{SbF}_{6}\right)_{2}$ as optimum catalyst and $\mathrm{Ag}_{2} \mathrm{CO}_{3}$ as oxidant. The presence of electron-releasing and electron-withdrawing groups at the aryl ring of the benzaldehyde did not affect the outcome of the reactions and good reactivity was demonstrated with $\mathrm{N}$ protected indoles irrespective of the position of the substituents. Benzaldehydes having $\mathrm{Me}, \mathrm{OMe}, \mathrm{NO}_{2}, \mathrm{CF}_{3}$, $\mathrm{COCH}_{3}, \mathrm{CHO}$ and $\mathrm{COOMe}$, etc. at the para-position gave the corresponding products in $50-92 \%$ yields. Notably, 2furaldehyde, thiopene-2-carbaldehyde and 2naphthaldehdye underwent $\mathrm{sp}^{2}-\mathrm{sp}^{2}$ coupling efficiently and delivered the respective products in $73 \%, 85 \%$ and $90 \%$ yield, respectively. Interestingly, coupling between $\mathrm{N}, \mathrm{N}$-dimethyl$1 \mathrm{H}$-indole-1-carboxamide and paraformaldehdye resulted in the formation of dimeric 2,2'-biindolyl product with complete regiocontrol in $54 \%$ yield. Moreover, $\mathrm{N}$-protected indoles having both electron-donating (OMe) and electronwithdrawing $\left(\mathrm{CF}_{3}, \mathrm{NO}_{2}, \mathrm{Br}\right.$ etc.) groups at the $\mathrm{C} 6$-position were readily converted into the targeted products in good to excellent yield (Scheme 41).

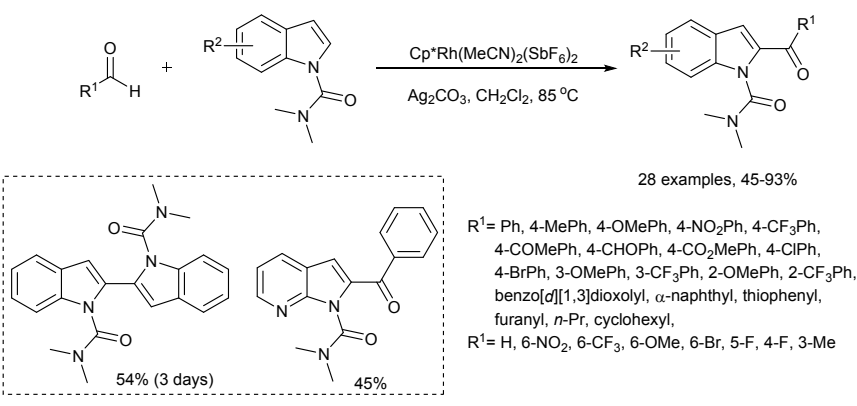

Scheme 41: Rh-catalyzed regioseletive oxidative $C_{2}$-acylation of indole by coupling with aryl/alkyl aldehydes.
Later in 2014, Yan et al. described a Pd-catalyzed C-2 acylation

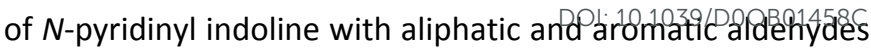
by direct $\mathrm{C}$ - $\mathrm{H}$ functionalization. ${ }^{76}$ Various $\mathrm{N}$-protected indoles were coupled with various aliphatic and aromatic aldehydes in the presence of $\mathrm{Pd}(\mathrm{OAc})_{2}$ as catalyst, TBHP as oxidant and $\mathrm{PivOH}$ as additive. Benzaldehydes having electronwithdrawing groups or electron-releasing groups at the paraposition provided the corresponding products in good yields. However, relatively lower yield were observed in case of ortho-substituted benzaldehydes, because of steric hindrance. $\alpha$-naphthaldehdyde and $\beta$-naphthaldehdyde also underwent the acylation reaction smoothly to afford the products in good yields. Interestingly, 5-methylfuran-2carbaldehyde and thiophene-2-carbaldehyde also participated in this oxidative coupling to give the products in $64 \%$ and $74 \%$ yields, respectively. The reaction scope was not found to be limited to aryl aldehydes as several aliphatic as well as conjugated aldehydes also effectively participated in the reaction to give the products in good yields (Scheme 42A). Likewise aldehydes, several indoles containing functional groups such as methoxy, chloro, bromo, ester, etc. reacted smoothly to give products in moderate to good yields. However, 3-substituted indole afforded a lower yield of the acylated product due to steric crowding. The proposed mechanism for this protocol is depicted in scheme 42B 


\section{ARTICLE}

A
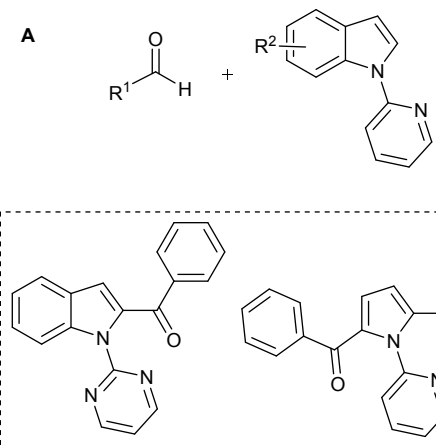

$83 \%$

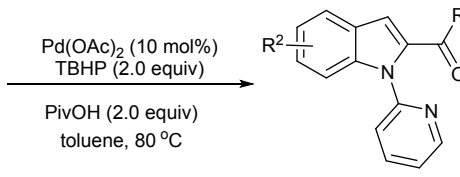

30 examples, $40-95 \%$

$1=\mathrm{Ph}, 4-\mathrm{OMePh}$, 4-MePh, 4-BrPh, 4-CIPh 4-CF 3 Ph, 4-CNPh,3-CIPh, 3-MePh, 2-OMePh, 2-FPh, 2-CIPh, 3,4-MePh, benzo[d][1,3]dioxol-5-yl,b-naphthyl, $\alpha$-naphthyl, 5-methylfuran-2-yl, thiophenyl, cyclohexyl, $n$-hexyl, 2-methylprop-1-enyl, 2,6-dimethylhepta-1,5-dienyl $\mathrm{R}^{2}=\mathrm{H}, 6-\mathrm{CO}_{2} \mathrm{Me}, 5-\mathrm{Br}, 6-\mathrm{Cl}, 5-\mathrm{OMe}$ 3-Me, 3-CN,

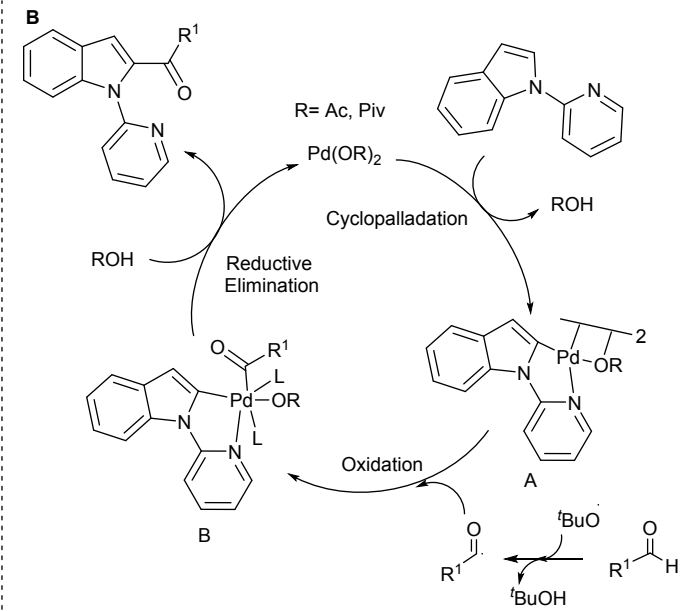

Scheme 42: (A) Pd-catalyzed C-2 acylation of N-pyridinyl indoline with aliphatic and aromatic aldehydes; (B) plausible reaction mechanism.

A method describing the selective C-2 monoacylation and C-

2, C-7 diacylation through $\mathrm{C}-\mathrm{H}$ bond functionalization of $1-$ (pyrimidin-2-yl)-1H-indole using aldehydes was disclosed by Govindasamy Sekar and his group in 2015.77 The authors synthesized fourteen C-2 monoacylated products, three C-2, C-7 symmetric diacylated products and two C-2, C-7 unsymmetric diacylated products in moderate to good yields using $\mathrm{PdCl}_{2}$ catalyst and TBHP (70\% aqueous solution in toluene) as oxidant in toluene. For monoacylation, 3 equivalents of TBHP were used, whereas, for diacylation, 5 equivalents of TBHP were required. Aromatic aldehydes containing both electron-releasing and electron-withdrawing groups yielded 2-acylated products of 1-(pyrimidin-2-yl)- $1 \mathrm{H}$ indole in moderate to good yields. Sterically hindered $\alpha$-naphthaldehyde and heteroaromatic aldehydes like 2- furaldehyde and thiophene-2-carbaldehyde provided the corresponding C-2 acylated products in $79 \%, 58 \%$ and $54 \%$ yield, respectively. Indoles with electron-releasing and electron-withdrawing groups at the $\mathrm{C}-5$ position coupled effectively and yielded C2-acylated products in moderate yields. Moreover, aliphatic and $\alpha, \beta$-unsaturated aldehydes, when subjected to these reaction conditions, resulted in the expected products in good yield (Scheme 43A). The use of 3 equiv of aldehyde and 5 equiv of TBHP under the same reaction conditions provided the symmetric $\mathrm{C} 2, \mathrm{C} 7$-diacylated products through dual $\mathrm{C}-\mathrm{H}$ bond functionalization with good yields (Scheme 43B). Whereas using two different aldehydes (1.5 equiv. each) one after another resulted in the formation of unsymmetrical diacylated products (Scheme $43 \mathrm{C}$ ). 


\section{ARTICLE}

A

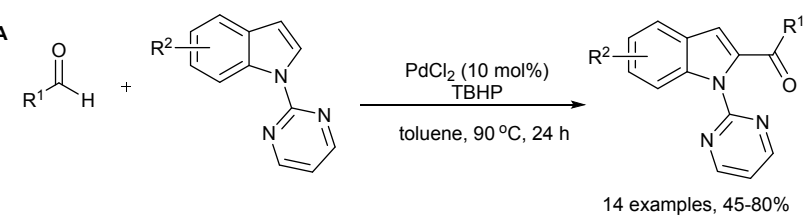

$\mathrm{R}^{1}=\mathrm{Ph}, 4-\mathrm{MePh}, 4-\mathrm{CNPh}, 4-\mathrm{CO}_{2} \mathrm{MePh}$ 4-CIPh, 2-MePh, $\alpha$-naphthyl, furanyl, thiophenyl, pentyl, cyclohex-3-en-1-yl, prop-1-enyl

$\mathrm{R}^{1}=\mathrm{H}, 5-\mathrm{OMe}, 5-\mathrm{B}$

B

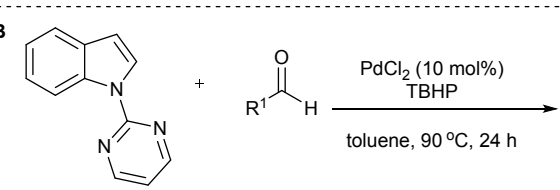

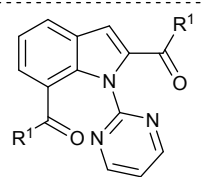

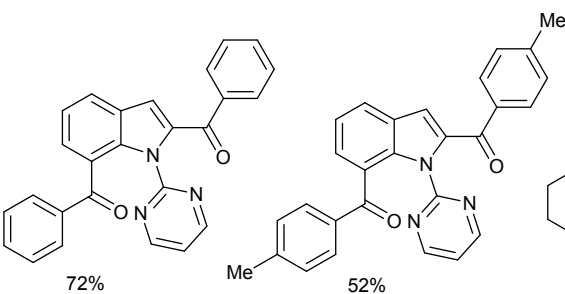

$72 \%$ $52 \%$<smiles>COC(=O)c1cc2cccc(C(=O)C3CCCCC3)c2n1-c1ncccn1</smiles>

$50 \%$

Scheme 43: (A) Selective C-2 monoacylation of 1-(pyrimidin-2-yl)-1H-indole with aldehydes; (B) Symmetric and (C) Unsymmetric C-2, C-7 diacylation of 1-(pyrimidin-2-yl)-1H-indole with aldehydes.

Balachandran and co-workers in 2014 reported metal-free and solvent-free direct acylation of thiazoles through cross dehydrogenative coupling (CDC) using TBHP as an oxidant. ${ }^{78}$ In this method 16 acylated thiazole derivatives were synthesized with moderate to good yield by coupling various aldehydes with thiazoles (Scheme 44A). The reaction conditions worked well with ortho-, meta- and parasubstituted aldehyde derivatives. There appeared no alteration in the product yield due to electronic and steric hindrance as all the 2-acylated thiazole derivatives were obtained in good yield under optimized reaction conditions. Aldehydes having electron-donating groups and halides as substituents resulted in acylated products in good yields whereas, hetero-aromatic and aliphatic aldehydes provided products in moderate yield.

While analyzing the mechanistic pathway, it appeared that the reaction proceeds with hydroxyl and alkoxyl radical generation through hemolytic cleavage of TBHP. In the subsequent step, generated radicals abstract hydrogen from $\mathrm{sp}^{2} \mathrm{C}-\mathrm{H}$ of 4,5-dimethylthiazole and the aldehydic $\mathrm{C}-\mathrm{H}$ of benzaldehyde, generating the corresponding free radicals. At the closure, free radicals combines with each other to form a new carbon-carbon bond and produce the acylated derivatives as a major products and homo-coupled side products as minor one in the terminating step (Scheme 44B).

$$
\begin{aligned}
& \text { 至 } \\
& 16 \text { examples, } 47-80 \%
\end{aligned}
$$
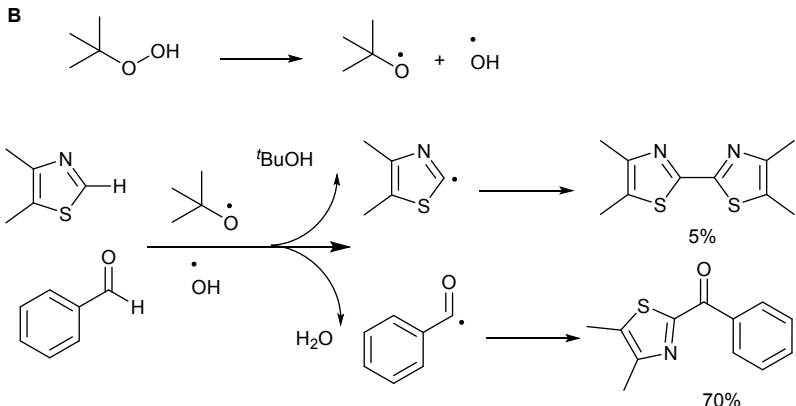

Scheme 44: (A) Metal and solvent-free direct acylation of thiazoles; (B) proposed mechanism. 
In 2017, Van der Eycken and his group established a mild and versatile method for $\mathrm{C} 2 \mathrm{C}-\mathrm{H}$ acylation of $\mathrm{N}$-pyrimidylindoles with aldehydes through dual photoredox/transition-metal catalysis in batch and flow at room temperature. ${ }^{79}$ Initially the authors explored various reaction parameters including solvent, catalysts, photocatalysts and ligands to achieve optimal reaction conditions. Finally, the use of $10 \mathrm{~mol} \%$ $\mathrm{Pd}(\mathrm{OAc})_{2}$ catalyst, 2 mol\% of photocatalyst fac-[Ir(ppy) $\left.)_{3}\right], 20$ mol\% Boc-Val-OH ligand and 4 equiv of $0.1 \mathrm{M}$ TBHP in acetonitrile delivered the best outcome after $20 \mathrm{~h}$ of blue LED irradiation in a batch process. Whereas in a flow process only 0.5 mol\% of photocatalyst fac-[Ir(ppy $\left.)_{3}\right]$ with slight excess of oxidant ( 6 equiv. of $0.2 \mathrm{M} \mathrm{TBHP}$ in acetonitrile) along with the rest of the other reagents was found to be enough to give good product yields in just $2 \mathrm{~h}$. With these optimized reaction conditions in hand, the scope of the reaction was determined by exploring various substituted benzaldehydes as coupling partners of $\mathrm{N}$-protected indoles. C2-Acylation of indole derivatives with benzaldehyde bearing alkyl/aryl groups or a methoxy group smoothly proceeded with good product yields. However, hydroxylated benzaldehydes delivered inferior yields. Furthermore, the acylated products were obtained in good yields (54-89\%) when benzaldebyde

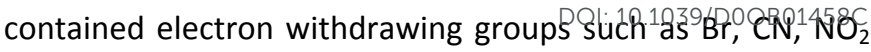
and $\mathrm{CF}_{3}$. Interestingly, heterocyclic aromatic aldehydes, aliphatic acyclic and cyclic/heterocyclic aldehydes reacted efficiently to afford $\mathrm{C} 2$-acylated $\mathrm{N}$-pyrimidylindoles in good to excellent yields (Scheme 45A). Based on observations of control experiments performed by authors and available literature reports, a plausible SET (single electron transfer) mechanism was designed as described in scheme 45B which initiates by the formation of a five membered palladacycle $A$ via interaction between $\mathrm{N}$-pyrimidylindole and $\mathrm{Pd}(\mathrm{OAC})_{2}$ catalyst. In the meantime, the photocatalytic process generated an acyl radical. The photo-excitation of the photocatalyst produced an excited state $\left(\mid \mathrm{r}^{3+*}\right)$ which get oxidatively quenched by TBHP to generate a key radical intermediate $t$-BuO . This radical abstracts a proton from the aldehyde to produce an acyl free radical, which on reaction with intermediate $\mathbf{A}$ resulted in intermediate $\mathbf{B}$. This undergoes a single electron oxidation to $\mathrm{Pd}^{\mathrm{IV}}$, which closes the photocatalytic cycle via a back-electron donation process. Finally, reductive elimination resulted in the targeted product and regenerated the $\mathrm{Pd}^{\prime \prime}$ catalyst. 


\section{ARTICLE}

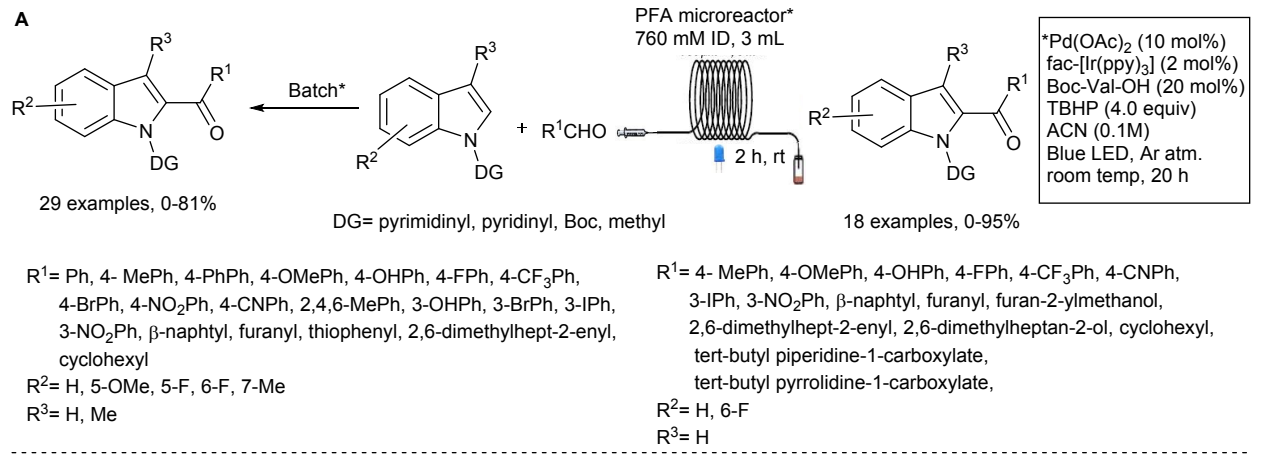

B

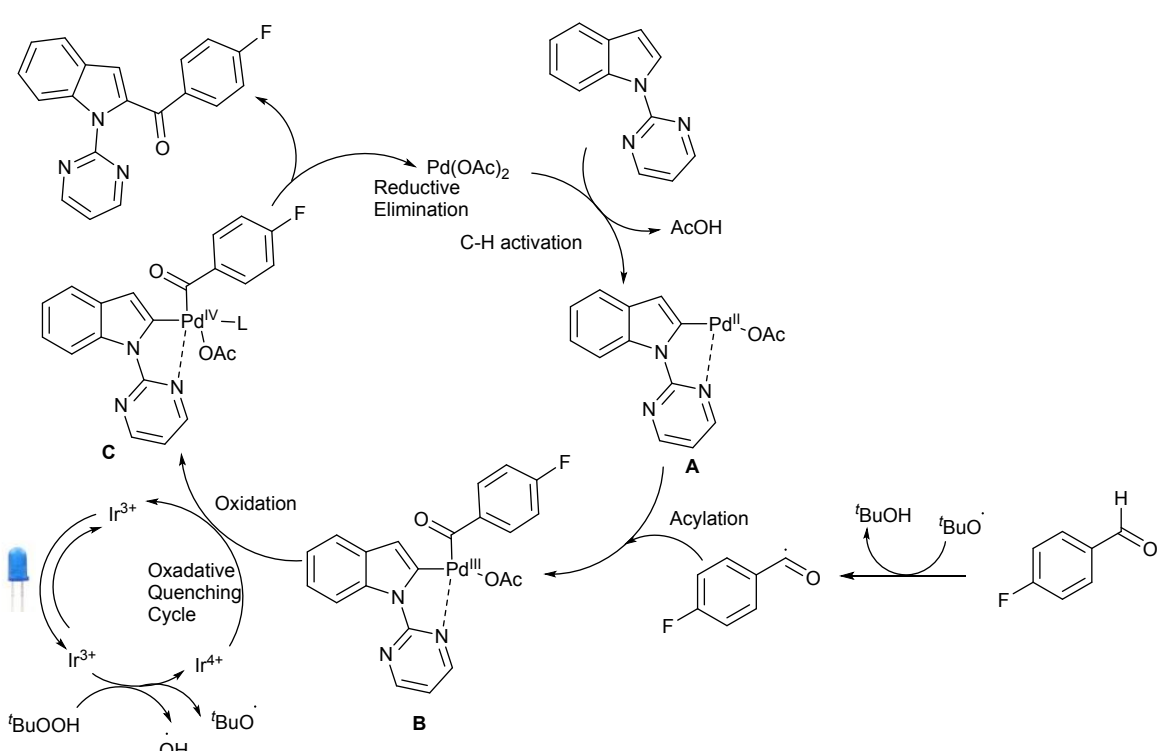

Scheme 45: Acylation of $N$-pyrimidylindoles with aldehdyes via dual photoredox/transition-metal catalysis in batch and flow and plausible reaction mechanism.

In early 2013, Antonchick and Matcha developed a metal-free cross-dehydrogenative coupling reaction between various heterocyclic compounds and aldehydes for selective $\mathrm{sp}^{2} \mathrm{C}-\mathrm{H}$ bond acylation (Scheme 46). ${ }^{80}$ The reaction proceeded efficiently with all the applied heterocyclic compounds and aldehydes giving a library of 62 compounds in the presence of $\mathrm{Phl}\left(\mathrm{OCOCF}_{3}\right)_{2}$ as oxidant and $\mathrm{TMsN}_{3}$ as additive. Employing the best reaction conditions, the scope of the isoquinoline synthesis with various aldehydes was explored.. The reaction provided a broad substrate scope and aromatic aldehydes having electron-releasing and electron-withdrawing groups at the aryl ring were selectively coupled to isoquinolines under metal-free conditions at ambient temperature. Polysubstituted benzaldehydes also provided the desiredcoupling products efficiently under the developed reaction conditions. Moreover, aliphatic aldehydes could be reacted competently with isoquinoline using smaller amount of iodide and $\mathrm{TMSN}_{3}$. Aromatic aldehydes with electronreleasing groups at the ortho, para and meta-position delivered comparable yields. Whereas, the benzaldehydes with electron-withdrawing groups at the para-position gave better yields of the corresponding products in comparison of their ortho- and meta-substituted derivatives. Moreover, polymethoxy substituted benzaldehydes were also tolerated and provided products in good to excellent yield. Notably, sulphur containing heterocyclic aldehydes provided crosscoupled products in good yields without over-oxidation to sulfoxides and sulfones (Scheme 46A). After exploring the effect of aldehydes, the scope of various heterocyclic molecules such as isoquinoline, quinoline, quinaxaline, 
acridine, benzothiazole and caffeine was also explored and all the heterocyclic compounds coupled smoothly under the optimized reaction conditions to yield the targeted molecules in good yields (Scheme 46B).

Through the observations of control experiments, a plausible mechanism has been proposed for this transformation (Scheme 46C). The mechanism starts with a ligand exchange between $\mathrm{Phl}\left(\mathrm{OCOCF}_{3}\right)$ and $\mathrm{TMSN}_{3}$, which provides the intermediate $\mathbf{B}$. A double exchange of trifluoracetyl groups in
A by azide ions give $\operatorname{Phl}\left(\mathrm{N}_{3}\right)_{2}$. Intermediate $\mathbf{B}$, ien $_{\text {Arthermal }}$

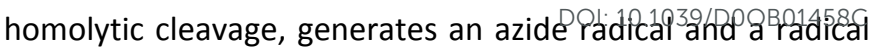
intermediate $\mathbf{C}$. Reaction between azide radical and aldehyde generates nucleophilic acyl radical intermediate D. Subsequent attack of generated acyl radical onto protonated heterocyclic $\mathbf{E}$ delivers intermediate $\mathbf{F}$. Finally, rearomatization of the intermediate $\mathbf{F}$ results the anticipated products.

A

(1)

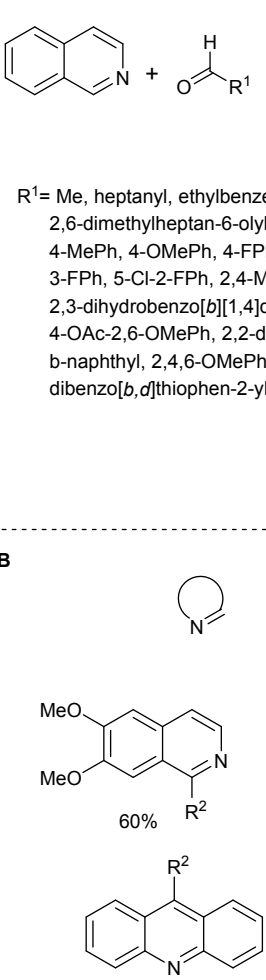

$72 \%$ dibenzo[b, $d]$ thiophen-2-yl

\section{$\left.\mathrm{CHCF}_{3}\right)_{2}$} $\mathrm{TMSN}_{3}, \mathrm{rt}, 2 \mathrm{~h}$

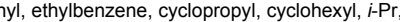

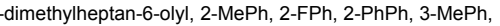
4-OAc-2,6-OMePh, 2, 2-difluorobenzo[d][1,3]dioxol-5-yl, b-naphthyl, 2,4,6-OMePh, pentamethylphenyl, thiophen-3-yl,

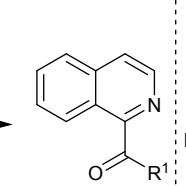

C
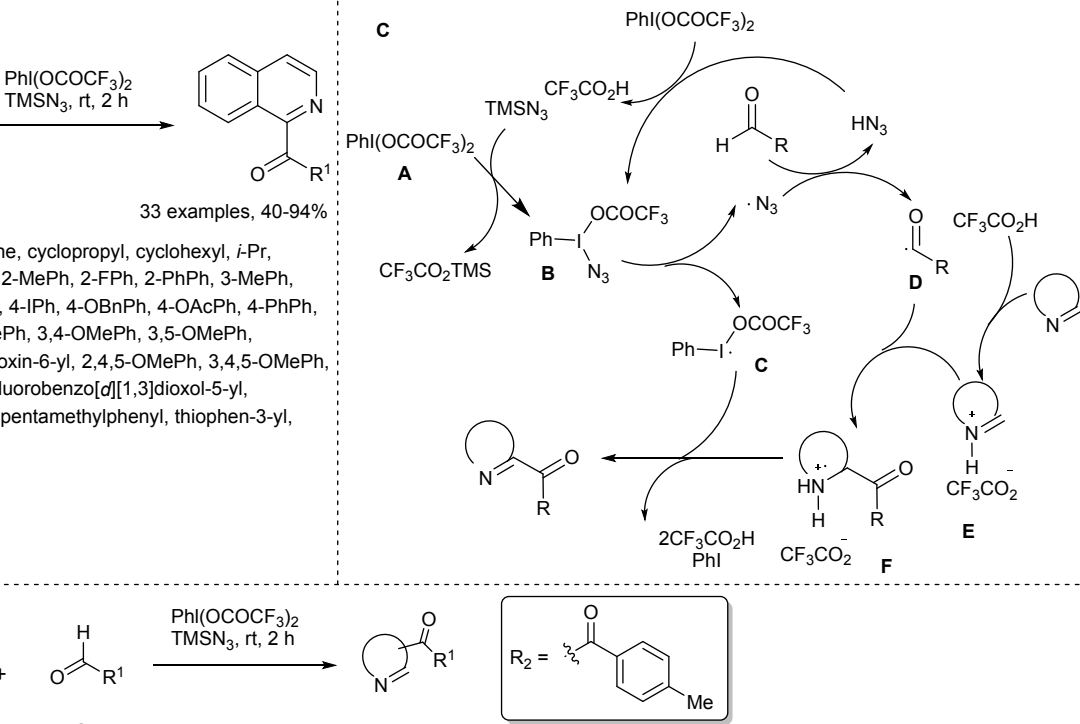<smiles>[R]c1nccc2c(OC)c(OC)c(OC)cc12</smiles><smiles>[R]c1nccc2cc3c(cc12)OCO3</smiles><smiles>Oc1nccc2nc(-c3ccccc3)c(-c3ccccc3)nc12</smiles><smiles>N#Cc1nccc2c([N+](=O)[O-])cccc12</smiles><smiles>[R]c1cc([NH+]([O-])[O-])nc2ccccc12</smiles>

$35 \% \quad A$

$84 \%$<smiles>[R]c1cc(Cl)c2ccc(Cl)cc2n1</smiles>

$77 \%$<smiles>[R]c1c(Br)cnc2ccccc12</smiles>

$65 \%$<smiles>[R]c1cc(C#N)ccn1</smiles>

$63 \%$<smiles>[R]c1cnc2ccccc2n1</smiles>

$81 \%$<smiles>[R]c1nc2ccccc2nc1N(C)C(=O)O[Na]</smiles>

Scheme 46: Metal-free cross-dehydrogenative coupling reaction between isoquinoline, isoquinoline, quinoline, quinaxaline, acridine, benzothiazole and caffeine with aldehydes for the $\mathrm{sp}^{2} \mathrm{C}-\mathrm{H}$ bond acylation and plausible reaction mechanism.

A similar transition metal-free cross-dehydrogenative coupling reaction for acylation of isoquinoline, quinoline and quinoxalines using aldehydes as acylating agents was reported by Prabhu and his group in $2014 .{ }^{81}$ This method involved the use of a substoichiometric amount of tetrabutylammonium bromide (TBAB) as an additive and $\mathrm{K}_{2} \mathrm{~S}_{2} \mathrm{O}_{8}$ as an oxidant. With optimized reaction conditions, several isoquinolines were acylated using aromatic and aliphatic aldehydes to give the respective acylated products with $32-78 \%$ yields. Notably, thiophene-2-carbaldehyde also underwent a facile coupling with 4-( $p$-methoxyphenyl)isoquinoline to afford the product in $41 \%$ yield. Moreover, quinoxaline, when coupled with 4-methoxybenzaldehdye and 4-methylbenzaldehdye delivered the acylated products were in $66 \%$ and $44 \%$ yield (Scheme 47A). To explore the further scope of the developed acylation method, quinoline was also subjected to this CDC strategy. Coupling of the quinoline with 4-methylbenzaldehyde and butanal furnished the mixture of 2-acylated and 2,4-diacylated products in 1.2:1 ratio. On the 
other hand, 4-benzyloxybenzaldehyde provided only 2,4diacylated product in just 24\% yield (Scheme 47B).

Based on the literature, the authors proposed a free radical mechanism (Scheme 48). The mechanism starts with the reaction between $\mathrm{K}_{2} \mathrm{~S}_{2} \mathrm{O}_{8}$ and TBAB resulting in sulfate radical A, which abstracts hydrogen from the aldehyde to form the

A

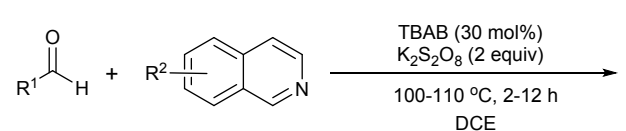<smiles>CC(C)CC(=O)c1ncc(Br)c2ccccc12</smiles><smiles>COc1ccc(C(=O)c2cnc3ccccc3n2)cc1</smiles>

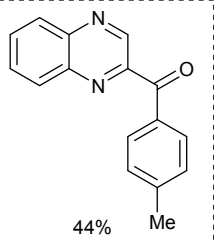

$$
\begin{aligned}
& 30 \text { examples, 32-78\% } \\
& \mathrm{R}^{1}=\text { 4-OMePh, 4-OBnPh, 3,4-OMePh, } \\
& \text { 4-Me, 2,3,4-OMePh, 3,4,5-OMePh, } \\
& \text { 4-BrPh, 3-MePh, 3-OMePh, } \\
& \text { 2,3-OMePh, 2,3,4-OMePh, 3-OBnPh, } \\
& i-\mathrm{Bu}, n-\mathrm{Pr} \text {, pentyl, hexyl, thionphenyl } \\
& \mathrm{R}^{2}=\mathrm{H}, 4-\mathrm{Ph}, 4-\mathrm{OMePh}, 5,6,7-\mathrm{OMe}
\end{aligned}
$$

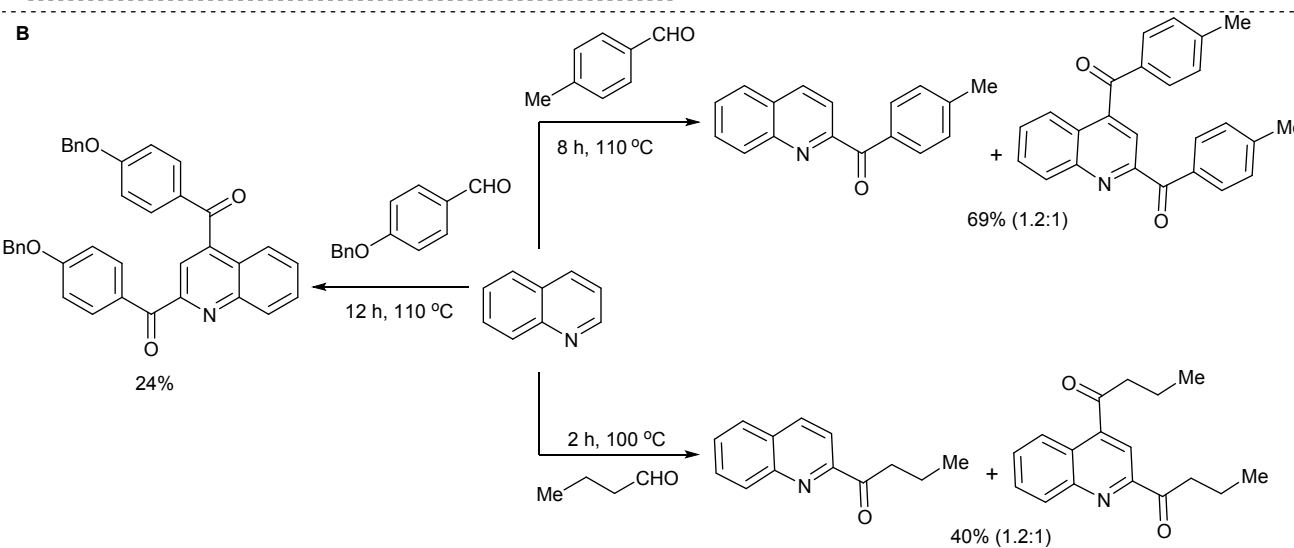

Scheme 47: Metal-free cross-dehydrogenative coupling reaction for the acylation of isoquinoline, quinoxaline and quinoline derivatives using aldehydes.

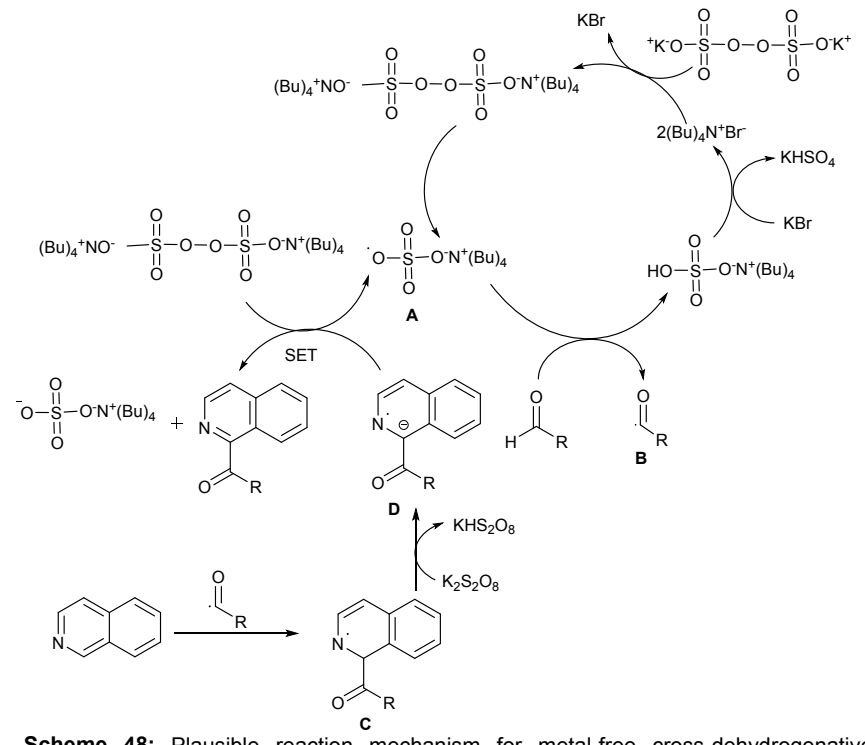

Scheme 48: Plausible reaction mechanism for metal-free cross-dehydrogenative coupling reaction of the acylation of isoquinoline, quinoline and quinoxaline derivatives.

Benzofurans and benzothiophenes are highly privileged structural moieties, which are present in several natural products and exhibit a broad spectrum of biological properties. $^{82}$ Moreover, benzofuran and benzothiopene scaffolds containing an acyl group at the C-3 position are of great interest for medicinal chemistry due to their antibacterial, anti-tumor, anti-arhythmic activities. ${ }^{83}$ Therefore, the development of new efficient protocols for the synthesis of 3-acylbenzofurans and 3-acylbenzothiophenes is highly desirable.

In 2013, Zhao et al. published a pyridinyl group-assisted Pdcatalyzed cross-dehydrogenative coupling reaction for the C3 acylation of benzofuran and benzothiophene derivatives using TBHP as an oxidant under air. ${ }^{84}$ Several derivatives of aldehyde were coupled with benzofuran and benzothiophene in the presence of $\mathrm{Pd}(\mathrm{OAc})_{2}$ as catalyst, TBHP as oxidant in chlorobenzene at $120{ }^{\circ} \mathrm{C}$. The reaction exhibited a broad scope and high compatibility with the functional groups such as OMe, $\mathrm{Me}, \mathrm{NO}_{2}, \mathrm{CN}$ and halogens, etc. and provided excellent yields (89-97\%) of the desired products regardless the position of the substituents on the benzene ring of benzaldehydes. However, dimethoxy-substituted benzaldehyde provided a slightly lower yield of acylated 
products of benzofuran and benzothiophene. Moreover, heterocyclic aldehydes such as thiopehen-2-carbaldehyde and 2-furaldehyde also reacted smoothly and the corresponding products were obtained in good to excellent yields. Unfortunately, no product was formed in case of aliphatic aldehyde (Scheme 49A). As per previous reports, the authors designed a plausible mechanism to rationalize this methodology as presented in scheme 49B.

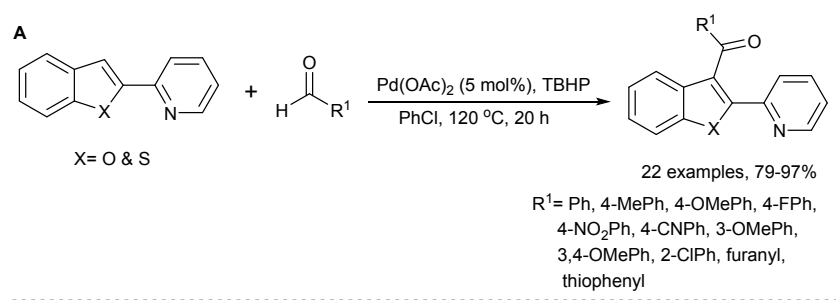

B

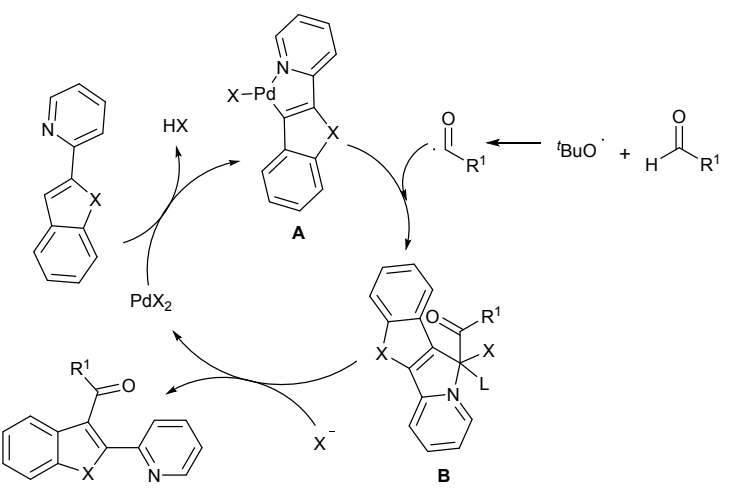

Scheme 49: Pd-catalyzed cross-dehydrogenative coupling reaction for the $\mathrm{C}-3$ acylation of benzofuran and benzothiophene derivatives and plausible reaction mechanism.

Kim and co-workers in 2014 disclosed a Pd-catalyzed oxidative coupling reaction for the selective $\mathrm{C}-7$ acylation of substituted indolines using aldehydes via a $\mathrm{C}$-H activation approach. ${ }^{85}$ The reactions were carried out between various $\mathrm{N}$-pivaloyl indolines/ $N$-pivaloyl carbazoles and aromatic/aliphatic aldehydes using Pd(TFA $)_{2}$ as catalyst, TBHP as oxidant in DCE as solvent at $80{ }^{\circ} \mathrm{C}$ to prepare 24 derivatives. The coupling reaction of C-2 or C-3 unsubstituted indolines with benzaldehyde afforded the corresponding acylated products in moderate yields. C-2 and C-3 alkyl/aryl substituted indolines also underwent the oxidative acylation reaction to provide products in moderate to good yields under the developed reaction conditions. Electron-rich as well as electron-deficient benzaldehydes were found to favor the acylation reaction irrespective the position of the substituents on the phenyl ring and afforded the products in good to high yields. Isobutyraldehyde, cyclohexanecarbaldehyde and 1hexanal provided moderate yields. However, 5-methylfuran2-carbaldehyde and 3-methylbut-2-enal delivered the products in poor yields (Scheme 50). Two parallel reactions of $N$-protected carbazole derivatives and their deuterated analogues with benzaldehyde were performed in order to gain mechanistic insight. The kinetic isotope effect $t_{A} / k_{H} / k_{\text {Din }} \overline{\bar{e}}$ 2.79) revealed that $\mathrm{C}-\mathrm{H}$ cleavage might Be involued in the rate $^{2}$ limiting step.
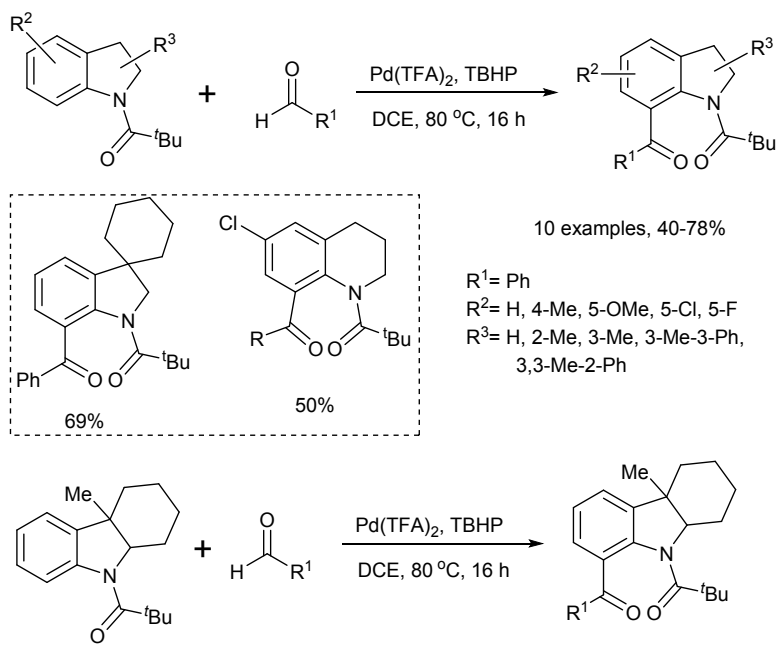

13 examples, $28^{-81} \%$

$\mathrm{R}^{1}=\mathrm{Ph}, 4-\mathrm{OMePh}, 4-\mathrm{CF}_{3} \mathrm{Ph}, 3-\mathrm{OMePh}, 3-\mathrm{NO}_{2} \mathrm{Ph}$ 2-CIPh, 2-F-4-OMePh, benzo[d][1,3]dioxolyl, 5-methylfuran-2-yl, cyclohexyl, $i-\mathrm{Pr}$, pentyl,

2-methylprop-1-enyl

Scheme 50: Pd-catalyzed oxidative C-7 acylation of indolines and carbazoles with aldehydes.

Later, in 2014 Cheng et al. reported a regiospecific Minisci acylation of phenanthridine based on a crossdehydrogenative coupling strategy via thermolysis or photolysis. ${ }^{86}$ Under thermal conditions $\left(100^{\circ} \mathrm{C}\right)$ the acylation of phenanthridine with aldehydes was carried out using a substoichiometric amount of the phase transfer catalyst tetrabutylammonium bromide (TBAB, 30 mol\%) and $\mathrm{K}_{2} \mathrm{~S}_{2} \mathrm{O}_{8}$ as oxidant. Interestingly, a preliminary research based on literature reports indicated that phenanthridine could be acylated selectively at room temperature replacing the TBAB $/ \mathrm{K}_{2} \mathrm{~S}_{2} \mathrm{O}_{8}$ system with $\left(\mathrm{NH}_{4}\right)_{2} \mathrm{~S}_{2} \mathrm{O}_{8}$ and using $5 \mathrm{~mol} \%$ of $\mathrm{fac}$ $\operatorname{Ir}(\mathrm{ppy})_{3}$ as photocatalyst under visible light irradiation. However, the reaction proceeded slowly (48 h) under photocatalytic reaction conditions in comparison to thermal reaction conditions (12 h). Several aromatic aldehydes with electron-releasing (Me, OMe) and electron-withdrawing $(\mathrm{F}, \mathrm{Cl}$, $\mathrm{Br}, \mathrm{OAc}$ etc.) groups at the aromatic ring were coupled with phenanthridine under the optimized thermal conditions as well as photo-catalytic conditions and targeted products could be obtained in moderate to good yields. Benzaldehydes with di- and tri-methoxy substituents triggered good results in both conditions. Interestingly, 4-fluorobenzaldehyde provided the maximum yield of $80 \%$ under thermal conditions. Unfortunately, no product was obtained with 4nitrobenzaldehdye and 4-N,N-dimethylbenzaldehydes in 
either of the conditions. Aliphatic aldehydes provided inferior product yields (Scheme 51A).

Based on the literature and experiments, a possible photocatalytic pathway was proposed (Scheme 51B). The persulfate anion can be reduced by visible light excited $\left[\operatorname{Ir}(\mathrm{ppy})_{3}\right]^{3+*}$ to give sulfate and the sulfate radical anion $\mathbf{A}$ along with $\left[\operatorname{Ir}(\mathrm{ppy})_{3}\right]^{4+}$. H-Atom abstraction from the aldehyde by radical $\mathbf{A}$ gives acyl radical $\mathbf{B}$ which on addition to phenanthridine afforded amidyl radical $\mathbf{C}$. Deprotonation of the $\alpha$-proton in the amidyl radical $\mathbf{C}$ by the sulfate anion generates radical anion $\mathbf{D}$. Reductive quenching of $\left[\operatorname{Ir}(\mathrm{ppy})_{3}\right]^{4+}$ by radical anion $\mathbf{D}$ through SET generates $\left[\operatorname{Ir}(\mathrm{ppy})_{3}\right]^{3+}$ sustaining the photocatalytic chain.

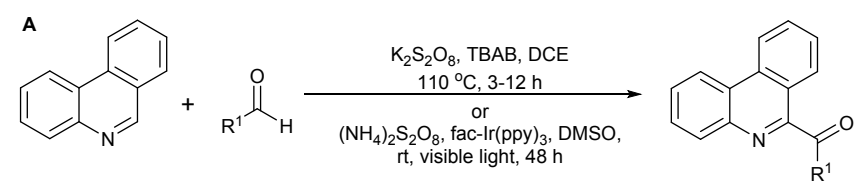

19 examples, $0-81 \%(0-73 \%)^{*}$

$\mathrm{R}^{1}=\mathrm{Ph}, 4-\mathrm{CIPh}, 4-\mathrm{BrPh}, 4-\mathrm{FPh}, 4-\mathrm{MePh}$ 4-OMePh, 4- $\mathrm{NO}_{2} \mathrm{Ph}, 2-\mathrm{CIPh}, 2-\mathrm{BrPh}$,

2-MePh, 2-OMePh 2-OAcPh, $\beta$-naphthyl, $\alpha$-naphthyl, 3,4-OMePh, 3,4,5-OMePh, 4- $\mathrm{N}(\mathrm{Me})_{2} \mathrm{Ph}, n-\mathrm{Bu}$, hexyl

*photocatalysis yield is given in parenthesis

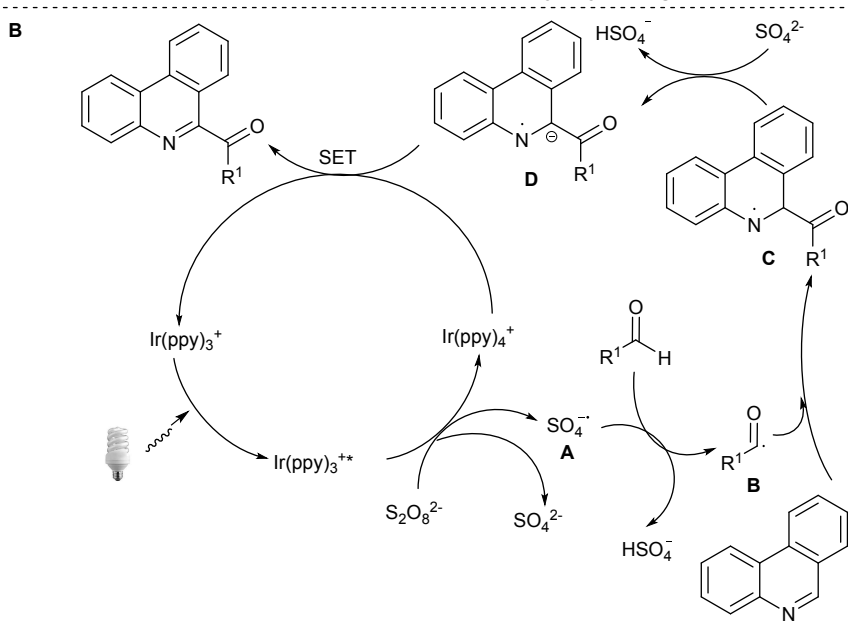

Scheme 51: (A) Acylation of phenanthridine with aldehydes via thermolysis or photolysis; (B) proposed reaction mechanism.

In a span of four years (2015-2018), four individual studies ${ }^{87}$ on the application of aldehydes as acylating agents were published for the selective direct C3-acylation of coumarins. In 2015, Fe-catalyzed cross-coupling of coumarins was carried out with aromatic aldehydes in the presence of TBHP oxidant under $\mathrm{N}_{2}$-atmosphere by the team of Ling-Bo Qu. ${ }^{87 a}$ Initially, several aromatic aldehydes $(1.0 \mathrm{mmol})$ were coupled with coumarin $(0.25 \mathrm{mmol})$ under the optimized reaction conditions using $\mathrm{FeCl}_{2}$ as catalyst, TBHP as oxidant in toluene at $120^{\circ} \mathrm{C}$ under nitrogen atmosphere. The targeted molecules were achieved in moderate to good yields after $12 \mathrm{~h}$. Aromatic aldehydes with electron-releasing $\left(\mathrm{CH}_{3}^{\mathrm{DO}}, \mathrm{OCH}_{3}, \mathrm{OCO}_{2} \mathrm{O} \mathrm{CO}_{2} \mathrm{O}\right)^{145 \mathrm{a}} \mathrm{d}$ mild electron-withdrawing $(\mathrm{F}, \mathrm{Cl}, \mathrm{Br})$ groups on the benzene ring smoothly favored the selective C3-acylation of coumarin in moderate to good yields. However, aromatic aldehydes with electron-withdrawing groups afforded inferior product yields in comparison to aldehydes bearing electron-releasing groups at the aryl ring. The steric hindrance on aromatic aldehydes did not affect this transformation since orthosubstituted aldehydes and $\alpha$-naphthaldehyde smoothly generate the corresponding products in moderate yields. Unfortunately, aliphatic aldehydes failed to deliver the targeted products. Furthermore, coumarin substituted with electron-rich $\left(\mathrm{OCH}_{3}, \mathrm{OCH}_{2} \mathrm{CH}_{3}\right.$, etc.) and electron-poor $(\mathrm{OH}$, $\mathrm{OCOCH}_{3}, \mathrm{NO}_{2}$, etc.) groups at the $\mathrm{C} 6$ or $\mathrm{C} 7$-position were found to give the corresponding products in moderate yields (Scheme 52A). A series of $\mathrm{N}$-methyl quinolinone derivatives was also examined successfully using the optimized reaction conditions and acyl groups were exclusively attached to the C3-position of 2-quinolinones delivering $55-77 \%$ yield of the products. On the bases of control experiments and previous reports, a plausible reaction mechanism was proposed by authors as depicted in scheme 52B.

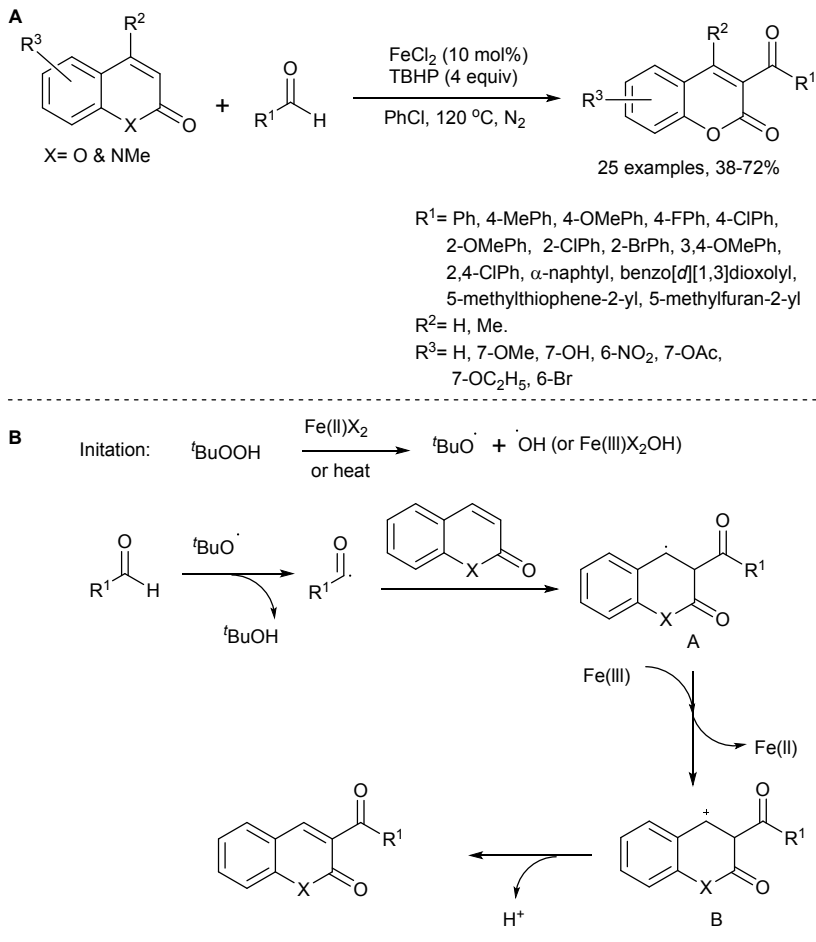

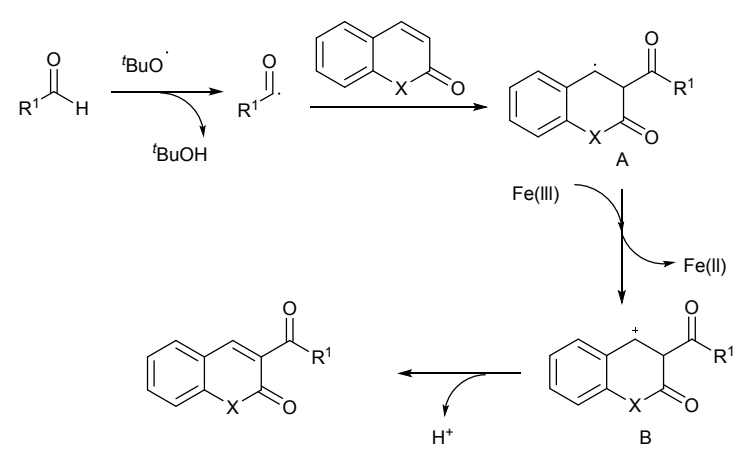

Scheme 52: (A) Fe(II)-catalyzed cross-coupling of coumarins for the selective direct C3-acylation; (B) plausible reaction mechanism.

Later in 2016, Aihua Zhou and co-workers developed a new coupling reaction for the selective C3-acylation of coumarins by a $\mathrm{sp}^{2} \mathrm{C}-\mathrm{H}$ functionalization process involving aldehydes in the presence of a Cu-catalyst and TBHP as oxidant (Scheme 
53A). ${ }^{87 b}$ Various coumarin derivatives were acylated regioselectively at the $\mathrm{C} 3$ position by aldehydes and all substrates reacted proficiently to produce the respective products in moderate to good yields in the presence of $\mathrm{CuO}$ as catalyst and TBHP as oxidant at $90{ }^{\circ} \mathrm{C}$ after $24 \mathrm{~h}$. Aromatic aldehydes with electron-releasing groups (OMe, $\mathrm{Me},{ }^{t} \mathrm{Bu}$, etc.) and the electron-withdrawing bromine group were found suitable for this transformation. Nevertheless, in case of nitrobenzaldehyde no expected product could be observed, whereas iso-butyraldehdye delivered the C3-acylated product in $48 \%$ yield. Noticeably, 2 -furaldehyde also afforded the product upon coupling with coumarin, and 6-methyl coumarin in $65 \%$ and $63 \%$ yield, respectively. Moreover, the presence of substituents on the coumarin did not alter the reaction outcome and good yields were obtained. The proposed mechanism for this protocol is presented in scheme 53B.

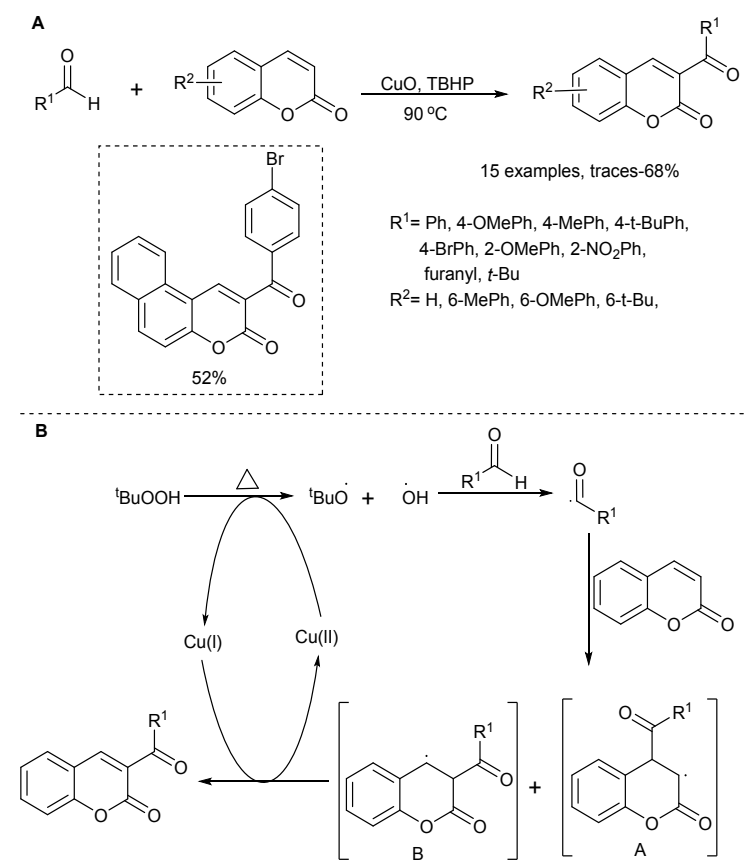

Scheme 53: (A) Cu-catalyzed C3-acylation of coumarin; (B) plausible reaction mechanism.

Subsequently in 2016, Peiman Mirzaei and his team worked on a transition metal-free cross-dehydrogenative coupling reaction for the synthesis of 3-acylcoumarins. Reactions were carried out by heating a mixture of coumarins and aldehydes in the presence of $\mathrm{K}_{2} \mathrm{~S}_{2} \mathrm{O}_{8}$ /Aliquat-336 system in chlorobenzene. Various substituted coumarin and aldehyde derivatives were coupled at $100{ }^{\circ} \mathrm{C}$ for $8 \mathrm{~h}$ to synthesize 14 derivatives of 3-acylcoumarins in good to excellent yields (Scheme 54A). ${ }^{87 \mathrm{c}}$ The electronic behaviour of the substituents present on the benzene ring of the aromatic aldehydes played a key role for the yields irrespective of their positions. Aromatic aldehydes having either electron-releasing (Me,
OMe) groups or mild electron-withdrawing groups $\left(F_{0 n} C l\right)$ reacted proficiently and delivered the products in/Righ The scope of substituted coumarins was also explored using 6-methyl-coumarin and 6-chlorocoumarin and the expected products could be obtained in good yields. Moreover, treatment of acetaldehyde with coumarin afforded $88 \%$ of the desired product. The control experiments revealed that the reaction followed a free-radical mechanism since the addition of free radical scavenger TEMPO to the reaction mixture inhibits the formation of the product completely. The proposed mechanism is depicted in scheme 54B. This starts with the reaction between Aliquat-336 (tricaprylmethylammonium chloride) $A$ and $\mathrm{K}_{2} \mathrm{~S}_{2} \mathrm{O}_{8}$ resulting in the formation of tricaprylmethylammonium persulfate $\mathbf{B}$, which generates tricaprylmethylammonium sulfate radical $\mathbf{C}$ on heating. Then, acyl radical $\mathbf{E}$ is generatedvia the reaction between benzaldehyde and the sulfate radical $\mathbf{B}$ and this process is accompanied by the removal of tricaprylmethylammonium hydrogensulfate D. Radical addition of $\mathbf{E}$ to the 3-position of coumarin forms resonance stabilized benzyl radical $\mathbf{F}$. Finally, removal of a hydrogen atom from $\mathbf{F}$ by another sulfate radical $\mathbf{C}$ afforded the desired product together with $\mathbf{D}$. Tricaprylmethylammonium chloride gets regenerated by the reaction between tricaprylmethylammonium hydrogensulfate $\mathbf{D}$ and $\mathrm{KCl}$.
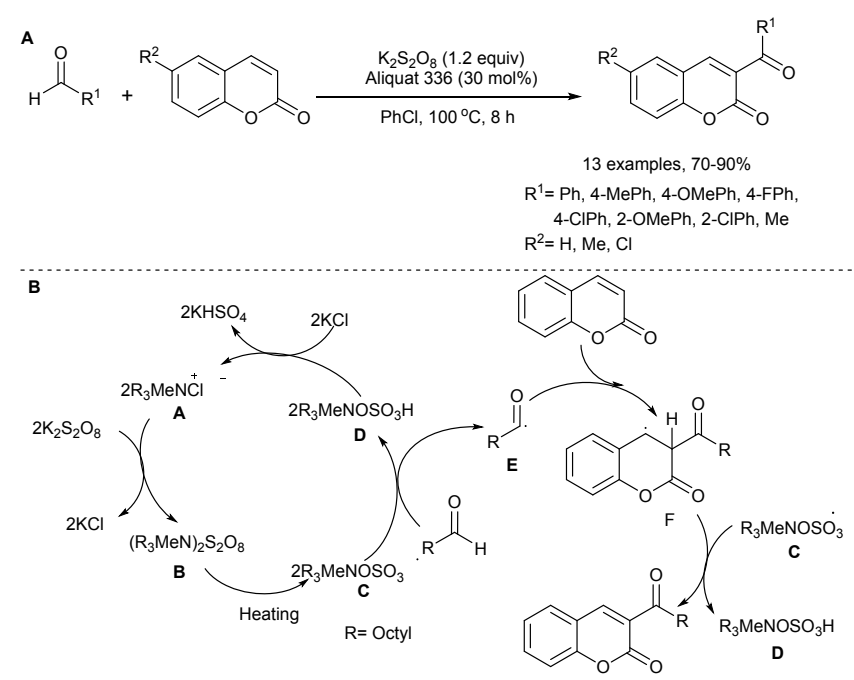

Scheme 54: (A) Metal-free cross-dehydrogenative coupling for $\mathrm{C}_{3}$-acylation of coumarin; (B) proposed reaction mechanism.

Recently, our group has developed a highly proficient, metalfree approach for the regioselective C3-acylation of coumarins with aromatic aldehydes using tert-butyl peroxybenoate (TBPB) as free radical initiator (Scheme 55). ${ }^{87 d}$ Various differently substituted aromatic aldehydes having electronreleasing and electron-donating groups were reacted with 7methoxy coumarin under the optimized reaction conditions. 
All applied aromatic aldehydes delivered the anticipated products in moderate to good yields at $90{ }^{\circ} \mathrm{C}$ after $24 \mathrm{~h}$. Also, other derivatives of coumarin produced the desired products in good yields upon treatment with benzaldehyde. Unfortunately, neither aromatic aldehyde nor coumarin having strong electron-withdrawing $\mathrm{NO}_{2}$-group furnished the corresponding acylated compound. Moreover, isobutyraldehyde and pyridine-2-carbaldehyde also resulted in the acylation of coumarin at C3-position in $41 \%$ and $60 \%$ yield, respectively. Furthermore, $\mathrm{N}$-methylquinolone also delivered the individual C3-acylated product upon treatment with simple benzaldehyde under the optimized reaction conditions.

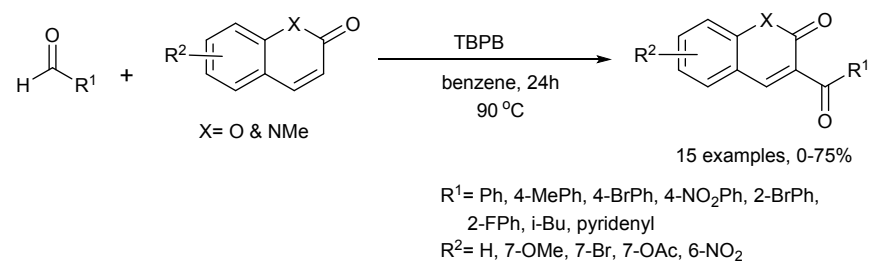

Scheme 55: Regioselective C3-acylation of coumarin with aldehydes.

In $2016 \mathrm{Wu}$ and his team described a one-pot process for the selective formation of 8-acylated-2-quinolinones starting from quinilone- $N$-oxides and aldehydes using a Pd-catalyst and TBHP as oxidant via the formation of $\mathrm{N}$-oxide-chelated palladacycle. ${ }^{88} \mathrm{~A}$ total of 26 8-acylated-2-quinolinones were synthesized in good to excellent yields starting from various quinoline- $N$-oxides and benzaldehydes in the presence of $\mathrm{PdCl}_{2}$ catalyst, TBHP (5-6 $\mathrm{M}$ in decane) as oxidant, water as additive and DCE as solvent at $140{ }^{\circ} \mathrm{C}$ for $24 \mathrm{~h}$. (Scheme 56A). Benzaldehydes having electron-releasing (Me and $\mathrm{OMe}$ ) and weak electron-withdrawing $(\mathrm{F}, \mathrm{Cl}$ and $\mathrm{Br})$ groups at the paraposition of the aryl ring gave the corresponding products in good to excellent yields. However, proficiency of acylation was slightly affected by steric hindrance as $p$ methylbenzaldehyde gave a higher yield than $o$ - and $m$ methylbenzaldehyde and a similar pattern was observed for methoxy and halogen-substituted benzadehydes. 3 (trifluoromethyl)benzaldehyde provided the acylated product in just $43 \%$ yield. Furthermore, disubstituted aromatic aldehydes also provided good yields of the desired products. Substituted quinoline- $N$-oxides were also coupled smoothly with benzaldehyde and the positions of the substituents did not interfere with reaction outcomes significantly improving the synthetic effectiveness of this protocol.

Based on several control experiments such as free radical trapping and kinetic isotope effect, a plausible mechanism was proposed by the authors as presented in scheme 56B. The mechanism starts with the formation of a palladacycle dimer intermediate A via co-ordination of the palladium with the $\mathrm{O}_{\mathrm{e}}$ atom of quinoline- $N$-oxide and subsequient 39 epectrophific attack at the C8-position. Subsequently, complex $\mathbf{A}$ gets converted into another intermediate $\mathbf{B}$ through nucleophilic addition of $\mathrm{H}_{2} \mathrm{O}$ at the C2-position of the quinoline. In the meantime, an acyl radical was generated from the aldehyde in the presence of TBHP. The reaction between intermediate $B$ and the acyl radical afforded the oxidative addition intermediate $\mathbf{C}$ as a $\mathrm{Pd}(\mathrm{III})$ or $\mathrm{Pd}(\mathrm{IV})$ complex. Finally, intermediate $\mathbf{C}$ gave the desired product through reductive elimination and regenerated $\mathrm{Pd}(\mathrm{II})$.
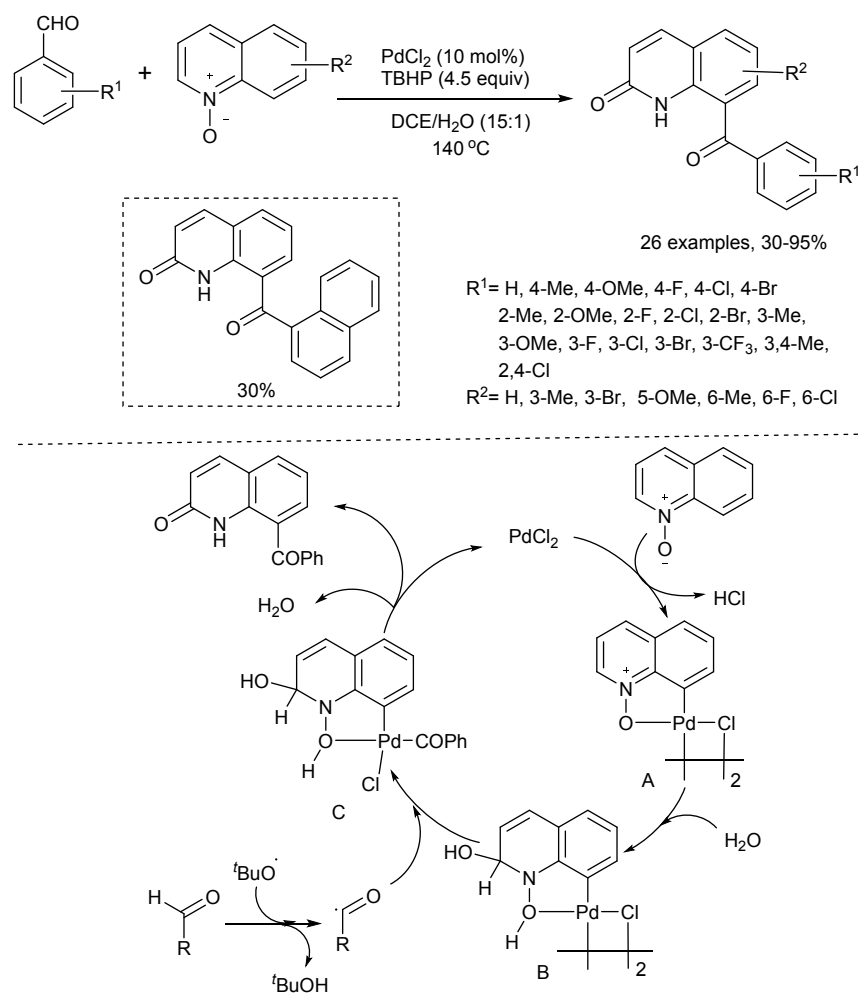

Scheme 56: (A) Pd-catalyzed selective $\mathrm{C}-8$ acylation of quinilone- $\mathrm{N}$-oxides using aldehydes; (B) plausible reaction mechanism.

Manna et al. in 2017 developed visible light photoredox and palladium (II) catalyzed regioselective direct C-2 acylation of $\mathrm{N}$-pyrimidine protected indoles using aldehydes as acylating agents and TBHP as acyl radical generator. ${ }^{89}$ Various differently substituted aromatic, heterocyclic and aliphatic aldehydes were coupled with $N$-pyrimidine protected indoles to synthesize a library of 27 acylated indole derivatives in good to excellent yield (Scheme 57A). Aromatic aldehydes having electron-releasing ( $\mathrm{Me}, \mathrm{OMe}$ ) groups resulted higher yield than those of containing electron-withdrawing $(\mathrm{Br}, \mathrm{CN})$ groups. $\quad \alpha$-Naphthaldehyde and thiophene-3carboxyaldehdye resulted the $75 \%$ and $74 \%$ yield of corresponding products. Aliphatic aldehydes such as cyclohexanecarbaldehdye, pentanal and 3-methylbut-2-enal 
delivered good product yields. Similarly the scope of substituted $\mathrm{N}$-pyrimidine protected indoles was established and high product yields were achieved irrespective of nature and position of substituent. Interestingly, protected tryptophan and carbazole also delivered the desired mono acylated products in moderate to good yields.

To get insight into reaction mechanism authors performed few control experiments. When standard reaction was carried out in presence of 2 equiv of TEMPO the reaction quenched completely and no desired product could be obtained. Moreover, in the absence of photoredox catalyst very poor yield was achieved and no reaction was observed in absence of TBHP. With the help of these experiments and literature reports a mechanism was given for this reaction (Scheme
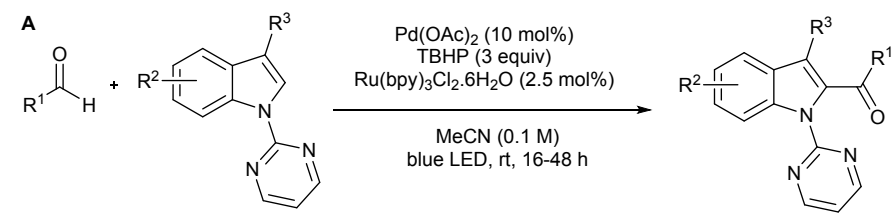

27 examples, $40-92 \%$

$\mathrm{R}^{1}=\mathrm{Ph}, 4-\mathrm{MePh}, 4-\mathrm{OMePh}, 4-\mathrm{BrPh}, 4-\mathrm{CNPh}, 4-\mathrm{OAcPh}, 4-\mathrm{CF} 3 \mathrm{Ph}$

3-OPhPh, 3,4-CIPh, 3,4-OMePh, 3,5-OMePh, 3-benzothiophenyl,

3-thiophenyl, $\alpha$-naphthyl, cyclohecyl, n-pentyl, 2-methylprop-1-enyl $\mathrm{R}^{2}=\mathrm{H}, 5-\mathrm{Br}, 5-\mathrm{OMe}, 5-\mathrm{F}, 4-\mathrm{CN}, 5-\mathrm{Me}, 5-\mathrm{Cl}$ $\mathrm{R}^{3}=\mathrm{H}, \mathrm{Me}$
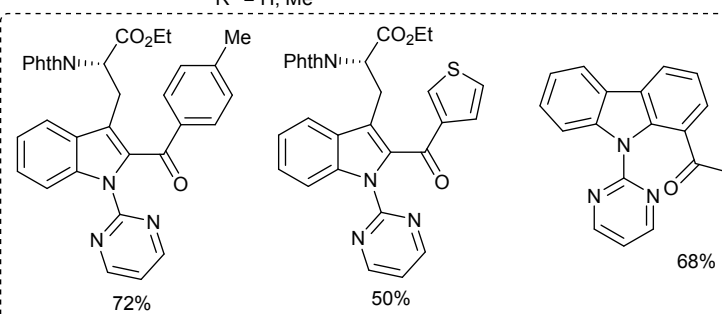

$68 \%$

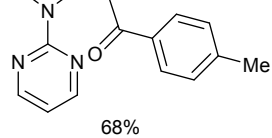

57B). Initally, $\mathrm{Ru}^{2+}$ get excited to $\mathrm{Ru}^{2+*}$ in presence of light,

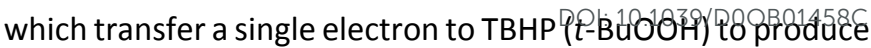
$\mathrm{OH}^{-}$and $t$-BuO via the cleavage of $\mathrm{O}-\mathrm{O}$ bond and oxidized to $\mathrm{Ru}^{3+}$. Then $t$-BuO abstracts hydrogen from aldehyde to generate acyl radical. On the other side, $N$-pyrimidyl indole undergoes cyclopalladation to form intermediate $\mathbf{A}$. Subsequent oxidative addition of intermediate $\mathbf{A}$ to acyl radical delivered cyclopalladated $\mathrm{Pd}(\mathrm{III})$ intermediate $\mathbf{B}$, which may be oxidized to $\mathrm{Pd}(\mathrm{IV})$ species $\mathbf{C}$ through a single electron transfer to $\mathrm{Ru}^{3+}$ resulting in reduction of $\mathrm{Ru}^{3+}$ to $\mathrm{Ru}^{2+}$. Species C finally delivered the corresponding acylated product and $\mathrm{Pd}$ (II) species by reductive elimination process.

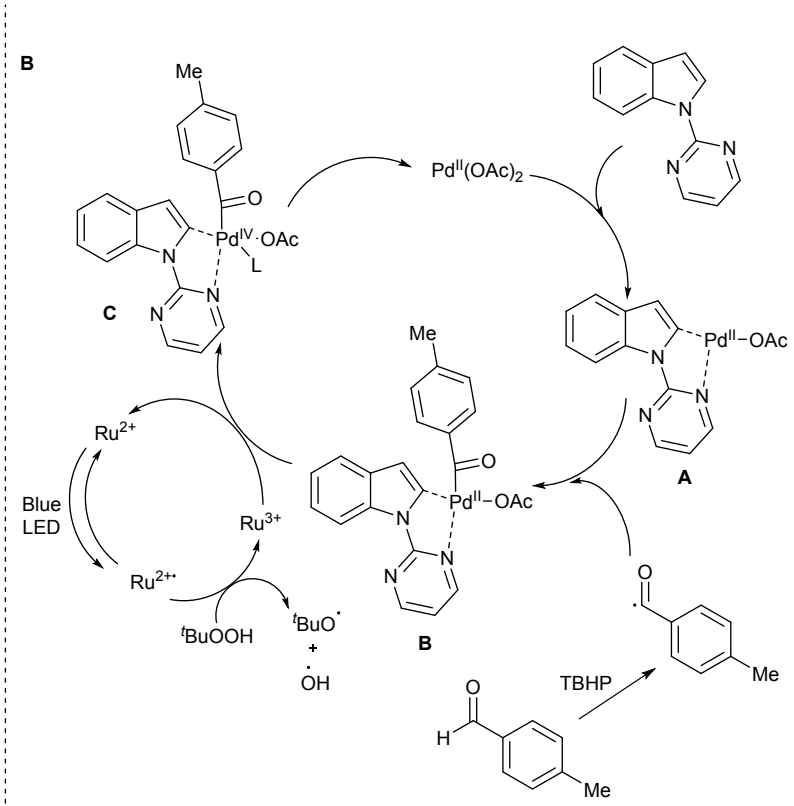

Scheme 57: (A) visible light photoredox and palladium (II) catalyzed regioselective direct C-2 acylation of $N$-pyrimidine protected indoles using aldehydes; (B) plausible reaction mechanism.

In 2017 Maiti et al. developed highly regioselective Pdcatalyzed direct ortho-mono and diacylation of carbazole at $\mathrm{C} 1$ and $\mathrm{C} 8$ positions using aldehydes as acylating agents via $\mathrm{C}$ $\mathrm{H}$ bond activation. ${ }^{90}$ Authors prepared 20 diacylatd and 4 mono acylated derivatives in $27-94 \%$ yields by coupling various aromatic and aliphatic aldehydes with $N$-pyridyl carbazoles (Scheme 58A). Aromatic aldehydes bearing electron withdrawing ( $\mathrm{Cl}, \mathrm{COOMe})$ at para-positions provided higher yield of diacylated products in comparison of aldehydes having electron-releasing (Me, OMe) groups. $\alpha-$ Naphthadehyde delivered the $92 \%$ yield of corresponding diacylated product. Moreover, aliphatic aldehyde such as cyclopropanecarboxaldehyde, cyclohexanecarboxaldehyde, heptaldehyde and isobutaraldehyde afforded the moderate to good yield. Substituted carbazoles also delivered their respective products in good yields. Interestingly, halogenated
$\mathrm{N}$-pyridyl carbazole resulted in monoacylated products on coupling with aromatic aldehydes under optimized reaction conditions (Scheme 58B). Authors have given a free-radical promoted plausible reaction mechanism for the diacylation of N-pyridyl carbazoles (Scheme 58C). 


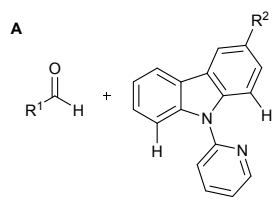

$\operatorname{Pd}(\mathrm{OAc})_{2}(10 \mathrm{~mol} \%)$ ${ }^{t} \mathrm{BuOOH}$ (4 equiv) Dichloroethane $80^{\circ} \mathrm{C}, 8 \mathrm{~h}$

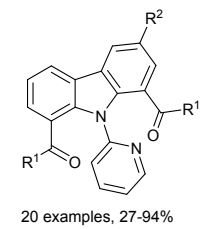

$\mathrm{R}^{1}=\mathrm{Ph}, 4-\mathrm{CIPh}, 3-\mathrm{CIPh}, 4-\mathrm{BrPh}, 2-\mathrm{BrPh}, 4-\mathrm{FPh}$ 4-OMePh, 3-OMePh, 2,5-OMePh, 4-MePh, 4-CO $\mathrm{CO}_{2} \mathrm{MePh}, 4-\mathrm{COMePh}, 4-\mathrm{CNPh}, \alpha$-naphthyl, cyclopropyl, cyclohexyl, $n$-hexyl, 'ipr, $\mathrm{R}^{2}=\mathrm{H}, \mathrm{Me}, \mathrm{COMe}$
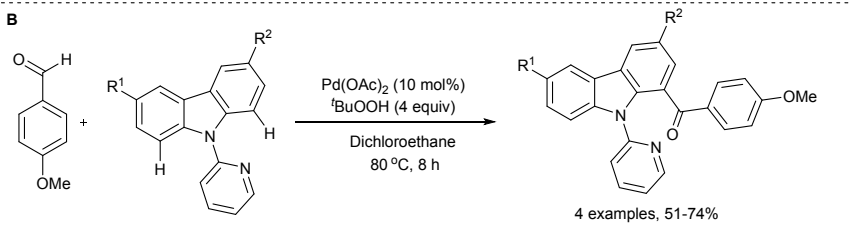

$\mathrm{R}_{1}=\mathrm{R}_{2}=\mathrm{Br}, \mathrm{I}$
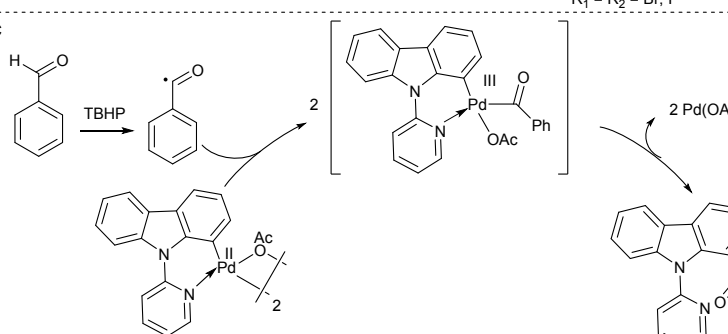
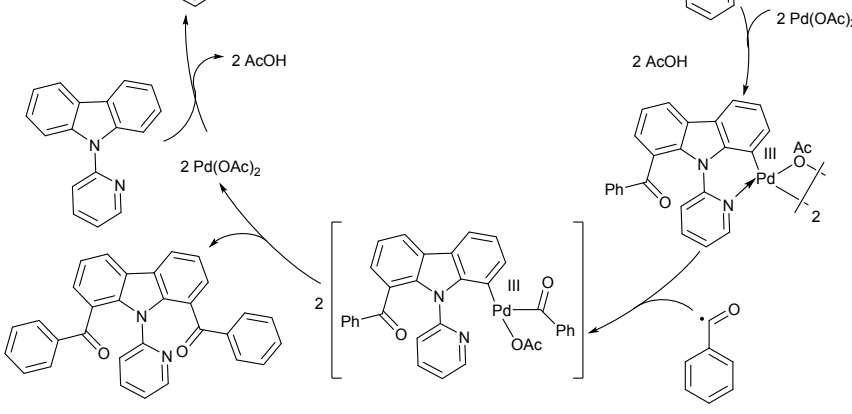

Scheme 58: (A) \& (B) Regioselective Pd-catalyzed direct ortho-mono and diacylation of carbazole at $\mathrm{C}_{1}$ and $\mathrm{C}_{8}$ positions using aldehydes; (C) plausible reaction mchanism.

Guin et al. attempted an aerobic radical approach for synthesizing unsymmetrical heteroaryl ketones. The approach primarily involved cross-dehydrogenative coupling between aldehydes and heteroaromatic bases in presence of molecular oxygen. ${ }^{91} \mathrm{~A}$ wide variety of nitrogen containing heterocyclic compounds were subjected to the aerobic radical acylation process and delightfully, the acylated products could be successfully obtained in good yield showing excellent regioselectivity at positions 2 and 4 (Scheme 59A). In a few cases, even the alkylated products could be synthesized. Apart from this, biologically relevant isoquinoline derivatives containing sulphonamides could also be generated with remarkable $99 \%$ selectivity. Several other nitrogen containing heterocycles including quinazoline, substituted quinazoline, benzimidazole, thiazole, etc. also smoothly underwent the acylation reaction, however pyridine and various derivatjives of pyridine were not very reactive and did hoth'furnish ${ }^{4}$ the target product in good yield. The synthetic methodology could also be extended for the formal synthesis of natural alkaloid $( \pm)$ angustureine. The homolytic activation of $\mathrm{C}-\mathrm{H}$ bond aldehyde using $\mathrm{O}_{2}$ as the oxidant led to the generation of acyl radical. On the basis of literature reports and the experimental results obtained, a radical pathway was suggested for the reaction (Scheme 59B). The mechanistic studies suggested that the auto-oxidation of aldehyde lead to the formation of acyl radical which reacted with the protonated nitrogen heterocyclic moiety to form the radical cation $\mathbf{A}$, this cation formed the targeted acylated product post oxidation.

Recently in 2020 Lete and co-workers described Pd(II)catalyzed C-2 acylation of pyrrole by aldehydes using 2pyrimidine or 3-methyl-2-pyridine as directing groups using TBHP as oxidant. ${ }^{92}$ Using 2-pyrimidine as directing group 15 mono C-2 acylated derivatives of pyrrole were obtained in 14$72 \%$ yield along with their corresponding C-2, C-5 diacylated byproducts ( $<5-41 \%$ yield) (Scheme 60A). Aromatic aldehydes with having halogens $(\mathrm{F}, \mathrm{Cl}, \mathrm{Br})$ on the para-position provided moderate to good yields of mono-acylayed products along with minor $<5-8 \%$ yield of diacylated product. Aryl aldehydes bearing strong electron-withdrawing $\mathrm{CF}_{3}, \mathrm{NO}_{2}$ and $\mathrm{CN}$ groups provided solely monoacyalted product but in very poor yields due to incompletion of the reaction. Although introduction of electron-releasing group on aryl ring of aldehyde provided good results but ortho-substituted aldehydes delivered lower yield due to steric effect. $\beta$-Naphthaldehyde resulted $51 \%$ yield of C-2 acylated product along with 19\% diacylated product. To avoid the formation of byproduct authors tried 3methyl-2-pyridine as directing group for the selective acylation of pyrrole and as was expected by authors all the carried out reactions selectively delivered C-2 acylated product without detection of formation of diacylated compound under the separately optimized. Aryl aldehydes with both electron-releasing as well as electron-withdrawing groups provided the corresponding derivatives in moderate to good yields. Heterocyclic aldehydes also provided the corresponding acylated products in good yields resulting in diheteroaryl ketones (Scheme 60B). 


\section{ARTICLE}

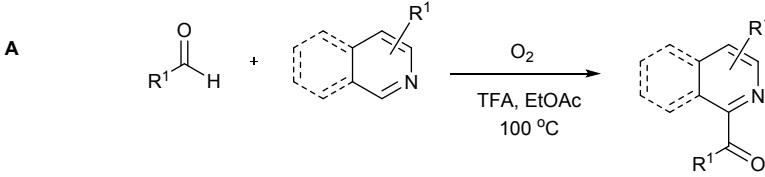

37 examples, traces- $77 \%$

$\mathrm{R}^{1}={ }^{n} \mathrm{Pr}$, ethyl, ${ }^{n} \mathrm{Bu}$, ethylbenzene, $n$-pentanyl, ${ }^{i} \mathrm{Bu}$, iso-pentyanyl, cyclohexyl, cyclopropyl, $\mathrm{CHEt}_{2}$, cyclohex-3-enyl, $\mathrm{Ph}, 4-\mathrm{OMePh}, 4-\mathrm{BrPh}$

$\mathrm{R}^{2}=4-\mathrm{Ph}, 4-(4-\mathrm{Ph}) \mathrm{Ph}, 4-(4-\mathrm{OMe}) \mathrm{Ph}, 4-(2,4-\mathrm{F}) \mathrm{Ph}, 4-\mathrm{Me}$ $\alpha$-napthyl, 4-Br, 5-NHCOPh, 5- $\mathrm{SO}_{2} \mathrm{NH}(3-\mathrm{Cl}-4-\mathrm{FPh})$ 5-(4-sulfonylpiperazin-1-yl)(phenyl)methanone, 4-(1-(4-sulfonyl-1,4-diazepan-1-yl)ethan-1-one), etc.

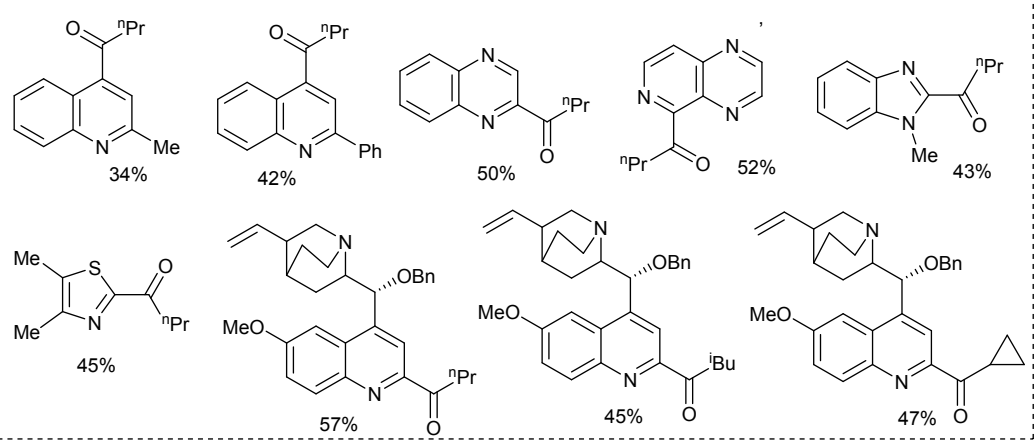

B

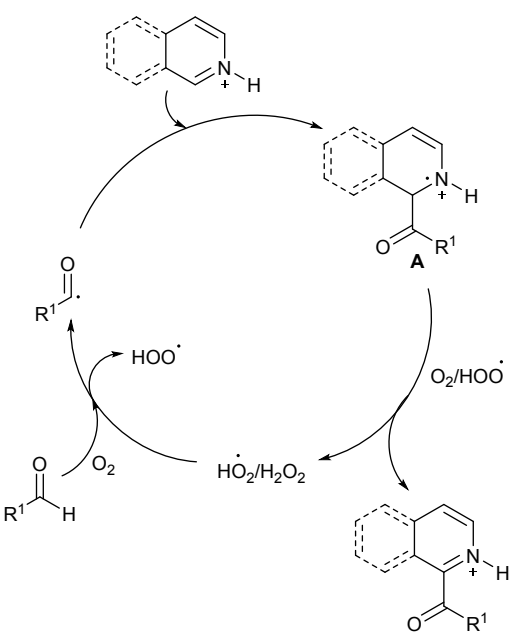

Scheme 59: (A) Aerobic cross-dehydrogenative coupling between heterocyclic compounds and aldehdyes; (B) plausible reaction mechanism.

A<smiles></smiles>
$\operatorname{Pd}(\mathrm{OAc}) 2(10 \mathrm{~mol} \%)$ Piv(OH) $(0.75$ equiv)
toulene, $60^{\circ} \mathrm{C}, 1.5-7 \mathrm{~h}$
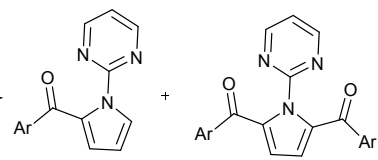

14 examples, $14-72 \%$

10 examples, $5-41 \%$

$\mathrm{Ar}=4-\mathrm{MePh}$, 4-tBuPh, 4-FPh, 4-CIPh, 4-BrPh, 4-CNPh, 4- $\mathrm{NO}_{2} \mathrm{Ph}, 3,5-\mathrm{OMePh}, 3,4,5-\mathrm{OMePh}, 2,6-\mathrm{OMePh}$ 2,4-OMePh, 4-CF 3 Ph, 3,5-CF 3 Ph, $\beta$-naphthyl
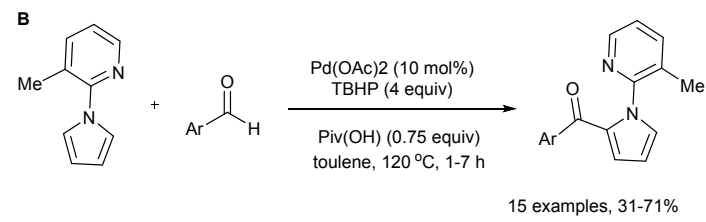

$\mathrm{Ar}=4-\mathrm{MePh}, 4-\mathrm{tBuPh}, 4-\mathrm{FPh}, 4-\mathrm{CIPh}, 4-\mathrm{BrPh}, 4-\mathrm{CNPh}$, 4-NO $\mathrm{Ph}_{2} \mathrm{Ph}, 3,5-\mathrm{OMePh}, 3,4,5-\mathrm{OMePh}, 2,6-\mathrm{OMeP}$ 1 -methyl-1 1 -pyrrolyl, furanyl

Scheme 60: Pd(II)-catalyzed C-2 acylation of pyrrole by aldehydes using (A) 2-pyrimidine or; (B) 3-methyl-2-pyridine as directing groups.

\section{Miscellaneous}

In 2012, Zhang and Hong reported the direct $\mathrm{N}$-acylation of lactams, oxazolidinones and imidzolidinones using aldehydes in the presence of Shvo's catalyst in toluene as solvent. ${ }^{93}$ The best reaction conditions were defined as stirring a mixture of lactam/oxazolidinone/imidzolidinone ( $0.25 \mathrm{mmol}, 1$ equiv.), aldehyde (3.0 equiv) in the presence of Shvo's catalyst ( 2.5 mol\%) in toluene $(0.5 \mathrm{~mL})$ as solvent at $100^{\circ} \mathrm{C}$ for $24 \mathrm{~h}$. In total $33 \mathrm{~N}$-acylated derivatives of lactams, oxazolidinones and imidzolidinones were synthesized in moderate to excellent yields using several aromatic, aliphatic, heterocyclic and $\alpha, \beta$ unsaturated aldehydes as acylating agents (Scheme 61A). Based on the mechanism of Shvo's catalyst, the authors proposed a plausible mechanism for this method as presented in scheme 61B. This involves nucleophilic attack of lactam A to the carbonyl carbon of the activated aldehyde to form a hemiaminal B, which further oxidizes via $\beta$-hydride elimination and undergoes proton transfer to produce the acylation product and ruthenium species $\mathbf{C}$. 


\section{ARTICLE}

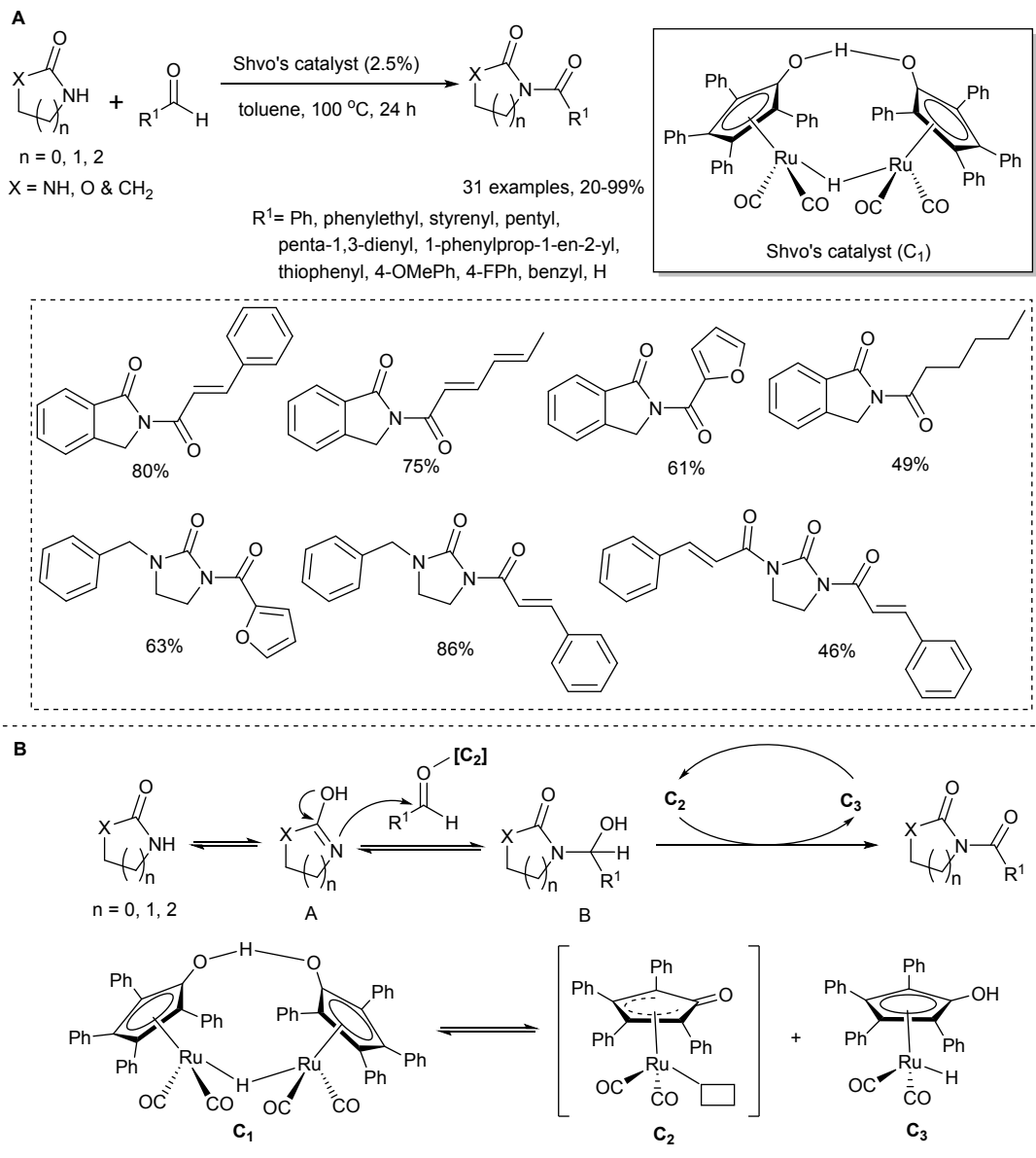

Scheme 61: (A) Direct $N$-acylation of lactams, oxazolidinones and imidzolidinones with aldehdyes using Shvo's catalyst; (B) proposed mechanism.

A copper catalyzed oxidative cross-coupling involving dual C$\mathrm{N} / \mathrm{N}-\mathrm{H}$ functionalization for $\mathrm{N}$-acylation of sulfoximines was disclosed by Wang et al. in 2013 by treating aldehydes with sulfoximines in the presence of TBHP as oxidant under mild reaction conditions (Scheme 62A). ${ }^{94} \mathrm{~A}$ set of 14 derivatives of $\mathrm{N}$-acylsulfoximines was prepared with good functional group tolerance. In addition to $S, S$-methylphenyl sulfoximine, the reaction proceeded smoothly with $S, S$-dimethyl and $S, S$ tetramethylenesulfoximines also and afforded their respective products in excellent yields. Also, benzaldehyde bearing a nitro group at the para- and meta-position furnished the targeted compounds in excellent yields. Not only a nitro group but also other electron-withdrawing groups such as $F$, $\mathrm{Cl}$ and electron-releasing groups such as methoxy, alkyl, etc. were well tolerated, delivering various $N$-benzoylsulfoximines in good to excellent yields. A redox process based plausible pathway for this protocol is described in scheme 62B. The proposed pathway involves the interaction of a $\mathrm{Cu}$ (II) catalyst with sulfoximine to give intermediate $\mathbf{A}$. This intermediate $\mathbf{A}$ reacts with an acyl radical generated from the aldehyde in the presence of TBHP. Subsequently, an electron transfer processes results in the construction of $\mathrm{N}$-acylsulfoximine and a $\mathrm{Cu}(\mathrm{I})$ species. The later re-oxidizes to $\mathrm{Cu}(\mathrm{II})$ in the presence of TBHP. 

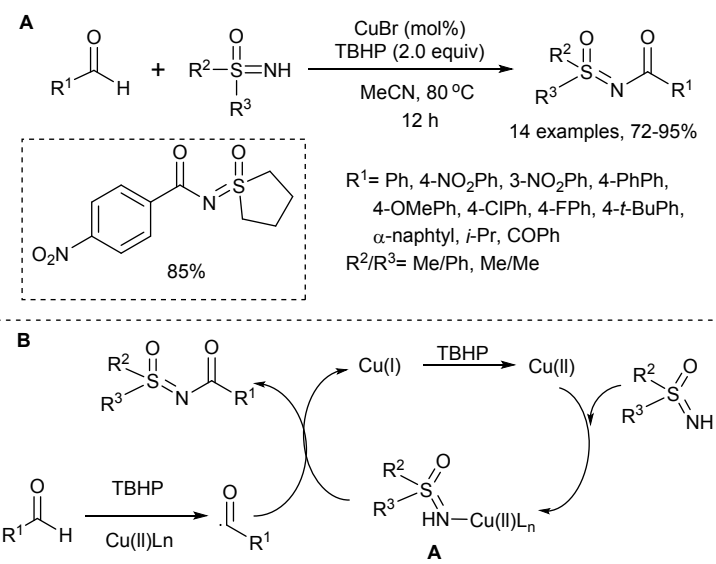

Scheme 62: (A) Cu(II)-catalyzed acylation of sulfoximines using aldehydes; (B) proposed mechanism.

In 2014, Luo and Liang developed a metal-free one-pot cascade cyclization of 1,6-enynes with aldehydes involving simultaneous one $\mathrm{C}\left(\mathrm{sp}^{2}\right)-\mathrm{C}\left(\mathrm{sp}^{2}\right)$ and two $\mathrm{C}\left(\mathrm{sp}^{2}\right)-\mathrm{C}\left(\mathrm{sp}^{3}\right)$ bond formation for the synthesis of carbonylated tricyclic fluorene derivatives by using $\mathrm{PivOH}$ and TBHP. ${ }^{95}$ The reaction conditions were optimized as the reaction of a 1,6-enyne $(0.2$ mmol) with an aldehyde $(1.0 \mathrm{mmol})$ in the presence of the oxidant TBHP ( $0.4 \mathrm{mmol}, 70 \%$ aqueous solution), the additive $\mathrm{PivOH}(0.4 \mathrm{mmol})$ in acetonitrile as solvent $(1 \mathrm{~mL})$ at $120^{\circ} \mathrm{C}$ for $48 \mathrm{~h}$ under argon atmosphere. The developed reaction conditions were initially examined for exploitation of aldehydes in this cascade oxidative cyclization process. Various aromatic aldehydes containing electron-releasing and electron-withdrawing groups participated in this reaction to give the targeted fluorene derivatives in good yields regardless the positions of substituents on the aryl ring of the benzaldehydes (Scheme 63A). Aliphatic aldehydes were not suited in this transformation and only traces of the products could be obtained. Remarkably, benzo[d][1,3]dioxole-5carbaldehyde and thiophene-2-carboxyaldehyde could also undergo the reaction giving the products in $45 \%$ and $35 \%$ yields, respectively. Delighted by these promising results, the scope of 1,6-enyne substrates was examined with benzaldehyde and the reaction progressed efficiently in most cases to give the desired products in moderate to good yields (Scheme 63A). 1,6-Enynes substituted with electron-releasing alkyl or alkoxy groups at the ortho, meta or para-position or containing either halogen or an electron-withdrawing COOMe or $\mathrm{CN}$ group at the para-position were suitable for this reaction affording the corresponding carbonylated fluorenes. Tosylamides also react with benzaldehyde to give products in moderate yield, whereas only trace amounts of the product (9,9-dimethyl-1,3,9,9a-tetrahydroindeno[2,1-c]pyran-4-

$\mathrm{yl}$ )(phenyl)methanonewas obtained from the corresponding enyne substrate.

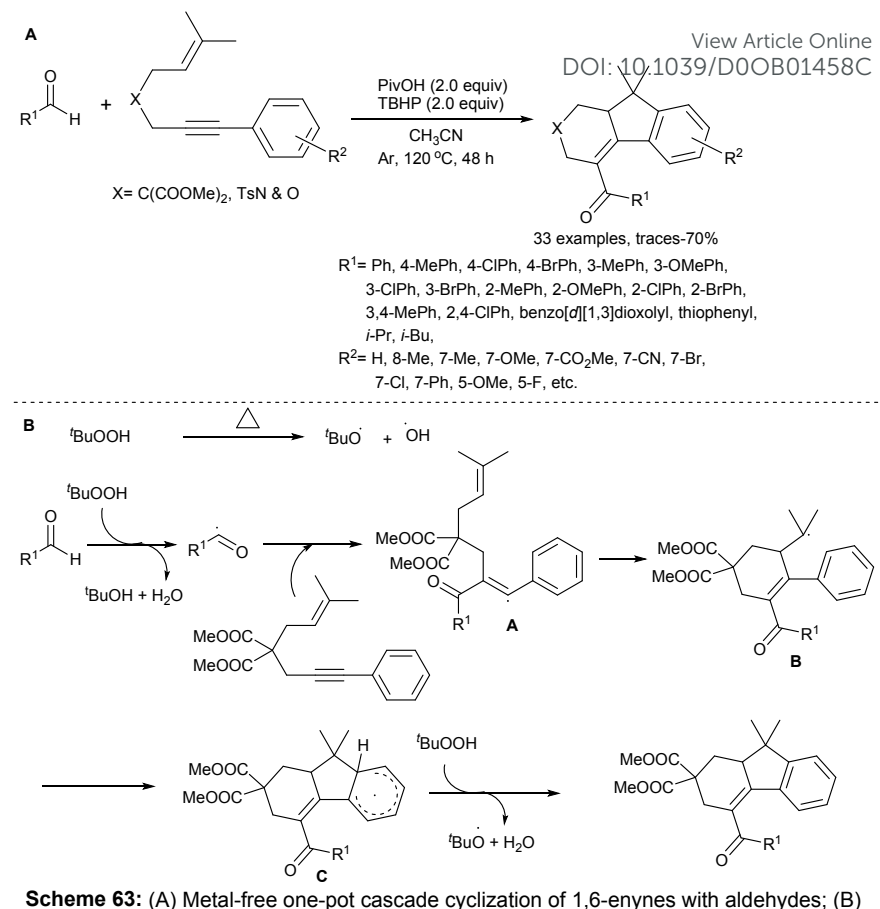

Scheme 63: (A) Metal-free one-pot cascade cyclization of 1,6-enynes with aldehydes; (B) plausible reaction mechanism.

To understand the mechanism, kinetic isotope effect and freeradical quenching experiments were examined. No kinetic isotope effect $\left(k_{H} / k=1.0\right)$ was found by the outcome of intramolecular and intermolecular reactions under standard reaction conditions. This ultimately revealed a free-radical or SEAR route for this reaction. Also, inhibition of the reaction in the presence of 4 equiv of TEMPO clearly indicated that the reaction proceeds via a free-radical route. A large kinetic isotope effect $\left(\mathrm{KIE}, \mathrm{k}_{\mathrm{H}} / \mathrm{kD}=9.1\right)$ value for the 1:1 mixture of benzaldehyde and $\left[D_{6}\right]$-benzaldehyde implied that cleavage of the carbonyl $\mathrm{C}-\mathrm{H}$ bond is the rate-determining step for this conversion. Depending on these observations and previous reports in this field, ${ }^{96}$ a plausible mechanism was proposed (Scheme 63B). Initially, homolytic cleavage of TBHP under heating conditions generated alkyloxy and hydroxyl radicals. These radicals capture a hydrogen atom from benzaldehyde to form an acyl radical, and successive attack of this acyl radical at the $\mathrm{C} \equiv \mathrm{C}$ bond of the enyne afford the radical intermediate $\mathbf{A}$. Next, an intramolecular cyclization process generates a tertiary carbon radical $\mathbf{B}$, which subsequently by another intramolecular cyclization with an aryl ring give rise to radical intermediate $\mathbf{C}$. Lastly, direct oxidation and deprotonation of intermediate $\mathbf{C}$ by TBHP furnishes the final product.

Fuwei Li and his team in 2014 demonstrated a KI-catalyzed oxidative cross-coupling of $\mathrm{C}-\mathrm{N}$ and $\mathrm{N}-\mathrm{H}$ bonds between azoles and aromatic aldehydes for the direct $\mathrm{N}$-acylation of azoles in the presence of TBHP as oxidant. ${ }^{97}$ Various derivatives of azole 
$(0.3 \mathrm{mmol})$ were reacted with aldehydes $(0.45 \mathrm{mmol})$ in the presence of $\mathrm{KI}(0.06 \mathrm{mmol})$ as standard catalyst using TBHP $(0.9 \mathrm{mmol})$ as ideal oxidant in dichloroethane (DCE) as solvent at $100{ }^{\circ} \mathrm{C}$ for $12 \mathrm{~h}$. A total 28 derivatives were prepared in moderate to excellent yields irrespective of the positions and nature of the substituents on the azoles as well as on the aldehydes (Scheme 64A). When the scope of aldehydes was examined with pyrazoles, para-substituted benzaldehydes containing electron-donating ( $\left.\mathrm{OMe},{ }^{t} \mathrm{Bu}\right)$ groups and electronwithdrawing $(\mathrm{Cl}, \mathrm{Br}, \mathrm{CN})$ groups reacted effectively with 3phenyl pyrazole and delivered the products in $57 \%$ to $95 \%$ yield. Ortho-methoxybenzaldehydes resulted inferior yield in comparison to para-methoxybenzaldehydes. $\beta$ naphthaldehdyde and thiophene-2-carbaldehdydes were also found suitable for this transformation leading to $90 \%$ and $72 \%$ yield of the products, respectively. Encouraged by these findings, the authors further explored the scope of other azoles such as benzimidazole, benzotriazole and indazole with various substituted aromatic aldehydes. Benzaldehydes with electron-releasing groups provided products in $85 \%$ to $98 \%$ yield whereas electron-withdrawing substituents afforded yields of $24 \%$ to $78 \%$ upon reaction with benzimidazole. Surprisingly, benzotriazole reacted only with orthosubstituted benzaldehydes and no product formation was observed with para-substituted benzaldehydes. Furthermore, indazole upon treatment with para-bromobenzaldehyde gave $44 \%$ yield.

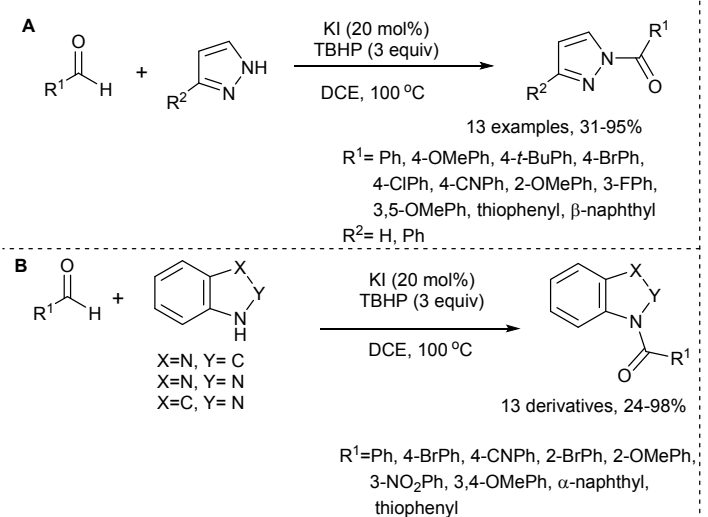

Scheme 64: (A) \& (B) Kl-catalyzed oxidative cross-coupling of $\mathrm{C}-\mathrm{N}$ and $\mathrm{N}-\mathrm{H}$ bonds for $\mathrm{N}$-acylation of azoles using aromatic aldehydes; (C) plausible reaction mechanism.

To improve the product yield, several other catalysts, oxidants and solvents were screened. Finally, by several combinations and permutations, the reaction conditions were optimized by stirring of a mixture of acetanilide $(0.5 \mathrm{mmol})$, benzaldehyde $(1 \mathrm{mmol})$ in the presence of $\mathrm{CuCl}_{2} \cdot 2 \mathrm{H}_{2} \mathrm{O}(10 \mathrm{~mol} \%)$ catalyst using TBHP (2 equivalents) as oxidant in DCE as solvent at 100 ${ }^{\circ} \mathrm{C}$ for $24 \mathrm{~h}$. With these optimized reaction conditions, the scope and versatility of the reaction was examined using
To investigate the reaction mechanism, control experiments were performed in the presence of free-radical/Bcavent 5 ers like TEMPO and 1,1-diphenylethylene. These experiments suggested the formation of an acyl radical and a free-radical pathway for this conversion. Based on these results, two possible pathways were proposed as shown in scheme $64 \mathrm{C}$. It was hypothesized that the tert-butoxyl and tert-butylperoxy radicals are generated initially in the catalytic system, which could abstract a hydrogen atom from the aldehyde to generate the acyl radical. This acyl radical on reaction with the azole give the acyl azole radical anion $\mathbf{A}$. Subsequently, radical anion $\mathbf{A}$ by losing an electron via a SET process in the presence of the tert-butoxyl or tert-butylperoxy radical afforded the desired $\mathrm{N}$-acyl azoles (Path $\mathbf{A}$ ). In path $\mathbf{B}$, it is represented that the tert-butoxyl and tert-butylperoxy could capture a single electron from the azoles leading to an azole cation species $\mathbf{B}$, which upon deprotonation with the help of tert-bytoxyl anion could convert to azole radical $\mathbf{C}$. Finally, the coupling between acyl radical and azole radical cation $\mathbf{B}$ or azole radical $\mathbf{C}$ provided the desired product.

In 2015, Singh and co-workers for the first time developed a mild oxidative amidation process of aldehydes using acetanilide as amine component in the presence of copper catalyst and TBHP as oxidant. ${ }^{98}$ Acetanilide and benzaldehyde were taken as model reactants and the reaction was carried out using NBS catalyst and TBHP as oxidant in acetonitrile at $100^{\circ} \mathrm{C}$, and $55 \%$ yield of benzanilide was obtained.

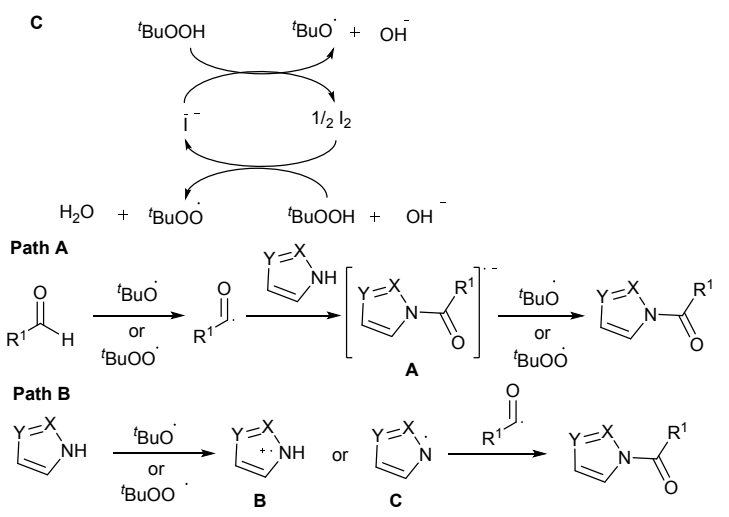

various substituted acetanilides and aldehydes, and finally a library of 24 benzanilide derivatives was prepared (Scheme 65A). Acetanilides as well as benzaldehydes containing electron-releasing and electron-withdrawing groups such as $\mathrm{Me}, \mathrm{OMe}, \mathrm{Cl}, \mathrm{Br}, \mathrm{NO}_{2}, \mathrm{CN}$, etc. underwent the reaction smoothly delivering the products in moderate to good yields. Thiopene-2-carbaldehyde gave the product in 52\% yield. However other heterocyclic aldehydes such as furfural and 
indole-3-carboxyaldehyde showed no product formation because of their decomposition in the presence of TBHP. Aliphatic aldehydes such as heptanal and cinnamaldehyde afforded the corresponding products in $64 \%$ and $76 \%$ yield,

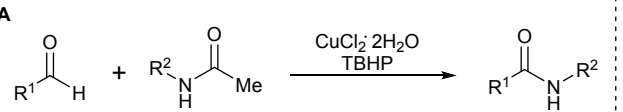

$$
\begin{aligned}
& 24 \text { examples, 0-82\% }
\end{aligned}
$$

respectively. Based on literature reports and experiments sine

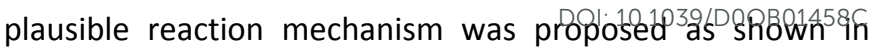
scheme 65B.

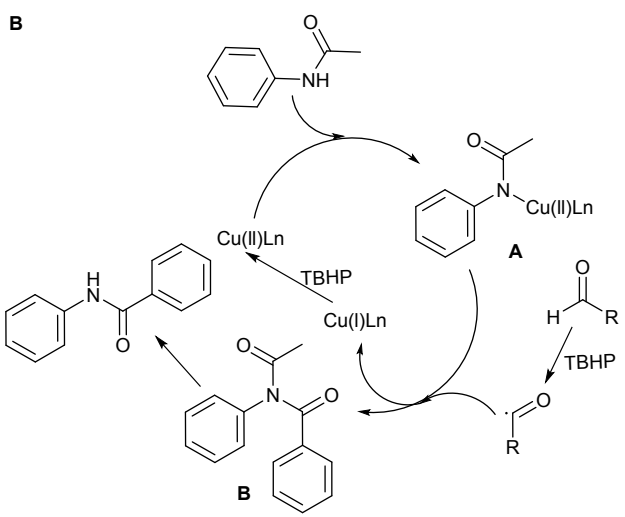

Scheme 65: (A) Cu-catalyzed oxidative amidation of aldehydes using acetanilide; (B) plausible reaction mechanism.

In the same year (2015), Achar et al. executed a metal-free oxidative cross-coupling for the amidation of aldehydes with $\mathrm{N}$-chloramines in the presence of TBAI (tetrabutylammonium iodide) in combination with TBHP under neat conditions at $50^{\circ} \mathrm{C}$ or ball-milling conditions at room temperature (Scheme 66A). ${ }^{99}$ Using this protocol, 19 amide derivatives were obtained in good yields by treating aromatic aldehydes, heteroaromatic aldehydes and aliphatic aldehydes with primary and secondary $N$-chloramines. Aryl aldehydes having electron-donating $\mathrm{Me}$ and OMe substituents give $84 \%$ and $82 \%$ yield of the respective amides. Furthermore, the presence of electron-withdrawing substituents such as $\mathrm{F}, \mathrm{Cl}$, $\mathrm{Br}, \mathrm{CF}_{3}, \mathrm{NO}_{2}$, etc. on the aryl system of aromatic aldehydes was found to be competent for this amidation reaction. Thiophene-2-carbaldehyde provided $76 \%$ yield of the product, whereas in case of aliphatic aldehydes, inferior yields (53\%$64 \%)$ were obtained. Similarly, various $N$-chloramine derivatives such as $\mathrm{N}$-chloro-1-phenylmethanamine, $\mathrm{N}$ chloro- $N$-methyl-1-phenylmethanamine, $N$-benzyl- $N$-chloro1-phenylmethanamine etc. also reacted smoothly and enabled good product yields. To get insight into the reaction mechanism, control experiments were performed under neat conditions (Scheme 66B). Based on the results of these experiments, a plausible reaction mechanism was proposed as shown in scheme $66 \mathrm{C}$.
In 2017, Cijil Raju and co-workers reported a Cu-catalyzed double $\mathrm{C}-\mathrm{H} / \mathrm{N}-\mathrm{H}$ activation protocol between sulfonimidamides and aldehydes affording a diversity of $\mathrm{N}$ acyl sulfonimidamides in low to moderate yields (Scheme 67). ${ }^{100}$ In this typical procedure, a mixture of sulfonimidamides (4.0 equiv.), aldehydes (1.0 equiv.) in the presence of $\mathrm{CuBr}(5 \mathrm{~mol} \%)$ as catalyst and TBHP $(2.0$ equivalent) as oxidant in acetonitrile was stirred at $82{ }^{\circ} \mathrm{C}$ for 2 h. Employing these optimal conditions, 26 different $N$-acyl sulfonimidamides were prepared in $18-56 \%$ yields, starting from aromatic, heterocyclic and aliphatic aldehydes and various sulfonimidamides. Various benzaldehydes with electron-donating and electron-withdrawing substituents in different positions display identical ease towards the $\mathrm{N}$ acylation of sulfonimidamides. Both mono- and di-substituted aromatic aldehydes worked well under these developed reaction conditions. Interestingly, the presence of the bulky ${ }^{t} \mathrm{Bu}$ group at the C-3 and C-5 position of the aryl aldehyde does not inhibit the product formation and $47 \%$ yield was obtained. The scope of the reaction was not limited only to aryl aldehydes as hetero-aromatic and aliphatic aldehydes were also found feasible for this transformation. The modifications in the aryl system of the sulfonimidamide moiety were well tolerated and replacement of the piperidine part with morpholine and pyrrolidine was also found to be compatible and yielded the corresponding products smoothly. 


\section{ARTICLE}

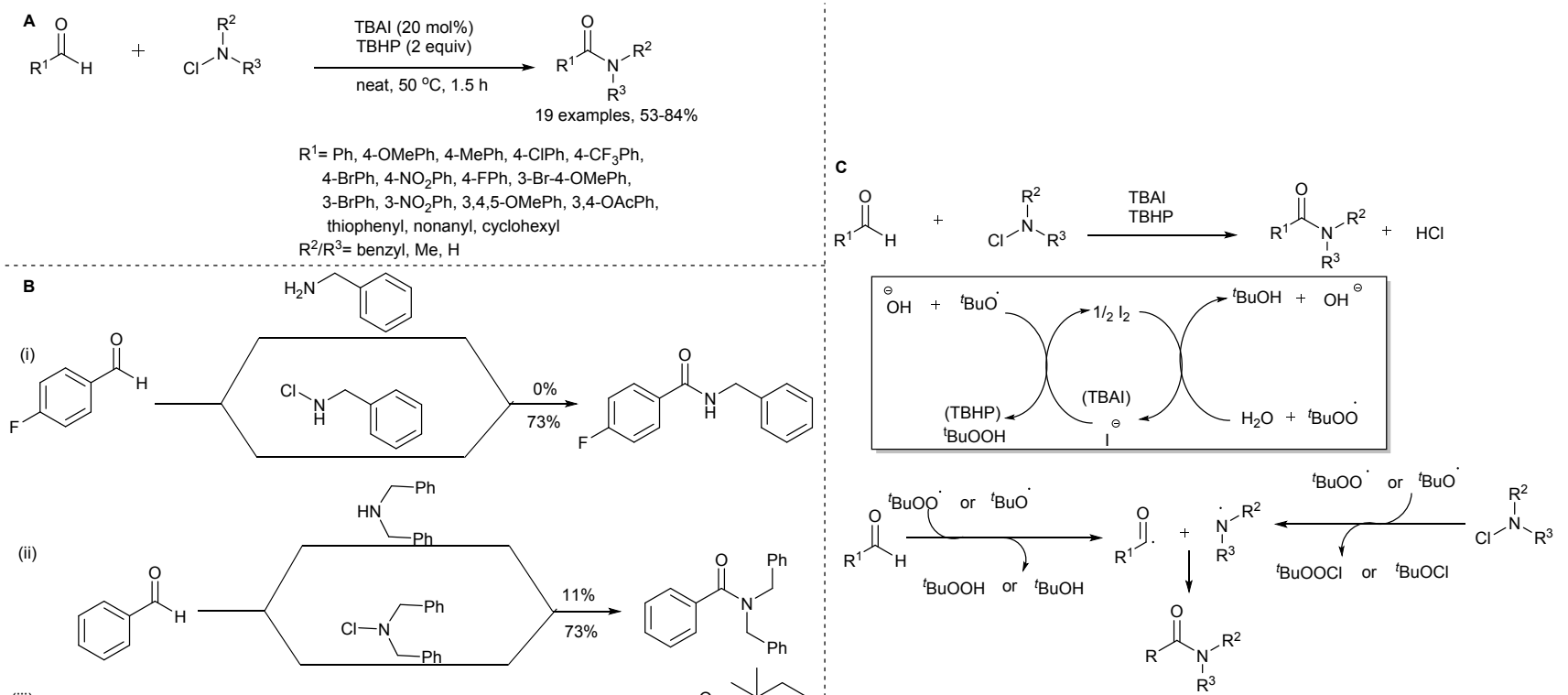

(iii)

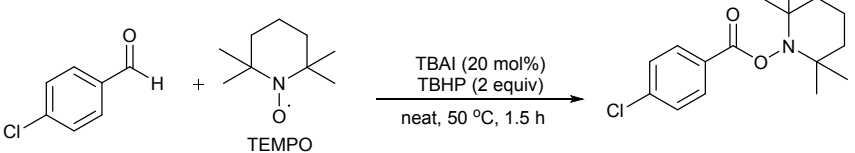

Scheme 66: (A) Metal-free oxidative cross-coupling for the amidation of aldehydes using N-chloramines; (B) control experiments; (C) plausible reaction mechanism.

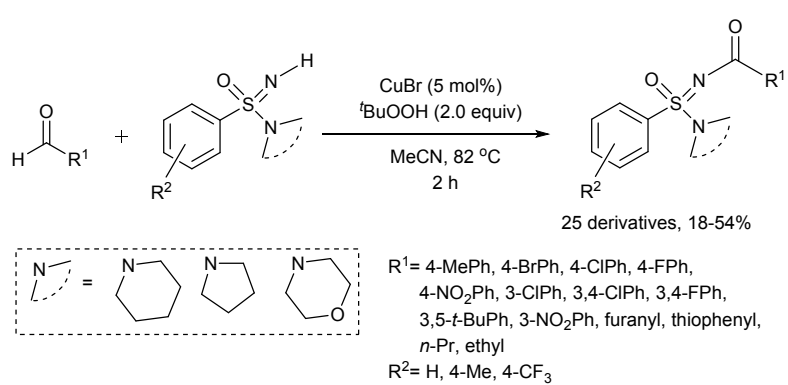

Scheme 67: Cu-catalyzed double $\mathrm{C}-\mathrm{H} / \mathrm{N}-\mathrm{H}$ activation between sulfonimidamides and aldehydes for the synthesis of $\mathrm{N}$-acyl sulfonimidamides.

Later in 2017, Zheng and Ma published a direct oxidative $N$ acylation reaction of primary amines with aryl/ $\alpha, \beta$-unsaturated aldehydes in the presence of the azolium salt of an $\mathrm{N}$-heterocyclic carbene and base such as ${ }^{t} \mathrm{BuOK}$ or $\mathrm{NaH}$ using 3,3',5,5'-tetra-tert-butyldiphenoquinone (DPQ) as oxidant at $25{ }^{\circ} \mathrm{C}$ (Scheme 68). ${ }^{101}$ This methodology provided a proficient approach for the synthesis of $N$ sulfonylcarboxamides, $\quad N$-sulfinylcarboxamides and dicarboxyimides in good yields. The reactions were carried out by reacting a mixture of the corresponding amine $(0.4 \mathrm{mmol})$ and aldehyde $(0.6 \mathrm{mmol})$ in the presence of NHC (10 mol\%) catalyst, $t$-BuOK $(0.8 \mathrm{mmol}) / \mathrm{NaH}(1.2 \mathrm{mmol})$ base in THF as solvent under $\mathrm{N}_{2}$ atmosphere at $25^{\circ} \mathrm{C}$ followed by quenching using $1 \mathrm{M} \mathrm{HCl}$ aqueous solution. The scope of the primary amines with aldehydes was investigated by synthesizing $24 \mathrm{~N}$ acylated derivatives of amines in high yields. Aryl aldehydes bearing substituents such as $\mathrm{F}, \mathrm{Cl}, \mathrm{OMe}$ and $\mathrm{NO}_{2}$ at different positions (ortho-, meta- and para-) of the aryl ring participated in the reaction with tosylamide to give the respective $N$ tosylcarboxamindes in high yields. Interestingly, thiophene-2carbaldehyde and 2-naphthaldehyde provided the respective imides in $87 \%$ and $91 \%$ yields with these newly developed conditions. Moreover, $\alpha, \beta$-unsaturated aldehydes including enals and ynals were well suited for this direct $N$-acylation protocol of tosylamide and conjugated ynals having aliphatic or aromatic substituents exhibited a wide scope resulting in $71-87 \%$ yields of the products. Unfortunately, alkylated aldehydes were found inactive under the current reaction conditions and could not afford the imide products probable due to competing enolization of the aldehyde substrate.

To expand the synthetic utility of this methodology, other amide substrates were examined. Electron-rich 
(unsubstituted) as well as electron-poor $\left(p-\mathrm{NO}_{2}\right.$ and $p-\mathrm{Cl}$ substituted) aryl sulfonamides upon reaction with 4chlorobenzaldehyde delivered the corresponding products in 93-96\% yields. Besides, methanesulfonamide was also witnessed as a competent reaction partner given that $92 \%$ yield of the product was obtained. Additionally, benzamide and its $p$-chloro and $p$-nitro derivatives could also be employed for the formation of dicarboxyamides using a stronger base $\mathrm{NaH}$ (3.0 equiv.) instead of ${ }^{t} \mathrm{BuOK}$, due to the inferior acidity of carboxamides compared with sulfonamides. (S)-tert-butylsulfinamide ( $99 \%$ ee) suited efficiently in this protocol and yielded the (S)-tert-butylsulfinamide-4chlorobenzamide in $81 \%$ yield with almost complete retention (98\% ee) of configuration (Scheme 68A).

A
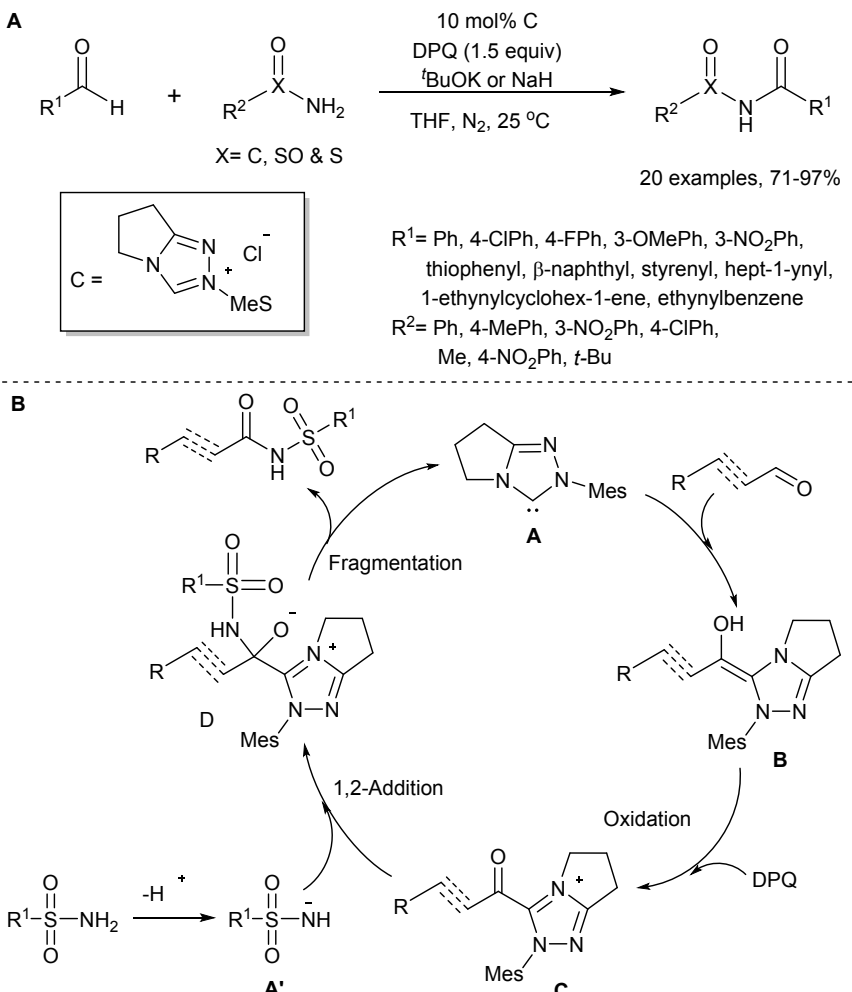

Scheme 68: (A) $N$-acylation reaction of primary amines with aryl $/ \alpha, \beta$ unsaturated aldehydes using azolium salt of an $N$-heterocyclic carbene; (B) plausible reaction mechanism.

The postulated catalytic cycle for this transformation is presented in scheme 68B. The pathway initially involved the formation of Breslow intermediate $\mathbf{B}$ through nucleophilic addition of in situ generated carbene $\mathbf{A}$ to aldehyde. The intermediate $\mathbf{B}$ oxidized to form acylazolium species $\mathbf{C}$ upon treatment with $D P Q$. Then attack of the deprotonated amide compound A' probably via 1,2-adduct D, on azolium intermediate $\mathbf{C}$, followed by a fragmentation sequence gave the final compound along with the carbene catalyst $\mathbf{A}$.
In the meantime, $\mathrm{Hu}$ and co-workers developed $\mathrm{an}_{\mathrm{A}}$ effficient

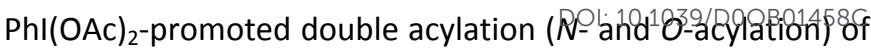
hydroxylamines with aldehydes at room temperature in acetic acid for the synthesis of $\mathrm{N}$-acetoxy- $\mathrm{N}$-arylamides in good to excellent yields. ${ }^{102}$ The acylation of $\mathrm{N}$-atoms in hydroxylamines are due to the acyl group of aldehydes whereas the $O$-atoms get acylated by the acetyl group of $\mathrm{Phl}(\mathrm{OAc})_{2}$. This transformation exhibited great substrate scope under the optimized reaction conditions. Initially, the effect of aromatic aldehydes was explored with $N$ phenylhydroxylamine and all the selected aryl aldehydes could give the desired products regardless of the nature (electron-releasing or electron-donating) of the substituents present on the aromatic ring. However, in some cases, the positions of the substituents on the aryl ring of the benzaldehydes were found to influence the reaction yield. For example, $m$-nitrobenzaldehyde delivered $85 \%$ yield whereas $p$-nitrobenzaldehyde resulted in $73 \%$ yield but unfortunately no product formation took place with o-nitrobenzaldehyde. The 2-furaldehyde and pyridine-2-carboxaldehdye offered their respective products in good yields; on the other hand, no product formation was observed with aliphatic aldehydes (Scheme 69).

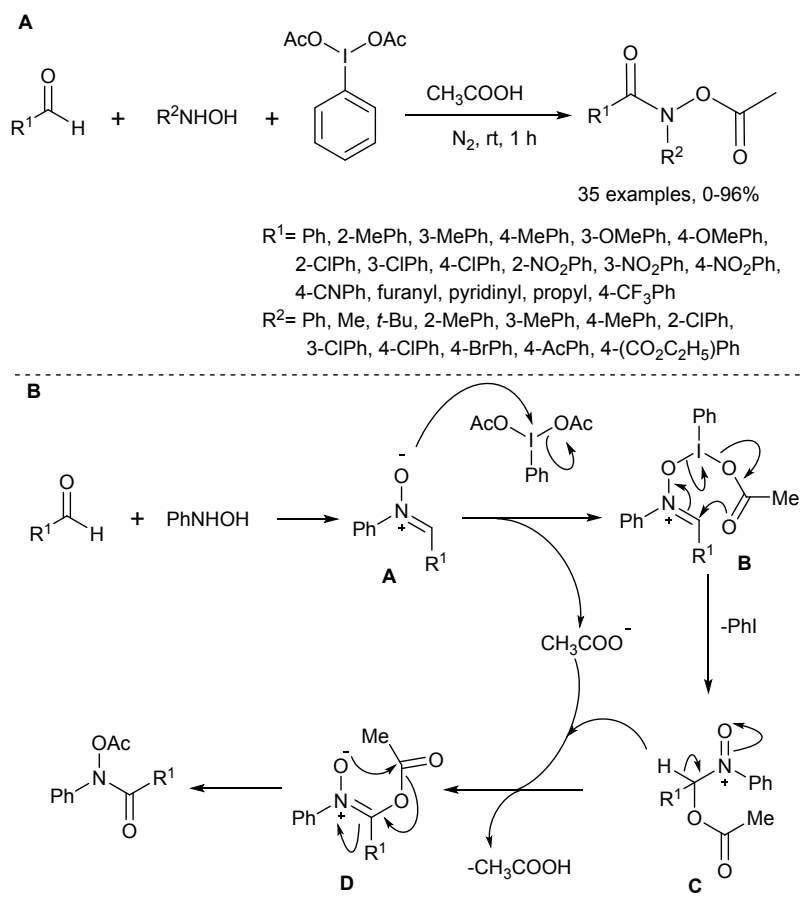

Scheme 69: (A) Phl(OAc)2-promoted double acylation ( $\mathrm{N}$ - and $\mathrm{O}$-acylation) of hydroxylamines with aldehydes; (B) plausible reaction mechanism.

Similarly, the applicability of various $\mathrm{N}$-aromatic hydroxylamines bearing an electron-rich methyl group or electron-poor chloro, bromo, acetyl or ester group reacted with benzaldehyde, and the corresponding products were obtained in $45-75 \%$ yields. However, no product could be 
obtained with aliphatic hydroxylamines such as $\mathrm{N}$ methylhydroxylamine and $N$-(t-butyl) hydroxylamine. The compatibility of the simultaneous in present substituents on aromatic aldehydes and aromatic hydroxylamine was also exploited. The aromatic aldehydes delivered a higher product yield when electron-withdrawing groups were present as substituents, compared to aromatic aldehydes having electron-withdrawing groups. On the other hand, aromatic hydroxylamines with electron-donating groups on their phenyl rings resulted in higher product yields than those with electron-withdrawing groups with the same aldehydes (Scheme 69A). A plausible mechanism for this reaction is shown in scheme 69B. At the beginning, the aldehyde reacted with hydroxylamine to form a nitrone intermediate $\mathbf{A}$. Then a ligand exchange process took place between nitrone $\mathbf{A}$ and $\mathrm{Phl}(\mathrm{OAc})_{2}$ to produce intermediate $\mathbf{B}$, which on intramolecular rearrangement produced another intermediate $\mathbf{C}$. The deprotonation of intermediate $\mathbf{C}$ by an acetate resulted in intermediate $\mathbf{D}$, which on subsequent migration of the acyl group and isomerization gave the final product.

In 2018, our lab disclosed a radical-induced Pd-catalysed approach for the direct functionalization of 2-phenyl-4Hbenzo[d][1,3]oxazin-4-ones with aldehydes. ${ }^{103}$ The reaction proceeded through the formation of the 0 -acylated 2-phenyl$4 H$-benzo[ $d][1,3]$ oxazin-4-one intermediate to give 6 phenyl-5H-benzo[4,5][1,3]oxazino[2,3-a]isoindole-5,11(6aH)diones in the presence of the TBHP oxidant. Various aryl aldehydes with electron-releasing groups ( $\mathrm{Me}, \mathrm{OMe}$ ) and electron-withdrawing groups $(\mathrm{F}, \mathrm{Cl}, \mathrm{Br}$, etc.) reacted smoothly with 2-phenyl-4H-benzo[ $d][1,3]$ oxazin-4-one in the presence of $\mathrm{Pd}(\mathrm{OAc})_{2}$ (5 mol\%) as catalyst using TBHP ( $5 \mathrm{mmol}$ ) oxidant in 1,4-dioxane as solvent at $120{ }^{\circ} \mathrm{C}$ for $18 \mathrm{~h}$ to afford 19 derivatives in $21-79 \%$ yields (Scheme 70A). Aliphatic aldehydes such as cyclohexanecarboxaldehyde and isobutyraldehyde delivered the corresponding products in $48 \%$ and $33 \%$ yields, respectively. A plausible reaction mechanism was proposed based on control experiments and previous literature reports (Scheme 70B). Initially, 2-phenyl$4 H$-benzo[ $d][1,3]$ oxazin-4-one underwent the orthopalladation reaction with $\mathrm{Pd}(\mathrm{OAc})_{2}$ to form complex $\mathrm{A}$ and byproduct $\mathrm{AcOH}$. At the same time, an acyl radical is formed from the aldehyde by action of TBHP. A subsequent reaction between complex $\mathbf{A}$ and acyl radical promoted the formation of complex $\mathbf{B}$, which goes through a reductive elimination process to give $\boldsymbol{o}$-acylated intermediate $\mathbf{C}$. In the next step, the $o$-acylated intermediate underwent an aryl ring migration in the presence of TBHP and gave intermediate $\mathbf{D}$ followed by biradical intermediate E. Biradical E undertook C-N bond

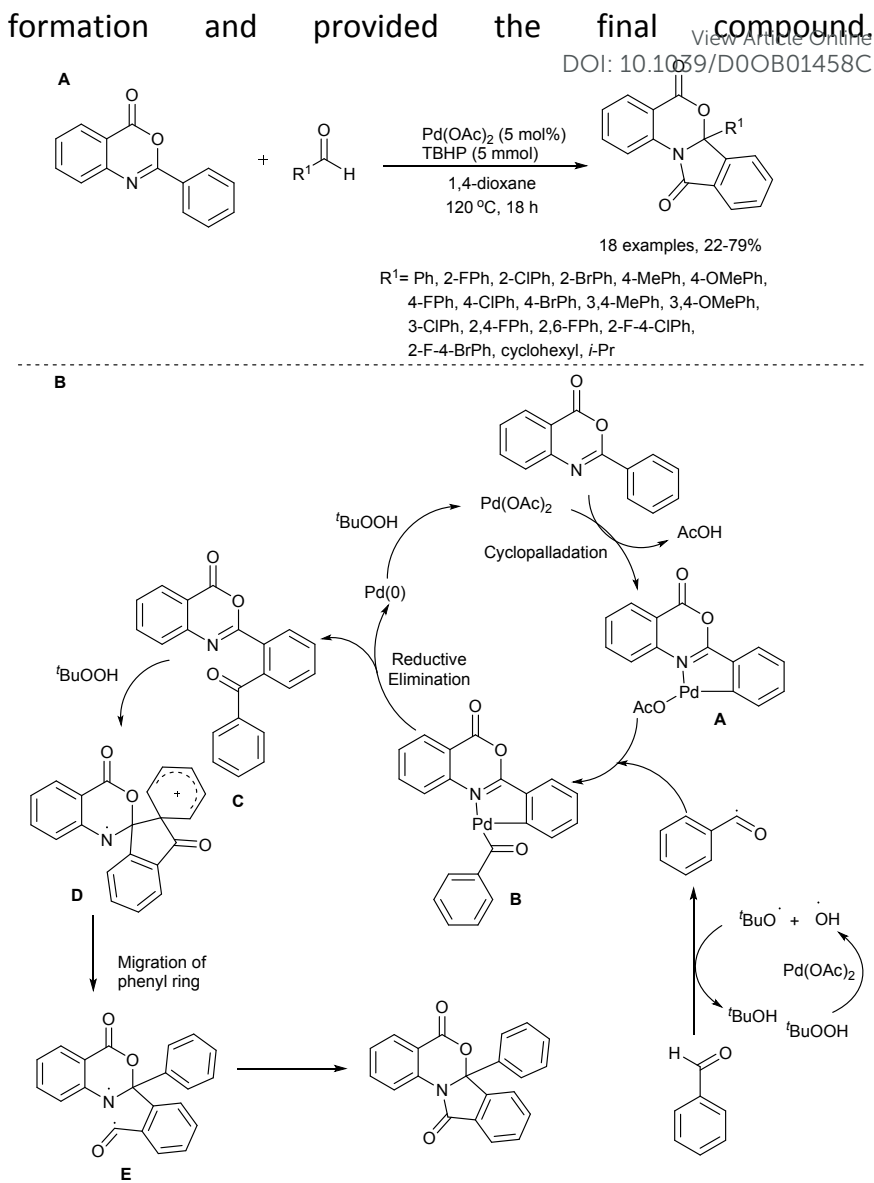

Scheme 70: (A) Pd-catalyzed direct functionalization of 2-phenyl-4H-benzo[d][1,3] oxazin-4-ones with aldehydes; (B) plausible reaction mechanism.

Segundo and Correa in 2019 reported Pd-catalyzed oxidative coupling between phenylalanine based peptides with aldehydes for site-selective $\mathrm{C}\left(\mathrm{sp}^{2}\right)-\mathrm{H}$ acylation using $\mathrm{DCP}$ (dicumyl peroxide) as oxidizing agent and $\mathrm{Ag}_{2} \mathrm{CO}_{3}$ as additive.$^{104}$ With the optimized reaction conditions the scope of $\mathrm{C}\left(\mathrm{sp}^{2}\right)-\mathrm{H}$ acylation of phenylalanine derivatives was investigated by coupling with a wide variety of aldehydes and the desired products could be obtained in moderate to excellent yields (Scheme 71A). Aryl aldehydes having electron-releasing ( $\mathrm{Me}, \mathrm{OMe}, \mathrm{Et}_{2} \mathrm{~N}, 2$,3-dihydrofuryl) groups resulted the mixture of mono- and di-acylated compounds, which could be easily separated. 2,4,6trimethoxybenzaldehdye delivered only di-acylated compound in $67 \%$ yield. Similarly, $p$-hydroxybenzaldehyde, 2chlorobenzaldehyde and $\beta$-naphthaldehyde delivered the mono-acylated products in 63\%, $45 \%$ and $54 \%$ yield, respectively. Heterocyclic and aliphatic aldehydes were also smoothly reacted to give the corresponding products in good yield. Moreover, substituted phenylalanine derivatives also afforded the monoacylated compounds in moderate to good yields. To expand the generality of the protocol the scope of phenylalanine based $\mathrm{di}$, tri and penta-peptides was also 


\section{Organic and Biomolecular Chemistry}

explored with optimized reaction conditions and targeted products was obtained in good to excellent yield irrespective of the effect of nature of side chains present in peptide chain reports authors have proposed a mechanism for this transformation (Scheme 71C).
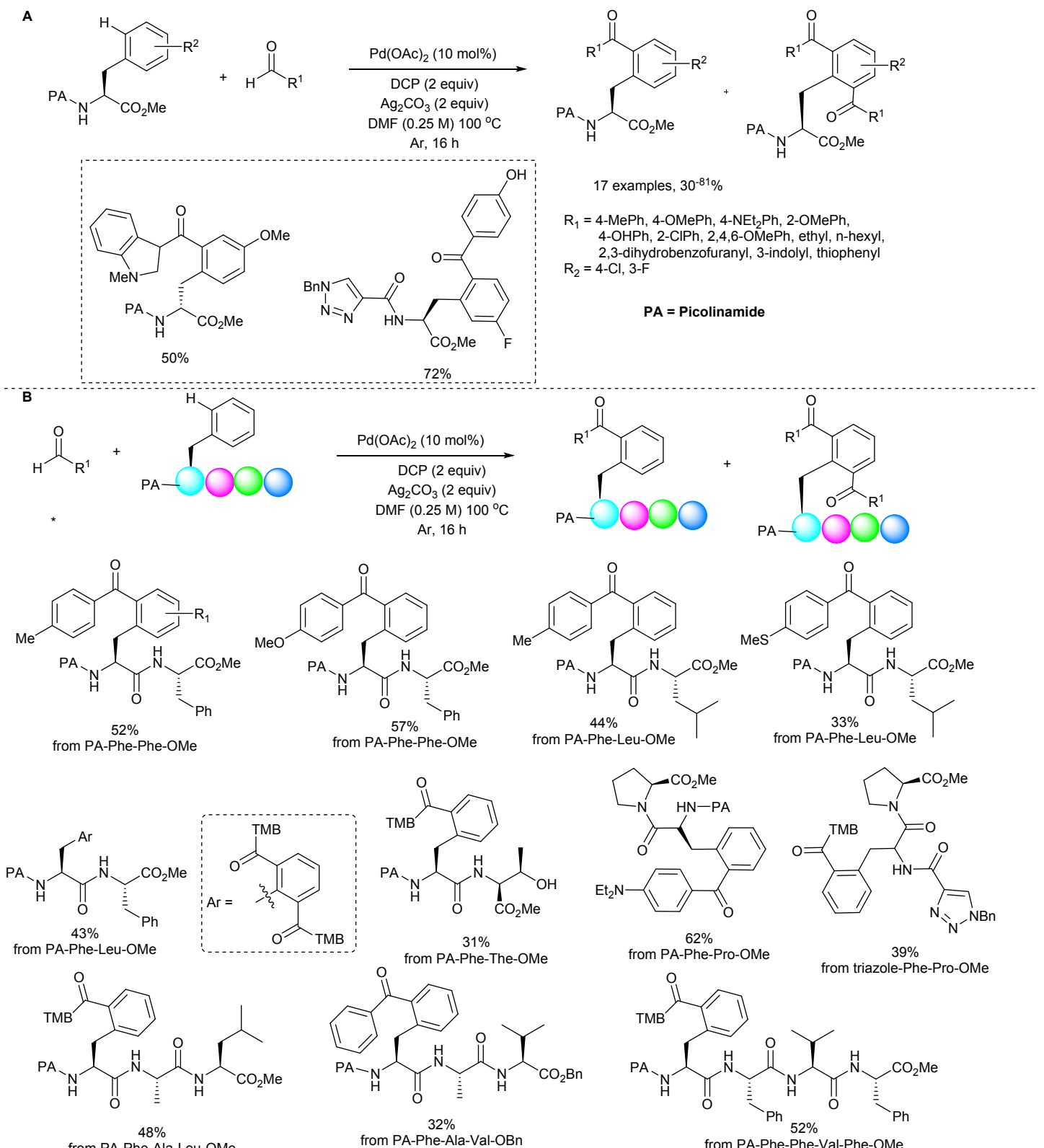

from PA-Phe-Ala-Leu-OMe

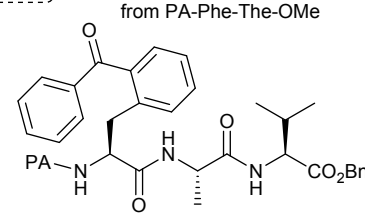

from PA-Phe-Ala-Val-OBn

from PA-Phe-Phe-Val-Phe-OMe

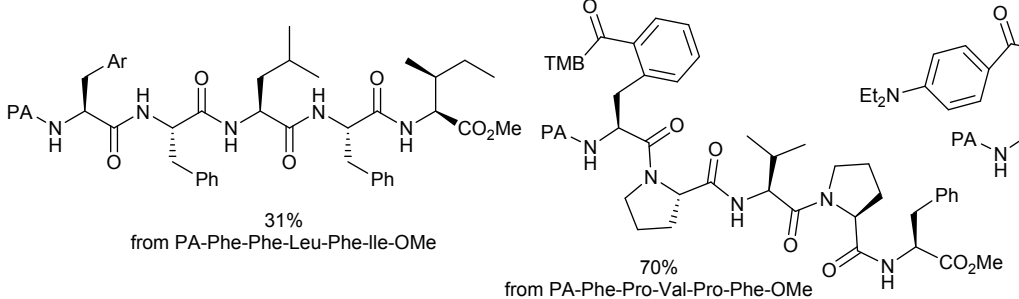

from PA-Phe-Pro-Val-Pro-Phe-OM $\mathrm{O}_{\mathrm{H}}^{\mathrm{Ph}} \mathrm{CO}_{2 \mathrm{Me}}$

from PA-Phe-Pro-Val-Pro-Phe-OMe

Scheme 71: Pd-catalyzed oxidative coupling between phenylalanine based peptides with aldehydes for site-selective $\mathrm{C}\left(\mathrm{sp}^{2}\right)-\mathrm{H}$ acylation. 


\section{ARTICLE}

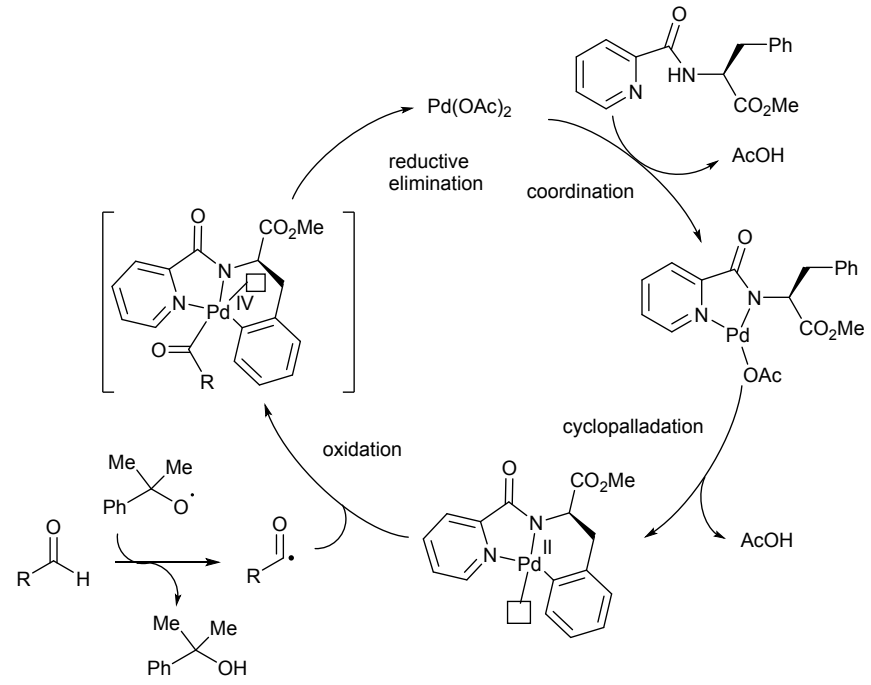

Scheme 71(C): Plausible reaction mechanism for Pd-catalyzed oxidative coupling between phenylalanine based peptides with aldehydes.

\section{Conclusions and Future Perspectives}

Over the past decades, aldehydes have emerged as excellent acylation surrogates for the direct forging of acylated compounds containing keto motifs. Consequently, there has been a profitable interplay of acylation and $\mathrm{C}-\mathrm{H}$ activation for gaining a ready access to these bioactive molecules with enhanced selectivity and improved atom economy under ambient reaction conditions. Also, considerable attention has been devoted by researchers to the exploration of the mechanisms behind these fascinating transformations, opening new horizons for further research in this area. There have been massive breakthroughs with more than 100 research articles published in high impact factor journals involving the selective acylation of arenes, heteroarenes and alkyls ( $\mathrm{sp}^{3}, \mathrm{sp}^{2}$ and $\mathrm{sp}$ ) $\mathrm{C}-\mathrm{H}$ bonds. Interestingly, this strategy is witnessing expanded applications in the fields of photocatalysis as well as flow chemistry. The pivotal findings from various studies clearly delineate prospects of large-scale industrial synthesis for obtaining diverse heterocyclic compounds.

Although tremendous accomplishments in this field have been achieved to change the landscape of organic synthesis, yet a lot of work remains to be accomplished. Particularly, future directions in this research area should focus on the post-functionalization of drug molecules and natural products and transient directing group mediated acylations. Research in the fields of visible light mediated synthesis and continuous flow synthesis are still in their infancy. There is a room for further improvements via the use of alternative energy sources like ultrasound and microwaves that have also played a crucial role in achieving the green chemistry objectives in organic synthesis via enhancing the efficiency and rapidity of organic reactions.

Nevertheless, we anticipate that in the upcoming years, the limitations and scope of these protocols shall be duly addressed, fuelling more interest in this area. This review has been an attempt to propagate the key findings on the use of less toxic and stable aldehyde motifs for the construction of a plethora of keto compounds; few examples discussed herein are quite motivating from the viewpoint of armouring the organic chemists with sustainable synthetic methodologies which is the pre-requisite of the hour.

\section{Conflicts of interest}

There are no conflicts to declare.

\section{Acknowledgements}

The authors gratefully acknowledge their respective universities/research organizations in particular, SRM University, Sonepat; Department of Chemistry, University of Delhi and Peoples' Friendship University of Russia (RUDN University) Miklukho-Maklaya, Moscow, Russia for extending all possible support for furtherance of research.

\section{Notes and references}

1. M. D. Barratt, J. V. Castell, M. A. Miranda and J. J. Langowski, J. Photoch. Photbio. B, 2000, 58, 54-61.

2. E. A. Smith, J. G. Marshall, S. S. Selph, D. R Barker and C. M. Sedgley, J. Endod., 2017, 43, 7-15.

3. V. Agarwal, M. Bajpai and A. Sharma, Recent Pat. Drug Deliv. Formul., 2018, 12, 40-52.

4. J. Zheng, Drug Metab. Pharmacokinet., 2018, 33, S70.

5. S. C. Zimmermann, T. Tichý, J. Vávra, R. P. Dash, C. E. Slusher, A. J. Gadiano, Y. Wu, A. Jančařík, L. Tenora, L. Monincová, E. Prchalová, G. J. Riggins, P. Majer, B. S. Slusher and R. Rais, J. Med. Chem., 2018, 61, 39183929. 
6. H. Firouzabadi, N. Iranpoor and F. Nowrouzi, Tetrahedron, 2004, 60, 10843-10850.

7. P. H. Tran, H. Q. Phung, P. E. Hansen, H. N. Tran and T. N. Le, Synth. Commun., 2016, 46, 893-901.

8. K. J. Liu, S. Jiang, L. H. Lu, L. L. Tang, S. S. Tang, H. S. Tang, Z. Tang, W. M. He and X. Xu, Green Chem., 2018, 20, 3038-3043.

9. X. Ye, M. D. Johnson, T. Diao, M. H. Yates and S. S. Stahl, Green Chem., 2010, 12, 1180-1186.

10. (a) J. A. Haugan, Acta Chem. Scand., 1997, 51, 10961103; (b) E. J. Corey and J. Suggs, Tetrahedron Lett., 1975, 16, 2647-2650; (c) G. Molle and P. Bauer, J. Am. Chem. Soc., 1982, 104, 3481-3487; (d) D. A. Otte and K. Woerpel, Org. Lett., 2015, 17, 3906-3909; (e) K. Conrad, Y. Hsiao and R. Miller, Tetrahedron Lett., 2005, 46, 8587-8589; (f) C. G. Swain, J. Am. Chem. Soc., 1947, 69, 2306-2309.

11. F. Penteado, E. F. Lopes, D. Alves, G. Perin, R. G. Jacob and E. J. Lenardão, Chem. Rev., 2019, 119, 71137278.

12. X. F. Wu, Chem. Eur. J., 2015, 21, 12252-12265.

13. M. Gupta, P. Kumar, V. Bahadur, K. Kumar, V. S. Parmar and B. K. Singh, Eur. J. Org. Chem., 2018, 896900.

14. P. Kumar, M. Gupta, V. Bahadur, V. S. Parmar and B. K. Singh, Eur. J. Org. Chem., 2018, 1552-1558

15. H. Surburg and J. Panten, 5th edition, Wiley-VCH Verlag, Weinheim, 2006.

16. M. Kochi, S. Takeuchi, T. Mizutano, K. Molhizukl, Y. Matsumoto and Y. Saito, Cancer Treat. Rep., 1980, 64, 21-23.

17. S. Takeuchi, M. Kochi, K. Sakaguchi, K. Nakagawa and T. Mizutani, Agric. Biol Chem., 1978, 42, 14491451.

18. E. O. Pettersen, OleNome, $\varnothing$. W. Rønning and R. Oftebro., Eur. Cancer Chn. Oncol., 1983, 19, 507-514

19. P. J. O'Brien, A. G. Siraki and N. Shangari, Crit. Rev. Toxicol., 2005, 35, 609-662.

20. S. Pizzimenti, E. Ciamporcero, M. Daga, P. Pettazzoni, A. Arcaro, G. Cetrangolo, R. Minelli, C. Dianzani, A. Lepore, F. Gentile and G. Barrera, Front. Physiol., 2013, 4, 242.

21. L. N. Ferguson, Chem. Rev., 1946, 38, 227-254.

22. L. Gattermann and J. A. Koch, Ber. Dtsch. Chem. Ges., 1897, 30, 1622-1624.

23. G. Ludwig, Justus Liebigs Annalen der Chemie, 1906, 347, 347-386.
24. B. Rosche, V. Sandford, M. Breuer, B. Hauer and Pe Rogers, Appl. Microbiol. BiotechridP.,12001,0930,130\%315

25. P. Siegert, M. J. McLeish, M. Baumann, H. Iding, M. M. Kneen, G. L. Kenyon and M. Pohl, Protein Eng. Des. Sel., 2005, 18, 345-357.

26. M. R. Luderer, W. F. Bailey, M. R. Luderer, J. D. Fair, R. J. Dancer, and M. B. Sommer, Tetrahedron Asymmetry, 2009, 20, 981-998.

27. P. Kumar, A. Matta, S. Singh, J. V. Eycken, C. Len, V. S. Parmar, E. V. V. Eycken and B. K. Singh, Synth. Commun., 2017, 47, 756-763.

28. P. Kumar, A. K. Singh, V. Bahadur, C. Len, N. G. J. Richards, V. S. Parmar, E. V. V. Eycken and B. K. Singh, ACS Sustainable Chem. Eng., 2016, 4, 2206-2210.

29. J. T. Bhanushali, I. Kainthla, R. S. Keri and B. M. Nagaraja., ChemistrySelect, 2016, 1, 3839-3853.

30. C. Palomo, M. Oiarbide and J. M. García., Chem. Soc. Rev. 2004, 33, 65-75.

31. M. A. Garralda, Dalton Trans., 2009, 3635-3645.

32. S. Sharma, N. K. Mishra, Y. Shin and K. Su, Curr. Org. Chem., 2016, 20, 471-511.

33. X. F. Wu., Chem. Eur. J., 2015, 21, 12252-12265.

34. Z. Chen, B. Wang, J. Zhang, W. Yu, Z. Liu and Y. Zhang, Org. Chem. Front., 2015, 2, 1107-1295.

35. X. Jia, S. Zhang, W. Wang, F. Luo and J. Cheng., J. Org. Lett., 2009, 11, 3120-3123.

36. S. Sharma, E. Park, J. Park and In Su Kim., Org. Lett., 2012, 14, 906-909.

37. N. Zhang, Q. Yu, R. Chen, J. Huang, Y. Xia and K. Zhao., Chem. Commun., 2013, 49, 9464-9466.

38. A. Banerjee, S. K. Santra, S. Guin, S. K. Rout and B. K. Patel, Eur. J. Org. Chem., 2013, 7, 1367-1376.

39. Q. Zhang, C. Li, F. Yang, J. Li and Y. Wu., Tetrahedron, 2013, 69, 320-326.

40. S. Sharma, A. Kim, J. Park, M. Kim, J. H. Kwak, Y. H. Jung, J. S. Park and I. S. Kim., Org. Biomol. Chem., 2013, 11, 7869-7876.

41. H. Li, P. Li and L. Wang, Org. Lett., 2013, 15, 620-623.

42. S. Sharma, J. Park, E. Park, A. Kim, M. Kim, J. H. Kwak, Y. H. Jung and I. S. Kima, Adv. Synth. Catal., 2013, 355, 332-336.

43. F. Szab, J. Daru, D. Simk, T. Z. Nagy, A. Stirling and Z. Novka, Adv. Synth. Catal., 2013, 355, 685-691.

44. Z. Wang, Q. Tian, X. Yu and C. Kuang, Adv. Synth. Catal., 2014, 356, 961-966.

45. Q. Tian, P. He and C. Kuang, Org. Biomol. Chem., 2014, 12, 7474-7477. 
46. M. Sun, L. K. Hou, X. X. Chen, X. J. Yang, W. Sun and Y. S. Zang, Adv. Synth. Catal., 2014, 356, 3789-3793.

47. A. Banerjee, A. Bera, S. K. Santra, S. Guin and B. K. Patel, RSC Adv., 2014, 4, 8558-8566.

48. S. K. Santra, A. Banerjee and B. K. Patel, Tetrahedron, 2014, 70, 2422-2430.

49. M. Yi, X. Cui, C. Zhu, C. Pi, W. Zhu and Y. Wu, Asian J. Org. Chem., 2015, 4, 38-41.

50. F. Xiao, S. Chen, H. Huang and G.-J. Deng, Eur. J. Org. Chem., 2015, 7919-7925.

51. H. Lee and C. S. Yi, Eur. J. Org. Chem. 2015, 18991904.

52. J. H. Chu, S. T. Chen, M. F. Chiang and M. J. Wu., Organometallics, 2015, 34, 953-966.

53. S. Tripathi, S. N. Singh and L. D. S. Yadav, Tetrahedron Lett., 2015, 56, 4211-4214.

54. Y.-F. Liang, X. Wang, C. Tang, T. Shen, J. Liu and Ning Jiao, Chem. Commun., 2016, 52, 1416-1419.

55. F. Zhao, Z. Chen, Y. Liu, K. Xie and Y. Jiang, Eur. J. Org. Chem., 2016, 5971-5979.

56. B. Suchand and G. Satyanarayana, J. Org. Chem., 2016, 81, 6409-6423.

57. X. Zhang and D. W. C. MacMillan, J. Am. Chem. Soc. 2017, 139, 11353-11356.

58. J. K. Vandavasi, X. Y. Hua, H. B. Halima and S. G. Newman, Angew. Chem. Int. Ed., 2017, 56, 1544115445.

59. J.-H. Chu, M.-F. Chiang, C.-W. Li, Z.-H. Su, S.-C. Lo and M.-J. Wu, Organometallics, 2019, 38, 2105-2119.

60. S. Ojha and N. Panda, Adv. Synth. Catal., 2020, 362, 561-571.

61. T. E. Schirmer, A. Wimmer, F. W. C. Weinzierl and B. König, Chem. Commun., 2019, 55, 10796-10799.

62. D. A. DiRocco and T. Rovis, J. Am. Chem. Soc., 2012, 134, 19, 8094-8097.

63. S. Campagna, F. Puntoriero, F. Nastasi, G. Bergamini and V. Balzani, Top. Curr. Chem., 2007, 280, 117-214.

64. O. Obulesu, K. H. Babu, J. B. Nanubolu and S. Suresh, J. Org. Chem., 2017, 82, 2926-2934.

65. C. Che, Z. Qian, M. Wu, Y. Zhao and G. Zhu, J. Org. Chem., 2018, 83, 5665-5673.

66. J. Wang, C. Liu, J. Yuan and A. Lei., Angew. Chem. Int. Ed., 2013, 52, 2256-2259.

67. M. D. Vu, M. Das and X.-W. Liu, Chem. Eur., J. 2017, 23, 15899-15902.

68. G. N. Papadopoulos, E. Voutyritsa, N. Kaplaneris and C. G. Kokotos, Chem. Eur. J., 2018, 24, 1726-1731.

69. S. Tripathi, R. Kapoor and L. D. S. Yadav, Adv. Synth. Catal., 2018, 360, 1407-1413.
70. G. F. P. de Souza, J. A. Bonacin and A. G S S Iride Qrige Chem., 2018, 83, 8331-8340. DOI: 10.1039/D0OB01458C

71. L. Lv, S. Lu, Q. Guo, B. Shen and Z. Li, J. Org. Chem., 2015, 80, 698-704.

72. L. Ge, Y. Li and H. Bao, Org. Lett., 2019, 21, 256-260.

73. X. H. Ouyang, R. J. Song, Y. Li, B. Liu and J. H. Li, J. Org. Chem., 2014, 79, 4582-4589.

74. X. Mi, C. Wang, M. Huang, Y. Wu and Y. Wu, J. Org. Chem., 2015, 80, 148-155.

75. B. Zhou, Y. Yang and Y. Li, Chem. Commun., 2012, 48, 5163-5165.

76. X. B. Yan, Y. W. Shen, D. Q. Chen, P. Gao, Y. X. Li, X. R. Song, X. Y. Liu and Y. M. Liang, Tetrahedron, 2014, 70, 7490-7495.

77. A. B. Khemnar, B. M. Bhanag, Synlett, 2014, 25, 110114.

78. G. Kumar and G. Sekar, RSC Adv., 2015, 5, 2829228298.

79. U. K. Sharma, H. P. L. Gemoets, F. Schrö der, T. Noel and E. V. V. Eycken, ACS Catal., 2017, 7, 3818-3823.

80. K. Matcha and A. P. Antonchick, Angew. Chem., 2013, 125, 2136-2140.

81. Y. Siddaraju, M. Lamani and K. R. Prabhu, J. Org. Chem., 2014, 79, 3856-3865.

82. (a) K. M. Dawood, H. A. Gawad, E. A. Rageb, M. Ellithey and H. A. Mohamed, Bioorg. Med. Chem., 2006, 14, 3672-3680; (b) S. M. Rida, S. A. M. ElHawash, H. T. Y. Fahmy, A. A. Hazzaa and M. M. M. El-Meligy, Arch. Pharmacal Res., 2006, 29, 826-833; (c) C. Kirilmis, M. Ahmedzade, S. Servi, M. Koca, A. Kizirgil and C. Kazaz, Eur. J. Med. Chem., 2008, 43, 300-308; (d) H. A. Abdel-Aziz and A. A. I. Mekawey., Bioorg. Med. Chem. Lett., 2009, 19, 4985-4997; (e) K. Manna and Y. K. Agrawal., Eur. J. Med. Chem., 2009, 44, 2688-2692; (f) H. F. Guo, H. Y. Shao, Z. Y. Yang, S. T. Xue, X. Li, Z. Y. Liu, X. B. He, J. D. Jiang, Y. G. Zhang, S. Y. Si and Z. R. Li, J. Med. Chem., 2010, 53, 18191829.

83. (a) X. Jiang, W. Liu, W. Zhang, F. Jiang, Z. Gao, H. Zhuang and Lei Fu., Eur. J. Med. Chem., 2011, 46, 3526-3530; (b) B. L. Flynn, G. S. Gill, D. W. Grobelny, J. H. Chaplin, D. Paul, A. F. Leske, T. C. Lavranos, D. K. Chalmers, S. A. Charman, E. Kostewicz, D. M. Shackleford, J. Morizzi, E. Hamel, M. K. Jung and G. Kremmidiotis., J. Med. Chem. 2011, 54, 6014-6027; (c) J. W. Mason, N. Engl. J. Med., 1987, 316, 455-463. 84. J. Zhao, H. Fang, C. Xie, J. Han, G. Li and Yi Pan, Asian J. Org. Chem., 2013, 2, 1044-1047. 
85. Y. Shin, S. Sharma, N. K. Mishra, S. Han, J. Park, H. Oh, J. Ha, H. Yoo, Y. H. Jung and I. S. Kim., Adv. Synth. Catal. 2014, 357, 594-600.

86. P. Cheng, Z. Qing, S. Liu, W. Liu, H. Xie and J. Zeng, Tetrahedron Lett., 2014, 55, 6647-6651.

87. (a) J. W. Yuan, Q. Y. Yin, L. R. Yang, W. P. Mai, P. Mao, Y. M. Xiao and L. B. Qu, RSC Adv., 2015, 5, 8825888265; (b) W. Zhao, L. Xu, Y. Ding, B. Niu, P. Xie, Z. Bian, D. Zhang and Aihua Zhou, Eur. J. Org. Chem., 2016, 325-330; (c) M. Adib, S. R. Daryasarei, R. Pashazadeh, M. Tajik and P. Mirzaei., Tetrahedron Lett., 2016, 57, 3701-3705.

88. M. K. Manna, G. Bairy and R. Jana, Org. Biomol. Chem., 2017, 15, 5899-5903.

89. S. Maiti, L. Burgula, G. Chakraborti and J. Dash, Eur. J. Org. Chem., 2017, 332-340.

90. S. Paul, M. Bhakat and J. Guin, Chem. Asian J., 2019, 14, 3154-3160.

91. Carlos Santiago, Ibon Rubio, Nuria Sotomayor and Esther Lete, Eur. J. Org. Chem. 2020, 4284-4295.

92. X. Chen, X. Cui and Y. Wu, Org. Lett. 2016, 18, 24112414.

93. J. Zhang, and S. Hyeok Hong, Org. Lett., 2012, 14, 4646-4649.

94. L. Wang, D. L. Priebbenow, L. H. Zou and C. Bolm, Adv. Synth. Catal. 2013, 355, 1490-1494.

95. J. Y. Luo, H. L. Hua, Z. S. Chen, Z. Z. Zhou, Y. F. Yang, P. X. Zhou, Y. T. He, X. Y. Liu and Y. M. Liang, Chem. Commun., 2014, 50, 1564-1566.

96. (a) J. Wang, C. Liu, J. Yuan and A. Lei, Angew. Chem., Int. Ed., 2013, 52, 2256-2259; (b) M. B. Zhou, R. J. Song, X. H. Ouyang, Y. Liu, W. T. Wei, G. B. Deng and J. H. Li., Chem. Sci., 2013, 4, 2690-2694; (c) X. Jia, S. Zhang, W. Wang, F. Luo and J. Cheng, Org. Lett., 2009, 11, 3120-3123; (d) C. J. Li, Acc. Chem. Res., 2009, 42, 335-344; (e) Y. Meng, L. N. Guo, H. Wang and X. H. Duan, Chem. Commun., 2013, 49, 75407542; (f) W. T. Wei, M. B. Zhou, J. H. Fan, W. Liu, R. J. Song, Y. Liu, M. Hu, P. Xie and J. H. Li., Angew. Chem., Int. Ed., 2013, 52, 3638; (g) Y. M. Li, M. Sun, H. L. Wang, Q. P. Tian and S. D. Yang., Angew. Chem., Int. Ed., 2013, 52, 3972-3976; (h) M. Ishida and K. Tanaka, Org. Lett., 2013, 15, 2120-2123; (i) G. B. Deng, Z. Q. Wang, J. D. Xia, P. C. Qian, R. J. Song, M. Hu, L. B. Gong and J. H. Li., Angew. Chem., Int. Ed., 2013, 52, 15351538; (j) K. Matcha, R. Narayan and A. P. Antonchick, Angew. Chem., Int. Ed., 2013, 52, 7985-7989; (k) S. L. Zhou, L. N. Guo, H. Wang, X. H. Duan., Chem. Eur. J., 2013, 19, 12970-12973.
97. J. Zhao, P. Li, C. Xia and F. Li, Chem. Commun 20144 50, 4751-4754.

DOI: 10.1039/D0OB01458C

98. S. Kumar, R. Vanjari, T. Guntreddi and K. N. Singh, RSC Adv., 2015, 5, 9920-9924.

99. T. K. Achar and P. Mal., J. Org. Chem., 2015, 80, 666672.

100.G. C. Nandi and C. Raju, Org. Biomol. Chem., 2017, 15, 2234-2239.

101.C. Zheng, X. Liu and C. Ma, J. Org. Chem., 2017, 82, 6940-6945.

102. H. Zhang, Y. Su, K. H. Wang, D. Huang, J. Lia and Y. Hu, Org. Biomol. Chem., 2017, 15, 5337-5344.

103.P. Kumar, M. Gupta, V. Bahadur, V. S. Parmar and B. K. Singh Eur. J. Org. Chem., 2018, 1552-1558.

104.M. S. Segundo and A. Correa, Chem. Sci., 2019, 10, 8872-8879. 